\title{
WestVirginiaUniversity
}

THE RESEARCH REPOSITORY @ WVU

Graduate Theses, Dissertations, and Problem Reports

2017

\section{Bioacoustics and Behavior of American Crocodiles in Belize}

\author{
Miriam Boucher
}

Follow this and additional works at: https://researchrepository.wvu.edu/etd

\section{Recommended Citation}

Boucher, Miriam, "Bioacoustics and Behavior of American Crocodiles in Belize" (2017). Graduate Theses, Dissertations, and Problem Reports. 5239.

https://researchrepository.wvu.edu/etd/5239

This Thesis is protected by copyright and/or related rights. It has been brought to you by the The Research Repository @ WVU with permission from the rights-holder(s). You are free to use this Thesis in any way that is permitted by the copyright and related rights legislation that applies to your use. For other uses you must obtain permission from the rights-holder(s) directly, unless additional rights are indicated by a Creative Commons license in the record and/ or on the work itself. This Thesis has been accepted for inclusion in WVU Graduate Theses, Dissertations, and Problem Reports collection by an authorized administrator of The Research Repository @ WVU. For more information, please contact researchrepository@mail.wvu.edu. 
Bioacoustics and Behavior of American Crocodiles in Belize

Miriam Boucher

Thesis submitted to the

Davis College of Agriculture, Natural Resources, and Design at West Virginia University in partial fulfillment of the requirements for the degree of

Master of Science in

Wildlife and Fisheries Resources

James T. Anderson, Ph.D., Chair

Marisa Tellez, Ph.D.

Kyle Hartman, Ph.D.

School of Natural Resources

Morgantown, West Virginia

2017

Keywords: American Crocodiles, Acoustics, Behavior, Activity-budget, Conservation, Crocodylus acutus, Spot pattern

Copyright 2017 Miriam Boucher 


\section{ABSTRACT \\ Bioacoustics and Behavior of American Crocodiles in Belize}

\section{Miriam Boucher}

American Crocodiles (Crocodylus acutus) are large-bodied crocodylians broadly distributed throughout coastal and lowland wetlands in the Americas. Despite their being large, charismatic megafauna, the study of American Crocodile ecology is still lacking in many areas. As such we assessed the behavior and bioacoustics of American Crocodiles in Belize to address the paucity of data regarding these two facets of American Crocodile ecology. We conducted behavioral observations from three sites in the coastal zone of Belize. We categorized American Crocodile behavior and recorded activity duration for observed behaviors. In conjunction with behavioral data, we also assessed study sites to quantify the intensity of anthropogenic impact. Our results determined that American Crocodiles spent the highest proportional time performing maintenance activities to fulfill basic biological needs. However, the proportion of social and agonistic activities differed between sites, and was greater at sites with higher human disturbance. The results from this project establish activity-budgets for American Crocodiles in Belize as well as indicate adverse behavioral responses to anthropogenic impact which should be further considered in management decision making, as should bioacoustics.

American Crocodiles, like most crocodylian species, have a repertoire of acoustic signals used to communicate intraspecifically and in interaction with their environment. Of the acoustic calls produced, distress calls play an important role in crocodile ecology, particularly for juvenile American Crocodiles. The distress call is produced to elicit a defense response from nearby conspecifics, enhancing the survivorship of young American Crocodiles. We recorded American Crocodile distress calls from three sites in the coastal zone of Belize. We recorded from 
captured hatchling, juvenile, sub-adult, and adult American Crocodiles. We measured temporal and spectral parameters of the calls to describe the call structure of this species for each size class. We compared call parameters among size classes and determined that call structure remained similar among size classes but call parameters differed. We found that hatchling and juvenile distress calls were highly modulated and higher in frequency, whereas sub-adult and adult calls were longer in duration, lower in frequency, and had less modulation. We determined that call parameters could be used to successfully classify $82.4 \%$ of individuals into the correct size class. We also recorded call production by captured individuals as not every capture resulted in successful acoustic recording. Proportion of calls produced by individuals differed by size class and site. We found that American Crocodiles at sites with high anthropogenic impact produced distress calls at a higher proportion. Our results indicate that anthropogenic activity in crocodile habitat may be impacting the acoustic ecology of American Crocodiles in Belize.

The study of crocodylians, in this case American Crocodiles, benefits from the ability to effectively discern individuals in the field. Conventional identification techniques are to physically alter captured crocodiles by clipping the upright caudal scutes. However, this technique is difficult to observe accurately in the field and has no passive marking alternative. In compliment to the behavioral and acoustical study of American Crocodiles in Belize, we implemented novel marking techniques through tail spot pattern coding and visual tagging. We used existing tail spot pattern coding methodology developed for Nile Crocodiles (Crocodylus niloticus), and adapted this technique to create a second method. The original coding protocol, numeric code, was $84 \%$ successful in differentiating tail spot patterns from American Crocodiles and sympatric Morelet's Crocodiles (Crocodylus moreletii). The second method, the additive code, integrated irregular scale groups and vertical caudal scutes into the original coding system. 
We were $99 \%$ successful in differentiating individual crocodiles using the additive code. In conjunction with tail spot coding, we applied flexible, self-piercing, plastic tags to tail scutes to mark sub-adult and adult American Crocodiles. We used the tail tags to verify spot pattern recapture and facilitate individual identification for behavioral observation. The use of these tags is beneficial to behavioral studies and short-term population monitoring and offer an opportunity to augment current marking techniques. We determined that spot pattern coding and visual tagging are effective means to individually identify crocodiles in Belize and are a tool that can be easily implemented by current managers as well as integrated into community based citizen science initiatives 


\section{ACKNOWLEDGMENTS}

Thanks to the Explorer's Club, the Crocodile Specialist Group Student Research Assistance Scheme, the West Virginia University Davis College Dr. David E. Samuel Faculty Excellence Award, the West Virginia University Natural History Museum, the James. T. Anderson lab, Carmen and Keith Bellingham, Carol and Tom Polanic, Dana Seiffert, and J. C. and Lori Lucas for financial support of this project. I express my immense gratitude to my committee members, James Anderson, Marisa Tellez, and Kyle Hartman for their knowledge and support of this project, and their dedicated review of this material. I thank Marisa Tellez, Karl Kohlman, Shawn Heflick, Helen Sung, and Danni Brianne for their assistance in the field, and Lydia Stiffler for her statistical support. Thanks to my amazing family and friends who gave the advice and unwavering support I needed to get through the challenges of this project. Lastly, a very big thanks to James T. Anderson for giving me the opportunity and means to pursue my dreams, I could never have done this without you. 


\section{TABLE OF CONTENTS}

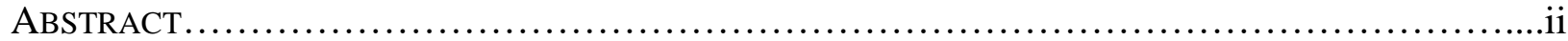

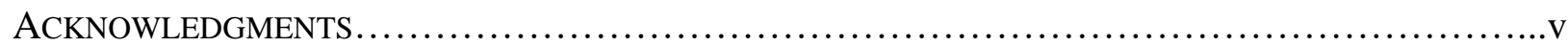

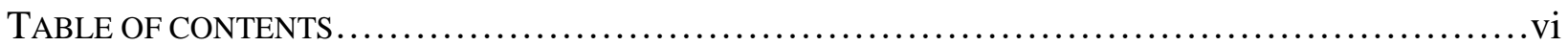

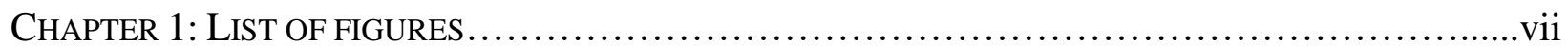

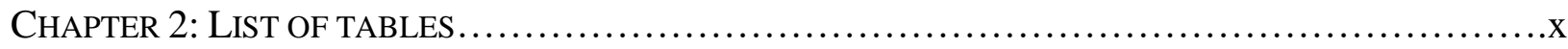

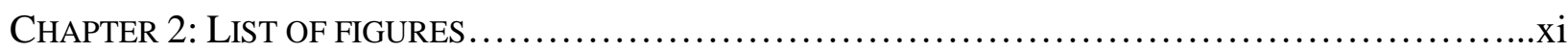

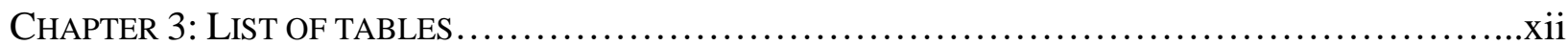

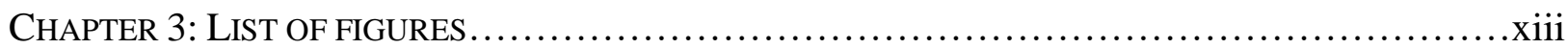

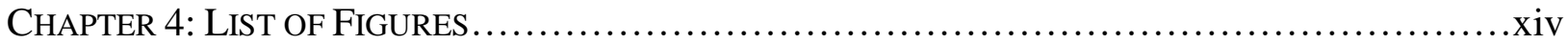

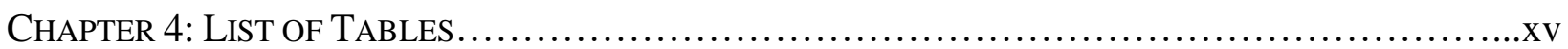

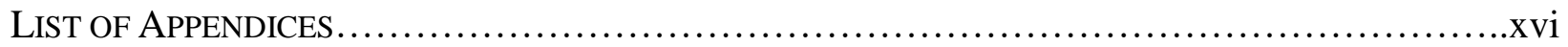

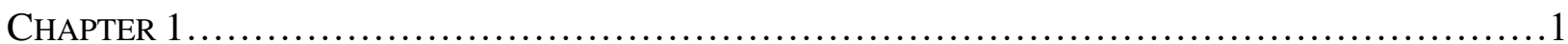

INTRODUCTION, LITERATURE REVIEW AND JUSTIFICATION FOR THE STUDY OF AMERICAN CRocodile (CROCODYLUS ACUTUS) BioACOUSTICS AND BEHAVIOR IN BELIZE...................

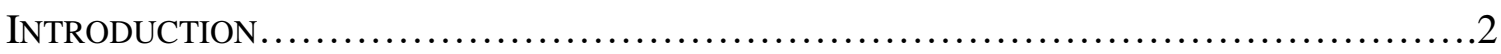

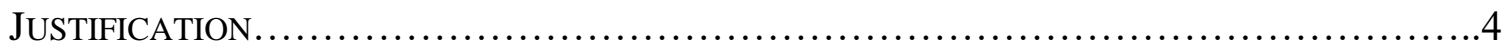

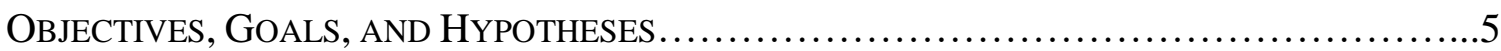

STUDY AREA..............................................................5

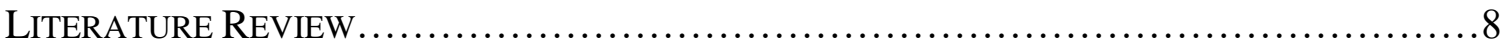

LiTERATURE CITED ....................................................... 24

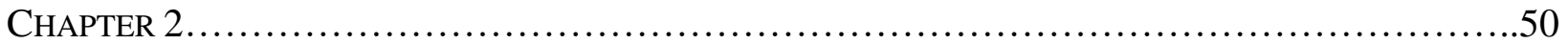

ACTIVITY BUdGET AND BEHAVIORAL PATTERNS OF AMERICAN CROCODILES (CROCODYLUS ACUTUS) IN THE COASTAL ZONE OF BELIZE. ..........................................5

ABSTRACT.........................................................................

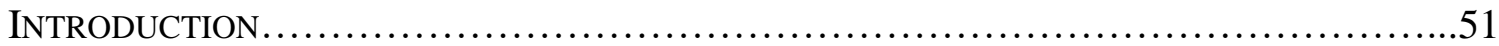

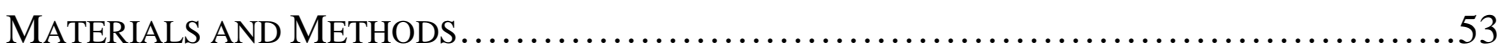

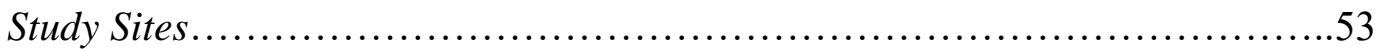

Wetland Impact Assessment.............................................54

Behavioral Observations...................................................54

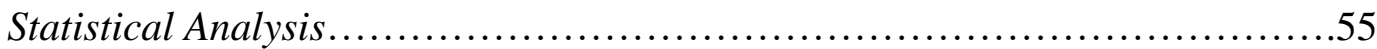

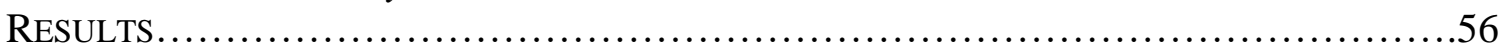

Wetland Impact Assessment ...........................................56

Behavioral Observations...............................................56

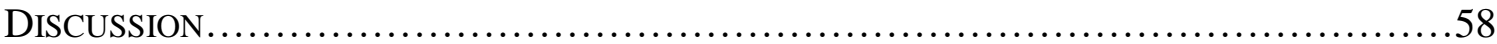

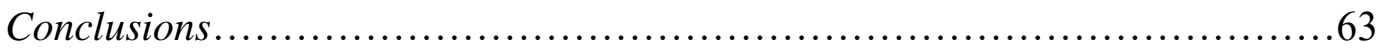

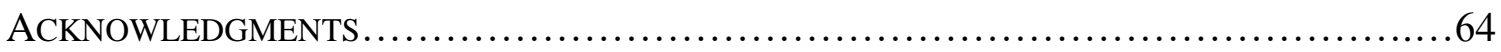

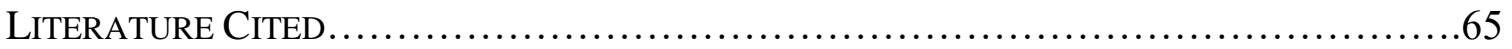

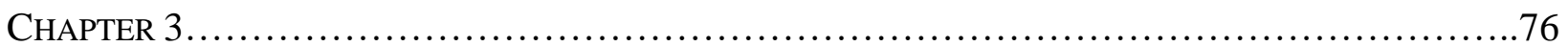


DifFERENCES IN Distress: VARIANCE ANd PRODUCTION OF AMERICAN CROCODILE (CROCODYLUS ACUTUS) DISTRESS CALLS IN BELIZE. ................................................... 76

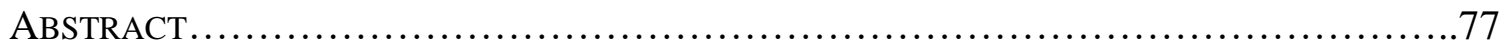

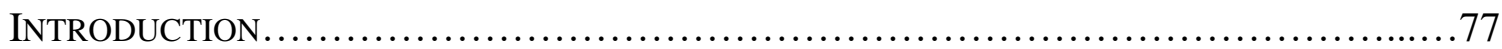

MATERIALS AND METHODS........................................................ 79

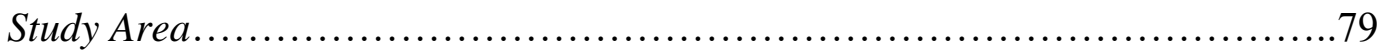

Wetland Impact Assessment .............................................8 80

Capture Techniques...................................................... 80

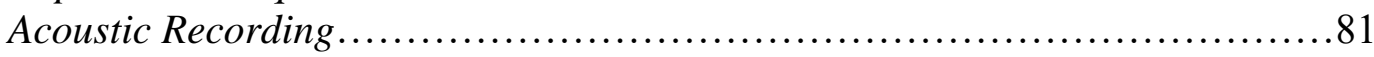

Sound Analysis ........................................................ 81

RESULTS.................................................................. 83

Wetland Impact Assessment ............................................83

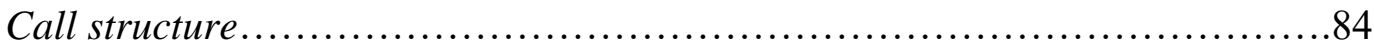

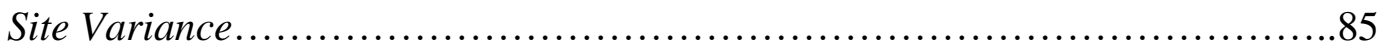

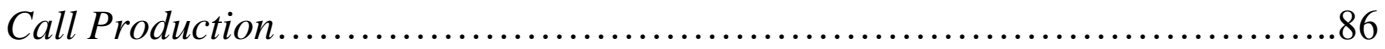

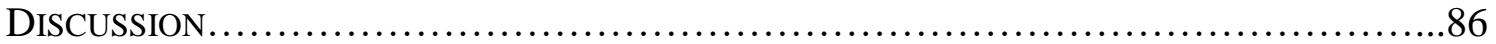

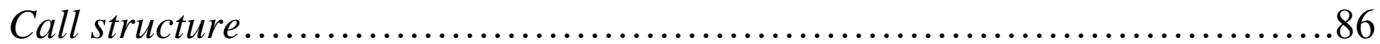

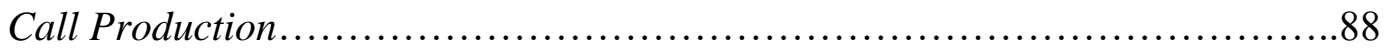

Conclusions............................................................... 91

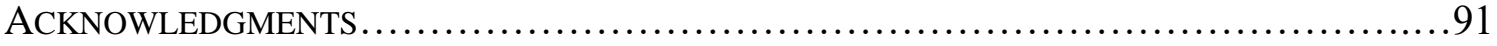

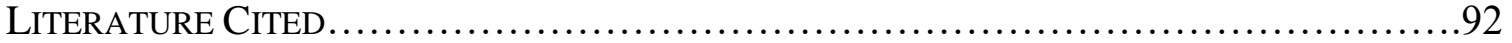

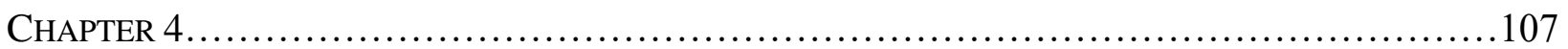

A TAIL OF TWO CROCS: INDIVIDUAL IDENTIFICATION OF AMERICAN (CROCODYLUS ACUTUS) AND MORELET'S (CROCODYLUS MORELETII) CROCODILES BY TAIL-SPOT PATTERNS..................107

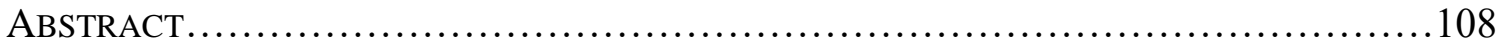

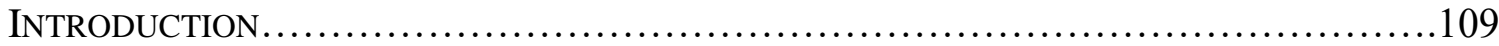

MATERIALS AND METHODS................................................... 111

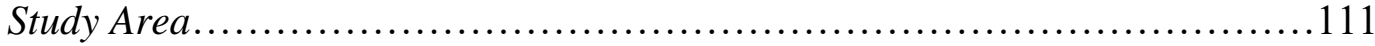

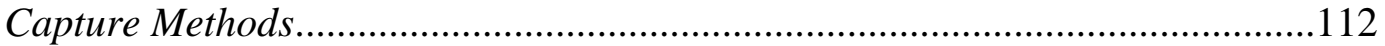

Tail Pattern Collection and Coding..................................................................113

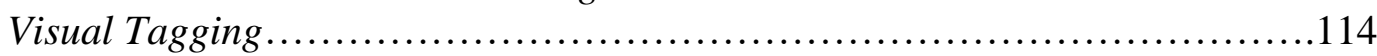

Data Analysis.......................................................... 115

RESULTS................................................................. 116

Tail-spot Pattern Coding.............................................116

Visual Tagging........................................................117

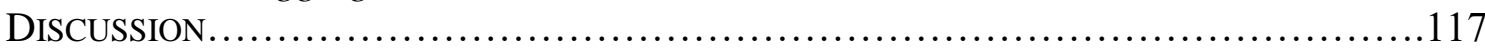

Pattern Coding ...................................................... 117

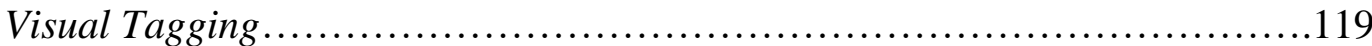

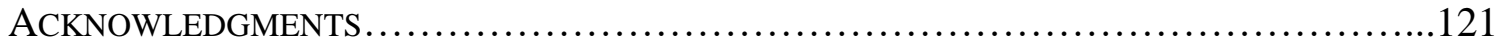

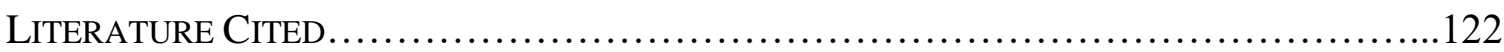

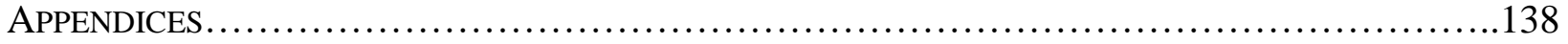

CHAPTER 1: LIST OF FIGURES 
Figure 1. American Crocodiles geographical range. Green depicts the current range of American Crocodiles while orange represents the historic range.

Figure 2. Belize, Central America. Numbers dictate study area location: (1) Ambergris Caye, (2) Caye Caulker, (3) Belize Aquaculture Limited west of the Placencia Peninsula.............32

Figure 3. (A) Study sites on Ambergris Caye in relation to the San Pedro. (B) Coco Beach Resort (C) Sewage ponds (red circle) and Mahogany Bay Village development (blue circle)....33

Figure 4. (A) Coco Beach study site showing sea wall to the left and dredged berms to the back of the lagoon. Main internal lagoon can be seen in the background ringed with mangroves. (B) Coco Beach showing shoreline being filled with industrial and household landfill. (C) San Pedro sewage ponds showing the left facultative lagoon........................................

Figure 5. Caye Caulker study area. Behavioral observation sites are marked by colored circles;

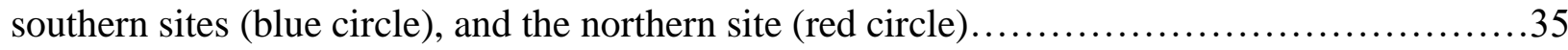

Figure 6. Northern behavioral observation site located in north Caye Caulker.................36

Figure 7. Belize Aquaculture Limited (BAL) property west of the Placencia Peninsula and

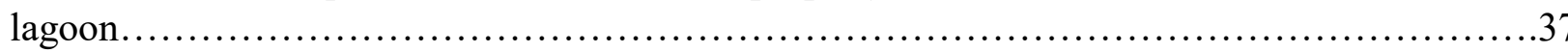

Figure 8. Tiger fern (Nephrolepis spp.) swamp and canal at Belize Aquaculture Limited North

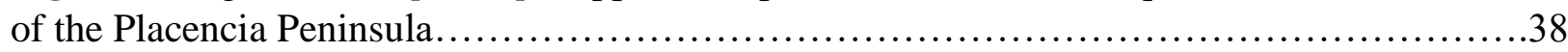

Figure 9. Acoustic structure of the principal vocalizations of juvenile American Crocodiles. (A) Spectrogram of a hatchling contact call recorded at approximately 2 weeks of age. (B) Spectrogram of a juvenile distress call $(30 \mathrm{~cm} 1$ month old) recorded during capture.......

Figure 10. Spectrogram of American Crocodile headslap and roar recorded in Everglades National Park, Florida, USA (Dinets 2011). Sharp peak indicates headslap followed by roar..............40

Figure 11. Adult American Crocodile hiss recorded during capture. Hiss is indicated by red bracket on the spectrogram and is characterized by low harmonic structure.

Figure 12. Head oblique tail arched (HOTA) position demonstrated by a large male American Crocodile in response to the proximity of another adult crocodile.

Figure 13. (A) Juvenile American Crocodile (1.2 $\mathrm{m}$ total length) displaying a raised tail in response to researcher presence on the shore. (B) Adult American Crocodile (2.5 m total length) displaying a raised tail to another crocodile (not shown) in close proximity as a possible warning to other crocodiles to stay away. .43

Figure 14. Snout lift by a submissive crocodile in response to being chased by a larger crocodile. 
Figure 15. Adult American Crocodile adopting an inflated posture in response to human presence on the shoreline.

Figure 16. (A) An adult American Crocodile gapes as another larger crocodile passes in close proximity behind it in a threat display. (B) Gaping is most commonly associated with thermoregulation to prevent the brain from overheating during basking

Figure 17. (A) Simplified numbering scheme for crocodile scute clipping in Belize. Caudal scutes are divided into a dorsolateral double row anteriorly and a single row extending medially to the posterior. (B) Example of scute clipping on a sub-adult American Crocodile illustrating the individual numerical code assigned through scute clipping................................... 47

Figure 18. (A) Self-piercing plastic ear being applied to a captured American Crocodile in Belize. (B) Visual recapture of a tagged American Crocodile in Belize. Different tag color combinations are used to distinctly identify individual crocodiles in the field .48

Figure 19. Example of a tail spot code generated for an American Crocodile using Swanepeol's (1996) method for numeric tail spot coding. Scute rows with markings are recorded and rows lacking markings are skipped. Rows with multiple markings are repeated in the sequence.......49 
TABLE 1.- Description of stressor severity ranks for wetland human disturbance assessment (Maine Department of Environmental Protection 2013).......................................69

TABLE 2.- List of characterized behavior and description of activities observed for American Crocodiles in Belize, Central America........................................................ 70

TABLE 3.- Time-activity budgets of American Crocodiles during morning $(0530 \mathrm{~h}-0930 \mathrm{~h} \pm 1)$ and evening $(1400 \mathrm{~h}-1800 \mathrm{~h} \pm 1)$ observation periods in Belize, $2015-2016 \ldots \ldots \ldots \ldots \ldots \ldots . . . .71$

TABLE 4.- Time-activity budgets of American Crocodile behaviors across three study areas in Belize, 2015 - 2016. Percents followed by the same uppercase letter are not significantly different among sites within a category or activity $(\mathrm{P}>0.05)$. Proportions followed by the same lowercase letter are not significantly different among categories or activities within a site $(\mathrm{P}>$ $0.05)$

TABLE 5.-Comparisons among sites (sample size, mean duration (minutes), and standard error) of observed behaviors for American Crocodiles in Belize, 2015 - 2016. Means followed by the same uppercase letter are not significantly different among sites within a category or activity ( $\mathrm{P}$ $>0.05$ ). Means followed by the same lowercase letter are not significantly different among

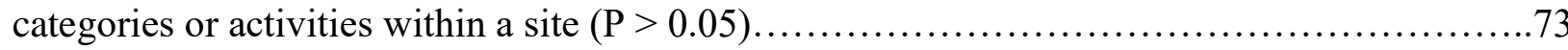




\section{CHAPTER 2: LIST OF FIGURES}

FIG 1.- Belize, Central America, located on the eastern Caribbean seaboard. Letters dictate study area location; (A) Ambergris Caye, (B) Caye Caulker, (C) Belize Aquaculture Limited...75 
TABLE 1.- Description of stressor severity ranks for wetland human disturbance assessment (Maine Department of Environmental Protection, 2013).............................. 96

TABLE 2.- Mean and standard error for total duration (DT), duration at first quartile $\left(\mathrm{D}_{1 / 4}\right)$, maximal frequency $\left(\mathrm{F}_{\max }\right)$, frequency at first quartile duration $\left(\mathrm{F}_{1 / 4}\right)$, end frequency $\left(\mathrm{F}_{\text {end }}\right)$, slope of the first quartile (Slope 1), and slope of the last three quartiles (Slope 2) for American Crocodile distress calls by size classes, Belize, 2015 - 2016

TABLE 3.- Mean and standard error of total duration (DT), duration at first quartile (D), maximal frequency $\left(F_{\max }\right)$, frequency at first quartile duration $\left(F_{1 / 4}\right)$, end frequency $\left(F_{\text {end }}\right)$, slope of the first quartile (S1), slope of the last three quartiles (S2), and total length (TL) of hatchling and juvenile American Crocodiles by location, Belize, 2015 - 2016.......................98

TABLE 4.- Number of American Crocodiles captured by size class, and proportion (\% Call) of captured crocodiles that produced distress calls at Ambergris Caye, Belize Aquaculture Limited (BAL), and Caye Caulker sites, Belize, 2015 - 2016. Caye Caulker and BAL data were combined to account for low sample size and facilitate analysis 


\section{CHAPTER 3: LIST OF FIGURES}

FIG 1.- Belize, Central America, located on the eastern Caribbean seaboard. Letters dictate study area location; (A) Ambergris Caye, (B) Caye Caulker, and (C) Belize Aquaculture Limited.....

FIG 2.- Spectrogram (A) and oscillogram (B) of a hatchling American Crocodile distress call, Ambergris Caye, Belize, 2016. Frequency parameter measurements; maximal fundamental frequency $\left(\mathrm{F}_{\mathrm{max}}\right)$, fundamental frequency at one-quarter duration $\left(\mathrm{F}_{1 / 4}\right)$, and frequency of the fundamental at the call end $\left(\mathrm{F}_{\text {end }}\right)$ shown as derived from spectrographic analysis. Temporal properties; total duration (DT), and duration of first quartile $\left(\mathrm{D}_{1 / 4}\right)$ shown from the measurement of distress call oscillogram

FIG 3.- Principal component analysis of parameters for total duration (DT), duration at first quartile (D), maximal frequency $\left(\mathrm{F}_{\max }\right)$, frequency at first quartile duration $\left(\mathrm{F}_{1 / 4}\right)$, end frequency $\left(\mathrm{F}_{\text {end }}\right)$, slope of the first quartile (S1), slope of the last three quartiles (S2), and individual size class of American Crocodile distress calls in Belize, 2015- 2016. Ordinal ellipse illustrates core size class groupings in relation to call parameters. Call variables on the principal component axes indicate the measured variables driving the separation of individuals by size class........104

FIG 4.- Variance of juvenile American Crocodiles call parameters between Ambergris Caye and aggregated Caye Caulker and BAL sites. (A) Total duration variance of juvenile distress calls in relation to total length, longer calls being produced by crocodiles at Ambe5gris Caye site. (B) Maximal frequency of juvenile distress calls plotted against total length. Ambergris Caye distress calls are produced at lower frequencies. (C) Slope of last three quartiles plotted against total length. Distress calls produced at Ambergris Caye site are less modulated. ...................105

FIG 5.- Proportion of American Crocodiles, by size class and location that produced distress

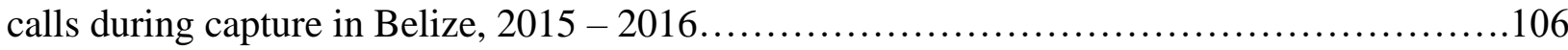




\section{CHAPTER 4: LIST OF FIGURES}

Figure 1. Belize, Central America, located on the eastern Caribbean seaboard. Numbers dictate study area location. (A) Ambergris Caye, (B) Caye Caulker, (C) Placencia Peninsula, (D) Chiquibul National Park, and (E) Corozal district study areas..........................133

Figure 2. Example of a numeric tail-spot code generated for an American Crocodile. Scutes with markings are recorded and rows lacking markings are skipped. The pattern is accessed working up the tail toward the torso of the crocodile........................................... 134

Figure 3. Left side tail pattern code using the additive method for a Morelet's crocodile. Black vertical scutes and irregular scale groups (intermediate scutes) are integrated into the code....136

Figure 4. (A) Application of visual tail tag on number 2 single row caudal scute. (B) Visual recapture of tagged American Crocodile by distinct tag orientation and color combination......137 


\section{CHAPTER 4: LIST OF TABLES}

Table 1. Numeric code generation guide. Steps $1-3$ are preceded by alphabetic character "L" (left) or "R" (right) denoting tail side. Steps begin at double scute row number 1 and repeated for

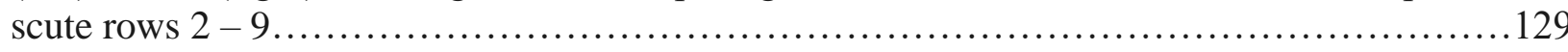

Table 2. Additive code generation guide. Steps $1-10$ are preceded by alphabetic character "L" (left) or "R" (right) denoting tail side. Steps begin at double scute row number 1 and repeated for scute rows $2-10$

Table 3. Tail pattern data by location, species, and completeness of acquired patterns (full or partial), 2014-2016 Belize.

Table 4. Number and percent of duplicate patterns derived from the numeric and additive coding methods. The additive coding method was superior in identifying individuals through distinct pattern codes 


\section{LIST OF APPENDICES}

APPENDIX I. Shapiro-Wilks test for normality, and Bartlett test for equal variance on measured American Crocodile acoustic call parameters for total duration (DT, s), duration at first quartile $\left(\mathrm{D}_{1 / 4}, \mathrm{~s}\right)$, maximal frequency of the fundamental $\left(\mathrm{F}_{\max }, \mathrm{Hz}\right)$, frequency of fundamental at first quartile duration $\left(\mathrm{F}_{1 / 4}, \mathrm{~Hz}\right)$, end frequency of the fundamental $\left(\mathrm{F}_{\text {end }}, \mathrm{Hz}\right)$, slope of the first quartile (Slope 1, Hz), slope of the last three quartiles (Slope 2, Hz) ......................139

APPENDIX II. Capture metadata of adult (A), sub-adult (SA), juvenile (J), and hatchling (H) American Crocodiles recorded from May 2015 - August 2016 in Belize....................140

APPENDIX III. Number of crocodiles recorded per size class and number of calls produced in 10, 20, and 30 second intervals beginning with the first call recorded, Belize, $2014-2016$. Analysis of variance found no significant difference in number of calls produced by size class within each call period 


\section{CHAPTER 1}

INTRODUCTION, LITERATURE REVIEW AND JUSTIFICATION FOR THE STUDY OF AMERICAN CROCODILE (CROCODYLUS ACUTUS) BIOACOUSTICS AND BEHAVIOR IN BELIZE

Miriam Boucher ${ }^{1}$

${ }^{1}$ School of Natural Resources, Wildlife and Fisheries Resources Program, West Virginia University, PO Box 6125, Percival Hall, Morgantown, WV 26506 


\section{INTRODUCTION}

Crocodylians use a variety of acoustic and behavior signals to communicate intraspecifically (Garrick and Lang 1977; Lang 1989; Vliet 1989; Senter 2008), yet our finetuned understanding of these communication pathways is relatively unexplored. Most studies of crocodylian communication have centered on short-distance communications during courtship and hatching. Along with limited research, a large proportion of studies have been conducted on captive individuals whose vocalizations may differ from wild populations (Dinets 2013; Vergne et al. 2011). While subsequent studies have enhanced understanding of crocodylian communication there still exists great paucity of data regarding wild crocodile communication and baseline data for many species, including American Crocodiles (Crocodylus acutus). Additionally, study of American Crocodile behavior in Belize has focused on reproductive behavior. There is no established time-activity budget for wild American Crocodiles in Belize or anywhere else in their range. As with American Crocodile bioacoustics, activity budgets and effects of anthropogenic activity on crocodile behavior have yet to be studied.

American Crocodiles are the most widely distributed crocodylian in the New World, inhabiting coastal and lowland wetlands along the Atlantic and Pacific coasts from southern Florida, USA, and Tamaulipas state in Mexico, to the limits of mangrove forest in northern South America (Ernst et al. 1999; Platt and Thorbjarnarson 2000; Fig. 1). In 1973, the American Crocodile was listed as endangered by the International Union for the Conservation of Nature (IUCN), and listed under Appendix I by the Convention of International Trade in Endangered Species (CITES) because of overexploitation, deliberate killing, illegal hunting, habitat loss, and drowning in fishing nets (Thorbjarnarson 1989; Thorbjarnarson et al. 2006). These threats led to a 30\% decline in many wild populations of American Crocodiles in the 75 years prior to the 
establishment of the IUCN, CITES, and national protection laws (Thorbjarnarson et al. 1992).

With the implementation of new management strategies, and national and international laws over the last 45 years, a few populations have recovered, thus the down-listing of American Crocodiles to Vulnerable by the IUCN (IUCN 2012). Despite population recovery in some areas, American Crocodile abundance and density throughout its historical range remain low and some populations remain at risk of extirpation, requiring continued conservation and evaluation of management strategies (Thorbjarnarson et al. 2006). This holds specific relevance for populations in Belize, a past stronghold of the American Crocodile (Ross 1998; Platt and Thorbjarnarson 2000).

American Crocodiles were nearly extirpated in Belize during the 1960s due to intense hunting pressure for meat and skins (Platt and Thorbjarnarson 2000). Although commercial hunting has stopped, populations remain low likely reflecting the small percentage of crocodiles still being eliminated through opportunistic killings and poaching, as well as the current rise of habitat destruction and pollution (Platt and Thorbjarnarson 2000; Tellez and Boucher unpublished). Development for tourism has greatly impacted shoreline and mangrove habitat, and lack of infrastructure has resulted in widespread polluting and illegal dumping in critical habitat, particularly nesting habitat (Platt and Thorbjarnarson 2000; Platt et al. 2004; Thorbjarnarson et al. 2006; Rainwater 2008; Author pers. obs.). Lack of quality nesting habitat hinders reproduction and nesting success, thus population sustainability (Platt and Thorbjarnarson 2000). Moreover, current observations suggest diminished habitat is currently forcing American Crocodiles to disperse into historical habitat of Morelet's crocodiles (Crocodylus moreletii), raising concerns for genetic conservation of both species as hybridization increases (Tellez, unpublished). As such it is increasingly important to monitor and quantify 
possible effects of anthropogenic influence on crocodiles in conjunction with furthering ecological knowledge of the species.

\section{JUSTIFICATION}

Apex predators, such as American Crocodiles, have strong top-down effects on ecological communities (Williams et al. 2004; Prugh et al. 2009; Frisch et al. 2016). As keystone species, they shape the ecosystems they inhabit (Roemer et al. 2009; Ritchie et al. 2012; Heupel et al. 2014). Protection and reestablishment of predator communities is vital to both the conservation of the species and the integrity of the ecosystem (Friedland and DeMartini 2002; Ritchie et al. 2012; Terborgh and Estes 2012). As such, understanding the relation between wildlife and their ecosystems is vital to management of species and protection of crucial habitat (Nifong and Silliman 2013). As the primary conservation concerns for American Crocodiles stem from anthropogenic influence it is critical to quantify human impact on crocodiles, but also collect baseline information to monitor for future trends in ecological responses to people. Conservation initiatives have identified the need for monitoring and protection programs along with further study of the ecology and behavior of this species in the wild (Thorbjarnarson 2010).

Bioacoustics is an emerging field that plays a significant role in understanding animal ecology and behavior, and provides new means for applied conservation (Laiolo 2010). Despite evidence regarding the importance of acoustic signals to animal ecology there are a lack of data regarding crocodylian acoustics. Our research addresses the paucity of data regarding American Crocodile acoustics as well as investigates behavior with the goal of providing new data to inform current and future conservation efforts. We performed comprehensive field observations to determine crocodile time-activity budgets, describe behavioral patterns, describe acoustic 
distress calls, and implement novel marking techniques. This information is imperative for determining patterns of behavior and bioacoustics, which may be altered by environmental stressors like anthropogenic expansion and climate change. Our work to determine behavioral patterns and better describe American Crocodile acoustic ecology can be used to inform management agencies and local communities of the overarching effects of anthropogenic impact in crocodylian habitat and enact better management through habitat protection and mitigating human-crocodile conflict.

\section{OBJECTIVES, GOALS, AND HYPOTHESES}

The overall objectives of our study are:

1) Collect baseline recordings of American Crocodile vocalizations and detail their acoustic structure;

2) Investigate differences in distress call production in relation to human disturbance in the environment;

3) Determine time-activity budgets for American Crocodiles in the coastal zone of Belize;

4) Investigate differences in behavioral trends between sites in relation to human disturbance in the environment; and

5) Implement and assess novel methods for identifying individual crocodiles in the field using tail tags and natural spot patterns.

\section{STUdy Area}

Belize is a small country $\left(22,965 \mathrm{~km}^{2}\right)$ situated south of Mexico's Yucatan Peninsula and bordering Guatemala along the eastern coast of Central America (Fig. 2). Terrain along the 
coastal areas is mostly low and flat, but low mountains in the southwestern interior of the country rise to a height of 1,124 m (Belize National Meteorological Society 2016). Belize has a tropical climate with yearly averages ranging from $23{ }^{\circ} \mathrm{C}$ to $30{ }^{\circ} \mathrm{C}$. Seasons are characterized by rainfall, the rainy season beginning in May and ending in August and the dry season generally running from November to May (Belize National Meteorological Society 2016). Although localized climate may vary slightly, all three study sites (Ambergris Caye, Caye Caulker, Stann Creek District) for this project had the same general microclimates and low elevations.

Ambergris Caye is a $40 \mathrm{~km}$ long island running parallel to Mesoamerican Barrier reef to the East. Although it is considered an island, the Caye is the southernmost tip of the Yucatan Peninsula separated from the eastern coast of Mexico by a channel believed to be dug by ancient Mayan inhabitants (Guderjan 1995). The eastern seaboard is approximately $1.6 \mathrm{~km}$ from the reef and natural seagrass beds exist in the calmer water between the reef and the island (Perkins 1983). The inland portion of the island is broken into lagoons characterized by brackish water, mangrove swamps (Rhizophora mangle, Avicennia germinans, Laguncalaria racemose, Conocarpus erectus) and turtle grass (Thalassia testudinum) beds. The southern portion of the Caye is commercially developed (approximately $40-50 \%$; M. Boucher, pers. obsv.), but the northern areas are not yet developed (approximately $80 \%$ undeveloped). Three main locations were accessed to collect both acoustic recordings and behavioral observations (Coco Beach Resort, San Pedro sewage ponds, Mahogany Bay Village development). Coco Beach Resort is

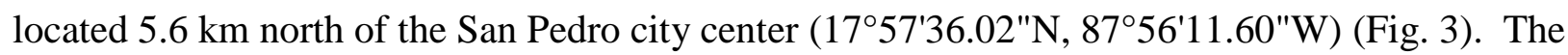
location consists of a small section of lagoon behind the main resort area approximately $0.01 \mathrm{~km}^{2}$ isolated from the main internal lagoon (4.3 ha) When last surveyed in September 2015 this small area contained 18 adult crocodiles (Personal obs.). The second location is the San Pedro sewage 
ponds $\left(17^{\circ} 53^{\prime} 50.58^{\prime \prime} \mathrm{N}, 87^{\circ} 59^{\prime} 32.02^{\prime \prime} \mathrm{W}\right)$ (Fig. 3; 4). The area consists of two facultative lagoons (each $0.028 \mathrm{~km}^{2}$ ) operating in series followed by one maturation pond (2.6 ha) with impermeable layers at their bottoms used to treat the collected sewage in San Pedro (Belize Water Services). These ponds have a relatively constant breeding population of adult crocodiles. The final study location on Ambergris Caye are the lagoon and canal area east of the sewage ponds at the

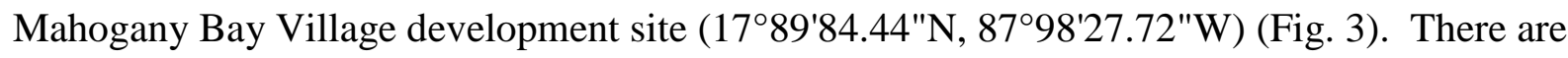
two large lagoon areas separated by a dredged roadway and a series of dredged canals extending to both north and south of the lagoons.

The second principal study site is Caye Caulker $\left(17^{\circ} 76^{\prime} 11.58^{\prime \prime} \mathrm{N}, 88^{\circ} 02^{\prime} 77.49^{\prime \prime} \mathrm{W}\right)$, an island located $8 \mathrm{~km}$ south of Ambergris Caye (Fig. 5; 6). Split by a deep channel the southern portion is quite developed ( $\sim 50 \%$ developed; M. Boucher, pers. obsv.) while the northern portion remains relatively natural with sporadic settlement ( 10\% developed; M. Boucher, pers. obsv.). The dominant vegetation is littoral forest and mangrove shoreline, and is mostly intact along the western seaboard. American Crocodiles are distributed along the entire island. Due to the difficulty in accessing and locating resident crocodiles, we obtained recordings and observations opportunistically throughout the study area.

The third principal study site is a commercial shrimp farm in Stann Creek District west of the Placencia Peninsula in southern Belize. The Placencia Peninsula forms a large natural lagoon with mangroves bordering both sides. Brackish water canals empty into the Placencia lagoon from inland rivers and streams, in addition to discharge effluent from the various shrimp farms on the mainland shoreline of the lagoon. Belize Aquaculture Limited is a large commercial shrimp farm located approximately $8.3 \mathrm{~km}$ west of the northern tip of the peninsula $\left(16^{\circ} 66^{\prime} 02.92^{\prime \prime} \mathrm{N}, 88^{\circ} 39^{\prime} 11.29^{\prime \prime} \mathrm{W}\right)$. The property encompasses approximately 3,642 ha and 
extends to the Placencia Lagoon (Fig. 7). Effluent from the farming ponds is treated in several settling ponds before being released into a man-made lagoon. The lagoon is fringed by a mix of vegetation including mangroves, tiger ferns (Nephrolepis spp.), grasses, coastal and pine forests, and bare-earth berms (Fig. 8). Water flows through the lagoon, over a spillway and down a canal that carries the effluent through the property to the Placencia Lagoon. The canals pass through a variety of biomes such as grass meadow, tiger fern swamp, jungle, pine forest, and mangrove swamp. There is an extremely high relative density of crocodiles located in the effluent lagoon (11 crocodiles/km surveyed), and crocodiles are present throughout the entire extent of the effluent lagoon and channels, with a mix of American and Morelet's crocodiles (including American x Morelet's hybrids). We collected acoustic recordings throughout the entire watercourse and behavioral observations were collected at the effluent lagoon.

\section{LITERATURE REVIEW}

\section{Crocodylian Hearing:}

Crocodylians have well-developed auditory capacity and rely on internal ear structures to interpret sound (Mathevon 2012). The crocodylian ear is similar to that of birds, and has sensitivity on par with most mammals (Staton 1978; Caldicott et al. 2005; Vergne et. al. 2009). The ear is located along the same lateral line as the eye and is positioned behind the eye socket. Designed for amphibious life, the outer ear is a small opening anterior to the inner ear and tympanic membrane which are protected by a muscular flap preventing water entry when submerged (Wever 1971; Vergne et al. 2009). Like birds and mammals, sound is transmitted through the tympanic membrane to the middle and inner ears for eventual interpretation in the brain (Vergne et al. 2009). Crocodylians also possess unique auditory physiology as the middle ear is connected by the interaural canal aiding in finer directional location of sound (Vergne et al. 
2009). Birds and crocodiles are also the only amniotes to have two different hair cell types. A more comprehensive description of the hearing apparatus of crocodylians can be found within Vergne et al. (2009).

Research on crocodylian hearing is limited, and of the available resources, few provide information for American Crocodiles (Wever 1971; Senter 2008; Vergner et. al. 2009). The only study found describing American Crocodile hearing notes a range of approximately 30-10,000 $\mathrm{Hz}$ with optimal hearing at approximately $1,000 \mathrm{~Hz}$, and best sensitivity around $-60 \mathrm{~dB}$ (Wever 1971). The lower limits of American Crocodile hearing suggest that they lack the auditory means to process sounds lower than $30 \mathrm{~Hz}$. As infrasound (sounds $<20 \mathrm{~Hz}$ ) is crucial to courtship, and is outside the lower limits of American Crocodile hearing range, it is likely this sound is processed differently than sound within the hearing range.

Although American Crocodile hearing range may not encompass low frequency sound it is plausible that other physiological adaptations are responsible for the interpretation of infrasonic frequencies. A study by Todd and McAngus (2006) suggests that the integumentary sensory organs (ISOs) along the jaw may be responsible for interpreting low frequencies. Crocodylian ISOs are located singularly on individual scales down the entire length of the body and in greater concentrations along the jaw line (Jackson et al. 1996). ISOs function as mechanoreceptors sensitive to water disturbances, osmoregulation, and physical contact, which allow crocodylians to sense and interpret waterborne vibrations, currents, and disturbances (Gabriel 2013). New research has investigated crocodylian ability to sense changes in pressure with integumentary sensory organs (Caldicott et al. 2005). This study on American Alligators (Alligator mississippiensis) has shown, that through slight pressure changes, alligators are able to sense a single water droplet hitting the water near their heads (Caldicott et al. 2005). Such 
sensitivity lends strength to the argument that crocodylians process infrasonic vibration via these mechanoreceptors. An alternative theory suggests that induction through the jawbone itself may assist in processing sounds outside of crocodylian hearing range (Vergne et al. 2009). This ability to process infrasonic sound suggests that crocodylians may have the ability to detect ultrasound as well. However, there is no literature supporting this hypothesis, and further research needs to be conducted.

\section{Sound Production and Acoustic Communication:}

There appears to be some disjoint in the literature as to what is responsible for the production of crocodylian acoustic signals. One theory attributes vocalization production to the air being forced through the larynx (Lang 1989), while another makes note that crocodylians possess no specialized sound production organ and instead rely on restriction of air through the palatal valve, a continuation of the tongue that separates the mouth from the throat and prevents water from entering the throat when animals submerge (Herzog and Burghardt 1977; Britton 2001; Senter 2008; Benko and Perc 2009; Vergne et al. 2009). In addition to the production of calls, crocodiles are able to modulate calls by altering the position of the palatal valve (Vergne et al. 2009). Supplementary sound production also occurs when air is forced through the nares, creating an unstructured hissing sound (Wang et al. 2007; Benko and Perc 2009).

Different authors have chosen to categorize calls in different ways, but this review focuses on two main categories. The first is juvenile communication, and the second describes adult communication. 


\section{Juvenile Communication.}

Juvenile communication commences in the egg before hatching via the production of intraegg vocalizations (Campbell 1973; Garrick and Lang 1977; Herzog and Burghardt 1977; Lang 1989; Senter 2008; Vergne et al. 2009, 2011). American Crocodile intraegg calls, are described as having a fundamental frequency beginning around $0.6 \mathrm{KHz}$ with downsweep (descending call frequency) to approximately $300 \mathrm{~Hz}$ in one-fifth of a second (Campbell 1973). These calls function to stimulate nest excavation by female crocodiles (Herzog and Burghardt

1977; Lang 1989; Senter 2008). Additional studies suggest that intraegg calls assist in hatching synchronicity, and may induce hatching in siblings (Lang 1989, Vergne et al. 2009).

Contact Calls. - Once hatching has occurred, hatchlings use contact calls to maintain contact within the hatchling pod and with their mother (Garrick and Lang 1977; Lang 1989; Vegne et al. 2009). These contact calls also function to alert conspecifics to danger (Staton 1978). Contact calls show species specificity, and although calls are similar in structure (complex sounds with multiple harmonics) calls vary among species (Lang 1989; Vergne et al. 2012). However, hatchlings of different caiman species do respond to the calls of other crocodylian species, illustrating that information coding within the calls is similar (Campbell 1973; Vergne et al. 2012). Response of American Crocodiles to calls of toher crocodilian species has not been documented. Crocodylians encode information by modulating frequency and pitch of contact and distress calls (Herzog and Burghardt 1977; Britton 2001; Vergne et. al. 2009, 2011, 2012). Calls modulated to communicate distress (distress calls) elicit defensive responses by adults as well as juvenile crocodiles regardless of kinship. 
Distress Calls.- Juveniles also emit what has been termed as the "distress call".

Distress calls have been confirmed in at least 11 of the 24 extant species of crocodylians (Staton 1978). Distress calls are differentiated from contact calls in that they are perceived to have a higher "behavioral threshold" and are, in general, greater in volume and higher in pitch (Neil 1971; Campbell 1973). These calls are produced in response to perceived threat and elicit protective responses from nearby crocodylians (Campbell 1973; Garrick and Lang 1977; Herzog and Burghardt 1977; Staton 1978; Lang 1989; Britton 2001; Senter 2008; Vergne et al. 2009; 2011). Distress calls are described as repetitive chirps (Garrick and Lang 1977) with multiple harmonics and downsweeping frequency modulation throughout call duration (Vergne et al. 2009, Fig. 9). American Crocodiles distress calls begin at a frequency of $0.5 \mathrm{KHz}$ downshifting to about $0.2 \mathrm{KHz}$ over one-third of a second (Campbell 1973). These calls can elicit a response from nearby adults, even those with no sympatric connection (Garrick and Lang 1977; Staton 1978; Lang 1989; Vergne et al. 2011, 2012). Distress calls are almost exclusively attributed to juvenile crocodylians, but there have been observed exceptions in which sub-adult and adult crocodiles have produced distress calls (Staton 1978; Personal obs.). It is unknown whether distress calls from sub-adults or adults elicit the same behavioral response from other conspecifics as do juvenile distress calls.

Snarls. - Snarls are classed as a "threat" call and coincide with an aggressive physical posture by juveniles in which individuals face the perceived threat, mouth agape, and body inflated (Campbell 1973; Britton 2001; Vergne et. al 2009). Snarls are commonly described in crocodylian acoustic literature and as a frequent aggressive behavior among American Crocodiles (Campbell 1973; Personal obs.). American Crocodile snarls begin at a frequency of $300 \mathrm{~Hz}$, changing to $1,500 \mathrm{~Hz}$ in one-fourth second and abruptly dropping off (Campbell 1973). 
Although described for juvenile American Crocodiles, there is a paucity of data on the overall production or structure of this call.

\section{Adult Communication.}

As crocodylians mature, the use of contact and distress calls falls drastically to be replaced with adult vocalizations (Staton 1978; Vergne et al. 2009). These vocalizations are broken down into long-distance and short distance signals. Long distance signals are most often described during courtship and territorial displays and are often referred to as "advertisement calls" (Garrick and Lang 1977; Lang 1989; Senter 2008; Vergne et al. 2009; Dinets 2011, 2013). These calls are described as being the loudest signals crocodylians produce and have the longest carrying capacity of all signals (Dinets 2011, 2013).

Long Distance Signaling: Bellows. - A bellow (or roar) is a common adult vocalization produced in water to attract females prior to mating (Garrick and Lang 1977; Lang 1989; Vliet 1989; Wang et al. 2007; Senter 2008; Dinets 2011, 2013). However, bellows and roars are also produced out of season and have been recorded as vocal responses in territorial disputes and offspring defense (Vergne et al. 2009; Dinets 2013). In alligatorids, bellows show most energy output at between 20 and $250 \mathrm{~Hz}$ with aquatic signal transmission that ranges up to $1.5 \mathrm{~km}$ (Vergne et al. 2009). Bellowing displays are often described as being "contagious" as one bellow may initiate an entire chorus from nearby conspecifics (Garrick and Lang 1977; Lang 1989; Vliet 1989; Wang et al. 2005, 2007). Although unconfirmed, there is brief mention of crocodylians being able to grade bellows, similar to juveniles, to communicate context (Lang 1989; Vergne et al. 2009). 
Long Distance Signaling: Sub-audible Vibrations. - Sound travels four times faster, and at greater sound pressure through water than through air, which makes aquatic acoustic sound more effective for crocodylians than terrestrial (Vliet 1989; Hopp et al.1998; Todd and McAngus 2006; Vergne et al. 2009; Dinets 2013). Some vocal signals are also accompanied by the production of sub-audible vibrations (SAVs) (Vliet 1989; Dinets 2011, 2013). Sub-audible vibrations are the production of infrasound created by the trunk muscles rapidly contracting beneath the surface of the water (Lang 1989). These signals are generally produced at around 10 Hz (Lang 1989; Vliet 1989; Dinets 2011, 2013). Sub-audible vibrations are associated with male displays, and are likely sex-dependent as there are no records of SAV production by female crocodylians (Garrick and Lang 1977; Vliet 1989; Senter 2008; Dinets 2013). Moreover, the production of infrasound outside of courtship events has not been reported. These infrasonic calls are difficult to record and reliable data from wild populations are scarce (Lang 1989; Dinets 2013). Sub-audible vibrations are also often accompanied with multiple audible vocalizations such as bellows or headslaps to act as locator beacons for nearby conspecifics to locate the vocalizing individual (Vliet 1989; Dinets 2011). The production of infrasound by American Crocodiles is noted to be a strong precursor to copulation (Garrick and Lang 1977).

Long Distance Signaling: Headslaps and Jaw Claps.- The headslap is another component of adult crocodylian signaling. This signal is produced when crocodylians slap the ventral surface of the lower jaw against the water's surface producing a loud sound (Lang 1989; Senter 2008). Headslaps have been observed in nearly all crocodylian species and produced by both sexes (Lang 1989). Unlike sub-audible vibrations, headslaps are produced outside courtship displays during territorial displays and offspring defense (Garrick and Lang 1977; Lang 1989; Dinets 2011, 2013). Headslaps may also be accompanied with a "jaw clap" which is produced 
by snapping the jaws shut at the surface creating a loud "pop" sound (Lang 1989; Vliet 1989). Lang (1989) describes the sound as resembling a flat shovel being stuck against the water's surface. Sound waves produced by headslaps have been recorded at a distance of $500 \mathrm{~m}$, illustrating that this mechanical signal travels well in aquatic environments (Dinets 2011). Headslapping displays by one individual will often incite responses from nearby individuals resulting in a chorus of headslaps (Lang 1989). American Crocodiles are noted to use headslaps more frequently than roars (Garrick and Lang 1977; Lang 1989; Dinets 2011, 2013), and dominant males will headslap multiple times in rapid succession (Garrick and Lang 1977). A combination of both the headslap and the roar exists, but only in new world crocodylians, American Crocodiles included (Senter 2008; Dinets 2011).

Short Distance Signaling.- Bellow and roars, sub-audible vibrations, and headslaps and jaw claps are all long-distance signals produced by crocodylians. Crocodylians also possess an entirely different set of acoustic signals more effective for short distance communication. Examples of these signals are hisses, coughs, grunts, moos, and toots. Three of these vocalizations appear most commonly in alligators. Chinese Alligators (Alligator sinensis) are the only crocodylians noted to make "tooting" or "mooing" sounds during courtship (Wang et al. 2007). American Alligators also produce "coughs" prior to copulation (Garrick and Lang 1977; Lang 1989; Vergne et al. 2009). These short distance vocalizations are not described in other crocodylians.

Short Distance Signaling: Hisses. - Unlike the previously described signals, hisses are employed by all crocodylians. Hisses are short-distance signals with poor harmonic structure and fundamental frequency below 1,000 Hz (Fig. 11) (Vergne et al. 2009). Hisses are produced by air exiting through the nares (Wang et al. 2007; Senter 2008) or through the throat (Lang 1989), 
and can be produced when the mouth is open or closed (Garrick and Lang 1977; Senter 2008).

Hisses are commonly associated with female nest protection, but are also used in nearly all social contexts (Garrick and Lang 1977; Wang et al. 2007; Senter 2008; Vergne et al. 2009). American Crocodiles of all sizes issue hisses in response to threatening situations and are often accompanied by gaping jaws and inflated posture (Personal obs.).

Short Distance Signaling: Grunts and Growls. - Grunts are soft signals and are poorly described. Garrick and Lang (1977) make mention of grunts as being used in nearly every social context, but do not elaborate further. Similarly, there is a lack of recording of growls in other crocodylians, with the exception of the American Alligator. Female alligators produce a combinatory call designated as the "bellow growl" in response to male activities or approach for courtship (Vliet 1989). Growls are also noted to be a response during aggressive encounters and are said to signal intent of aggression (Lang 1989).

\section{Physical Communication and Social Behaviors:}

In addition to acoustic communication, crocodylians also employ a variety of physical signals. These visual signals are often used in conjunction with acoustics cues and are used in a variety of social contexts.

\section{Head Oblique Tail Arched.}

The most common physical cue is the head oblique tail arched posture, more commonly referred to as HOTA (Fig. 12). Head oblique tail arched posture has been recorded in most crocodylian species and is described in courtship, territorial displays, and offspring defense (Garrick and Lang 1977; Lang 1989; Vliet 1989; Senter 2008; Dinets 2011; 2013). Vocal displays such as head and jaw slaps, bellows, and sub-audible vibrations are often preceded by 
the HOTA position (Neil 1971; Vliet 1989; Dinets 2011; 2013). In territorial displays HOTA posture signifies alertness and males are likely to approach intruders while in the position (Garrick and Lang 1977). The HOTA posture may also be used to indicate status of an individual as it gives honest indication of an animal's size (Lang 1989; Dinets 2011). Female crocodylians, specifically American Crocodiles, adopt the head oblique tail arched position while in the water in response to human presence near nests (Lang 1989). We observed that American Crocodiles in Belize often adopt this posture when in areas with multiple conspecifics and when humans are near (M. Boucher pers. obsv.). Our field observations have also identified a variant of HOTA in which American Crocodiles will "tail lift", raise single row of scutes out of the water, without displaying oblique head (Fig. 13). Behavior appears to be a signal of alertness to other individuals or potential threats in the area (M. Boucher pers. obsv.).

\section{Snout Lifting.}

Snout lifting in crocodylians is described as being an appeasement gesture produced to show submission (Garrick and Lang 1977; Lang 1989; Fig. 14). Subdominant males and females will deliberately lift its snout up out of the water with its jaws held slightly open in the presence of a more dominant individual (Lang 1989). The crocodylian will hold this position until the advance of the more dominant individual stops, or will raise it higher from the water if the approach does not stop (Lang 1989). This behavior is also attributed to precopulatory behavior, as female crocodylians will approach males with their snouts lifted to communicate readiness to mate (Garrick and Lang 1977; Lang 1989; Senter 2008). Snout lifting is described as a common behavior of American Crocodiles, but only females snout lift during daily social encounters (Garrick and Lang 1977, Lang 1989). 


\section{Snout and Dorsal Rubbing.}

Snout rubbing is a key physical behavior that occurs during courtship, in which one individual rubs the ventral side of their snout along the snout or dorsum of another individual (Senter 2008). In most cases, snout rubbing indicates female readiness to mate (Garrick and Lang 1977; Lang 1989; Senter 2008; Dinets 2011).

\section{Narial Geysering and Bubbling.}

Following headslap displays in a territorial display, male crocodylians will sometimes produce jets of water from their nostrils, termed narial geysering (Garrick and Lang 1977; Lang 1989; Senter 2008). Narial geysering is often present in courtship display and is given in response to female approach (Garrick and Lang 1977). Similarly, bubbling is performed during courtship routines by exhaling air through the nares underwater. Both sexes have been recorded producing these bubbles (Garrick and Lang 1977) and it is assumed to be precopulatory behavior to enhance pair bonding (Garrick and Lang 1977; Lang 1989; Wang et al. 2007; Senter 2008).

\section{Mock Biting.}

In social contexts, crocodiles establish territories and hierarchy through physical display and demonstration of dominance. These dominant behaviors are more commonly described for adult male crocodylians, specifically in a breeding context. During breeding activities males will compete for dominance and establish hierarchy (Garrick and Lang 1977; Lang 1989). Behavior common in American Crocodiles is mock tail or limb biting (Garrick and Lang 1977). Male American Crocodiles will also occasionally engage in physical disputes in which the two contesting individuals will spar with open jaws (Lang 1989). During these fights injury is not 
common and the "bites" serve to hold an individual while they are being overpowered (Lang 1989).

\section{Inflated Posture.}

Inflated posture serves as a signal of intimidation in response to agonistic behavior through the exaggeration of size (Garrick and Lang 1977; Lang 1989; Senter 2008; Fig. 15). Inflated posture communicates individual's status and aggression, and also serves to communicate intent to injure (Garrick and Lang 1977). During human confrontation, American Crocodiles will often assume this posture on land or in the water (Personal obs.). The posture is characterized by legs spread wide, gaping mouth, inflated torso, and is often accompanied with hisses and jaw claps (Vliet 1989; Personal obs.).

\section{Tail Wagging.}

Another behavior associated with agonistic encounters is tail wagging or tail thrashing. Prior to acoustic displays or territorial disputes, an individual will move its tail rigorously from side to side (Lang 1989; Vliet 1989). This behavior often precedes aggressive encounters, and is seen before an animal moves away from an aggressor or before it gives chase (Lang 1989).

\section{Circling.}

Once dominance is established in groups, males will systematically patrol their territories or circle around potential breeding partners in what is known as "circling" (Garrick and Lang 1977; Lang 1989; Senter 2008). In American Crocodile courtship, circling becomes a part of pair bonding and partner circling is a good indicator that copulation will soon follow (Garrick and Lang 1977). 


\section{Gaping.}

Gaping is a behavior most performed to facilitate thermoregulation during basking, but has been recorded in contexts outside of thermoregulation such as at night or by cool individuals. It has also been observed as a threat display in some species (Kofron 1993). We have observed American Crocodiles gaping as a threat or warning display during encounters with other crocodiles or in response to human approach. Animals basking on land will gape if another individual approaches from the water, or by smaller crocodiles when being approached or displaced by larger individuals (Fig. 16).

\section{Acoustic Recording Methods:}

There has been limited acoustic recording of crocodylians in both the wild and captivity. Recordings made in the late 1970s were gathered using magnetic tape recording equipment and either a parabolic or spot directional microphone (Garrick 1975; Herzog and Burghardt 1977). As technology has advanced, new recording equipment has been employed to capture crocodylian vocalizations. Digital recording equipment or portable digital recorders are now frequently used (Vergne et al. 2007, 2012). Digital camera equipment has also been used to record crocodylian vocalizations (Bonke et al. 2015). As with earlier techniques digital recording equipment can be coupled with a variety of microphones. Omnidirectional, shotgun, and dynamic microphones has all been used in current literature regarding the recording of wild and captive crocodylians (Vergne et al. 2007, 2012; Bonke et al. 2015). Past literature regarding recordings does not provide information regarding sampling frequencies, but more current literature specifies a sampling frequency of approximately $45 \mathrm{kHz}$ (Vergne et al. 2007, 2012; Bonke et al. 2015). Recording of crocodylian acoustic signals is often conducted at a set distance that standardizes recording procedure. This distance varies depending on the study and 
may not be applicable when recording larger animals in the wild (Vergne et al. 2007, 2012; Bonke et al. 2015).

\section{Behavioral Observation Methods:}

Crocodylian behavior has been observed in both captivity and the wild; however, there is still a lack of dedicated study of wild crocodiles (Vliet 1989). Behavioral observations of crocodylians are generally conducted during hours of peak activity in early morning and evening (Schaller and Crawshaw 1982; Thorbjarnarson and Hernández 1993; Dinets 2011). The majority of studies take place during daylight hours as crocodylian behavior is difficult to observe at night and the addition of light sources affects crocodylian behavior (Marioni et al. 2008; Personal obs.). Nocturnal observations have been conducted on captive individuals using a night vision scope (Garrick and Lang 1977). Observations are commonly recorded ad libitum (Altmann 1974) for both captive and wild crocodylians (Garrick and Lang 1977; Thorbjarnarson and Hernández 1993; Vliet 2001; Marioni et al. 2008). During behavioral observations observers may use blinds or maintain a distance from study animals to mitigate observer influence of crocodylian behavior (Hunt and Watanabe 1982; Thorbjarnarson 1993; Dinets 2011, 2013). With the availability of new technologies remote camera systems have also been used to monitor crocodylians specifically relating to nesting and hatchling behavior (Ogden 1978; Somaweera et al. 2011; Nifong and Silliman 2013; Chowfin and Leslie 2014). Furthermore, a recent study used animal-borne imaging equipment to provide new insight into foraging and aquatic behavior of wild American Alligators (Nifong et al. 2014). 


\section{Individual Identification:}

Individual identification is a useful tool for managers and conservationists to monitor crocodile populations (Chabreck 1963). The most common method of identification is through physical alteration by clipping the caudal scutes of captured crocodylians. Caudal scutes are keratinized, triangular upright scales that extend down the tail (Richardson et al. 2002). Removal or clipping of these scutes has been used in both captivity and in the field to permanently mark crocodylians (Bustard and Choudhury, 1981; Chabreck, 1963; Webb et al., 1989; Jennings et al., 1991; Soberon et al., 1996; Platt et al., 2002; Richardson et al., 2002; Elsey et al., 2004). Scutes on the tail are assigned numerical values so that a numeric code can be created for each individual based on which scutes are clipped (Singh and Bustard 1976; Plummer and Ferner 2012; Fig. 17). This technique has been used in this project in Belize to provide an additional marking metric to identify crocodiles.

Apart from scute clipping, tagging is also a common practice to identify individual animals. Toe tagging of crocodylians is done by clipping a self-piercing monel tag to the webbing between the toes on the front or rear feet (Chabreck 1963; Jones 1965, Chabreck and Joanen 1979; Jennings et al. 1991, Ferreira and Pienaar 2011). The placement of the tag can also be used to generate an individual numeric marker by assigning numerical values to the placement of the tag (Chabreck 1963). Tail scutes are also tagged using plastic livestock ear tags to facilitate easier visual identification of animals in the field. Tags are punched through the upright caudal scutes in varied locations and affixed with stainless steel bolts or self-piercing plastic tags (Bayliss 1987; Swanepoel 1996; Lang and Whitaker 2010; Ferreira and Pienaar 2011; Calverley and Downs 2014). We also used visual tagging during this project to identify American Crocodiles in the field and it has been successful in allowing visual identification of 
crocodiles during behavioral observations (Personal obs.; Fig. 18). The use of these plastic tags is somewhat limited as they are unlikely to remain attached for the duration of the tagged animal's life and can be fouled by algae or discolored by sunlight (Bayliss et al 1986; Swanepoel 1996; Personal obs.).

Natural markings have been used to distinguish a variety of taxa from fish to mammalian species (Katona and Whitehead 1981; Bradfield 2004; Silvy et al. 2005; Van Tienhoven et al. 2007; Oliveira-Santos et al. 2010). Natural markings have also been used to identify crocodylian species. Methods of identifying crocodylians from natural markings focus on the lateral tail sides as some crocodylian species possess unique marking patterns along the tail sides. These patterns are noted not to change over the life of the crocodylian and are thus a way to accurately distinguish individuals (Nair et al 2012; Bouwman and Cronje 2016). Identification protocol varies depending on method but all generally use coloration patterns to distinguish individuals based on pattern arrangement or use the markings to create a code (Singh and Bustard 1976; Swanepoel 1996; Nair 2010; Nair et al 2012; Bouwman and Cronje 2016). The marking method used by Singh and Bustard (1976) records markings along designated scute sections in addition to other markings such as missing scutes and scars along the tail. Swanepoel (1996) builds on this technique by creating numeric codes based on presence or absence of dark markings on the lateral sides of the double row scute section (Fig. 19). In this way a numeric code is generated for each crocodile and can be referenced directly as opposed to comparing spot placement and pattern. Another variation of this technique was used to create 11 digit numerical codes for the upright scutes on Nile Crocodiles (Crocodylus niloticus) (Bouwman and Cronje 2016). Similarly to Swanepoel's method this system records the type of natural coloration present on the first 10 single-crest scutes using designated numerical values (Bouwman and Cronje 2016). 


\section{Literature Cited}

Altmann, J. 1974. Observational study of behavior: sampling methods. Behavior 49:227-266.

Bayliss, P. 1987. Survey methods and monitoring within crocodile management programmes. Wildlife management: crocodiles and alligators. Pp. 157-175.

Bayliss, P., G. J. W. Webb, P. J. Whitehead, K. Dempsey, and A. Smith. 1986. Estimation of the abundance of saltwater crocodiles, Crocodylus porosus Schneider, in tidal wetlands of the Northern Territory: A mark-recapture experiment to correct spotlight counts to absolute numbers, and the calibration of helicopter and spotlight counts. Australian Wildlife Research 13:309-320.

Belize National Meteorological Society. 2016. Belize Topographical and Meteorological Information. http://www.hydromet.gov.bz/about-us/meteorological-information.

Benko, T., and M. Perc. 2009. Nonlinearities in mating sounds of American Crocodiles. Biosystems 97:154-159.

Bonke, R., N. Whitaker, D. Roedder, and W. Boehme. 2015. Vocalizations in two rare crocodylian species: A comparative analysis of distress calls of Tomistoma schlegelii (Müller, 1838) and Gavialis gangeticus (Gmelin, 1789). North-Western Journal of Zoology 11:151-162.

Bouwman, H., and E. Cronje. 2016. An 11-digit identification system for individual Nile crocodiles using natural markings. Koedoe 58:1-6.

Bradfield, K. S. 2004. Photographic identification of individual Archey's frogs, Leiopelma archeyi, from natural markings. Wellington, New Zealand: Department of Conservation.

Britton, A. 2001. Review and classification of call types of juvenile crocodylians and factors affecting distress calls. Crocodylian biology and evolution. Pp. 364-377.

Bustard, H. R., and B. C. Choudhury. 1981. Marking of crocodiles for release back into the wild for subsequent identification. Indian Forester 107:477-85.

Caldicott, D., D. Croser, C. Manolis, G. Webb, and A. Britton. 2005. Crocodile attack in Australia: An analysis of its incidence and review of the pathology and management of crocodylian attacks in general. Wilderness \& Environmental Medicine, 16:143-159.

Calverley, P. M., and C. T. Downs. 2014. Population Status of Nile Crocodiles in Ndumo Game Reserve, Kwazulu-Natal, South Africa (1971-2012). Herpetologica, 70:417-425.

Campbell, H. W. 1973. Observations on the acoustic behavior of crocodylians. Zoologica, 58:111. 
Chabreck, R. H. 1963. Methods of capturing, marking and sexing alligators. In Proceedings of the Annual Conference of the Southeastern Association of Game and Fish Commissioners 17:47-50.

Chabreck, R. H., and T. Joanen. 1979. Growth rates of American alligators in Louisiana. Herpetologica. pp. 51-57.

Chowfin, S. M., and A. J. Leslie. 2014. A multi-method approach for the inventory of the adult population of a critically endangered crocodylian, the Gharial (Gavialis gangeticus) at Dhikala, Corbett Tiger Reserve incorporating direct counts and trail cameras. International Journal of Biodiversity and Conservation 6:148-158.

Dinets, V. 2011. The role of habitat in crocodylian communication. Open Access Dissertations. Paper 570.

Dinets, V. 2013. Long-distance signaling in crocodylia. Copeia 2013:517-526.

Elsey, R. M., P. L. Trosclair, and J. T. Linscombe. 2004. The American alligator as a predator of mottled ducks. Southeast Nat 3:381-90.

Ernst, C. H., F. D. Ross, and C. A. Ross. 1999. Crocodylus acutus (Cuvier) American Crocodile. Catalogue of American Amphibians and Reptiles 700:1-17.

Ferreira, S. M., and D. Pienaar. 2011. Degradation of the crocodile population in the Olifants River Gorge of Kruger National Park. Aquatic Conservation: Marine and Freshwater Ecosystems 21:155-164.

Friedlander, A. M., and E. E. DeMartini. 2002. Contrasts in density, size, and biomass of reef fishes between the northwestern and the main Hawaiian Islands: the effects of fishing down apex predators. Marine Ecology Progress Series 230:253-264.

Frisch, A. J., Ireland, M., Rizzari, J. R., Lönnstedt, O. M., Magnenat, K. A., Mirbach, C. E., and J. P. A. Hobbs. 2016. Reassessing the trophic role of reef sharks as apex predators on coral reefs. Coral Reefs 35:459-472.

Gabriel, S. 2013. Integumentary sensory organs in crocodylians. Portland State University Dissertation Chapter 19.

Garrick, L. D. 1975. Structure and pattern of the roars of Chinese Alligators (Alligator sinensis Fauvel). Herpetologica 31:26-31.

Garrick, L. D., and J. L. Lang. 1977. Social signals and behaviors of adult alligators and crocodiles. American Zoologist 17:225-239.

Guderjan, T. H. 1995. Maya settlement and trade on Ambergris Caye, Belize. Ancient Mesoamerica 6:147-159. 
Herzog, H. A., and G. M. Burghardt. 1977. Vocalization in juvenile crocodylians. Zeitschrift für Tierpsychologie 44:294-304.

Heupel, M. R., D. M. Knip, C. A. Simpfendorfer, and N. K. Dulvy. 2014. Sizing up the ecological role of sharks as predators. Marine Ecology Progress Series 495:291-298.

Hopp, S. L., M. J. Owren and C. S. Evans. 1998. Animal acoustic communication: Sound analysis and research methods. Springer, Berlin and New York. Pp. 421.

Hunt, R. H., and M. E. Watanabe.1982. Observations on maternal behavior of the American alligator, Alligator mississippiensis. Journal of Herpetology 16:235-239.

IUCN. 2012. IUCN Red List of Threatened Species (ver. 2012.2). http://www.iucnredlist.org.

Jackson, K., D. G. Butler, and J. H. Youson. 1996. Morphology and ultrastructure of possible integumentary sense organs in the estuarine crocodile (Crocodylus porosus). Journal of morphology 229:315-324.

Jennings, M. L., D. N. David, and K. N. Portier. 1991. Effect of marking techniques on growth and survivorship of hatchling alligators. Wildlife Society Bulletin 19:204-207.

Jones, F. K. 1965. Techniques and methods used to capture and tag alligators in Florida. In Proceeding of the Southeast Association of Game and Fish Commission 19:98-101.

Katona, S. K., and H. P. Whitehead. 1981. Identifying humpback whales using their natural markings. Polar Record 20:439-444.

Kofron, C. P. 1993. Behavior of Nile Crocodiles in a seasonal river in Zimbabwe. Copeia 1993: 463-469.

Kushlan, J. A., and F. J. Mazzotti. 1989. Population biology of the American Crocodile. Journal of Herpetology 23:7-21.

Laiolo, P. 2010. The emerging significance of bioacoustics in animal species conservation. Biological Conservation 143:1635-1645.

Lang, J. W. 1989. Social behavior. Pp. 102-117 in Webb, G. J., S.C. Manolis, and P.J. Whitehead, P. J. (Eds.), Crocodiles and Alligators. Surrey Beatty \& Sons, Chipping Norton, Australia.

Lang, J. W., and S. Whitaker. 2010. Spatial ecology of Gavialis gangeticus in the Chambal River, India. Crocodiles. pp. 183.

Marioni, B., R. Da Silveira, W. E. Magnusson, and J. Thorbjarnarson. 2008. Feeding behavior of two sympatric caiman species, Melanosuchus niger and Caiman crocodilus, in the Brazilian Amazon. Journal of Herpetology 42:768-772.

Mathevon, N. 2012. Acoustic communication in crocodiles. Acoustics 2012. 
Nair, T. 2010. Ecological and anthropogenic covariates influencing gharial Gavialis gangeticus distribution and habitat use in Chambal River, India. Unpublished Master's Thesis.

Nair, T., J. B. Thorbjarnarson, P. Aust, and J. Krishnaswamy. 2012. Rigorous gharial population estimation in the Chambal: implications for conservation and management of a globally threatened crocodylian. Journal of Applied Ecology 49:1046-1054.

Neill, W. T. 1971. The last of the ruling reptiles: alligators, crocodiles, and their kin. Smith II.

Nifong, J. C., and B. R. Silliman. 2013. Impacts of a large-bodied, apex predator (Alligator mississippiensis Daudin 1801) on salt marsh food webs. Journal of Experimental Marine Biology and Ecology 440:185-191.

Nifong, J. C., R. L. Nifong, B. R. Silliman, R. H. Lowers, L. J. Guillette Jr, L. J. Ferguson, M. Welsh, K. Abernathy, and G. Marshall. 2014. Animal-borne imaging reveals novel insights into the foraging behaviors and diel activity of a large-bodied apex predator, the American alligator (Alligator mississippiensis). PloS One 9:839-853.

Ogden, J. C. 1978. Status and nesting biology of the American Crocodile, Crocodylus acutus, (Reptilia, Crocodilidae) in Florida. Journal of Herpetology 12:183-196.

Oliveira-Santos, L. G. R., C. A. Zucco, P. C. Antunes, and P. G. Crawshaw Jr. 2010. Is it possible to individually identify mammals with no natural markings using camera-traps? A controlled case-study with lowland tapirs. Mammalian Biology-Zeitschrift fur Saugetierkunde.

Perkins, J. S. 1983. The Belize Barrier Reef Ecosystem: an assessment of its resources, conservation status and management. Pp 148. New York Zoological Society, New York.

Platt, S. G., T. R. Rainwater, and S. Nichols. 2004. A recent population assessment of the American Crocodile (Crocodylus acutus) in Turneffe Atoll, Belize. Herpetology Bulletin 89:26-32.

Platt, S. G. and J. B. Thorbjarnarson. 2000. Status and conservation of the American Crocodile, Crocodylus acutus, in Belize. Biological Conservation 96:13-20.

Platt, S. G., T. R. Rainwater, and S. T. McMurry. 2002. Diet, gastrolith acquisition, and initiation of feeding among hatchling Morelet's Crocodiles in Belize. Herpetological Journal 12:81-4.

Plummer, M. V., and J. W. Ferner. 2012. Marking reptiles. Reptile Biodiversity: Standard Methods for Inventory and Monitoring. Pp. 143-150. R. Shine (Eds). University of California Press, London, England.

Prugh, L. R., C. J. Stoner, C. W. Epps, W. T. Bean, W. J. Ripple, A. S. Laliberte, and J. S. Brashares. 2009. The rise of the mesopredator. Bio Science 59:779-791. 
Rainwater, T. R. 2008. Population assessment of American Crocodiles (Crocodylus acutus) in Turneffe Atoll, Belize, 2008. Report to Oceanic Society, San Francisco, CA.

Richardson, K. C., G. J. W. Webb, and S. C. Manolis. 2002. Crocodiles: inside out: a guide to the crocodylians and their functional morphology. Pp. 172. Sydney: Surrey Beatty and Sons, Ltd.

Ritchie, E. G., B. Elmhagen, A. S. Glen, M. Letnic, G. Ludwig, and R. A. McDonald. 2012. Ecosystem restoration with teeth: what role for predators?. Trends in Ecology \& Evolution 27:265-271.

Roemer, G. W., M. E. Gompper, and B. Van Valkengurgh. 2009. The ecological role of the mammalian mesocarnivore. BioScience 59:165-173.

Ross, J. P. 1998. Crocodiles: Status survey and conservation Action Plan 2nd edition. IUCN/SSC Crocodile Specialist Group, IUCN, Gland, Switzerland and Cambridge, UK.

Schaller, G. B., and P. G. Crawshaw Jr. 1982. Fishing behavior of Paraguayan Caiman (Caiman crocodilus). Copeia 1982:66-72.

Senter, P. 2008. Homology between and antiquity of stereotyped communicatory behaviors of crocodylians. Journal of Herpetology 42: 354-360.

Silvy, N. J., R. R. Lopez, and M. J. Peterson. 2005. Wildlife marking techniques; Techniques for wildlife investigations and management. Pp. 339-376. In N. J. Silvy (Eds), The Wildlife Society, Bethesda, MD.

Singh, L. A. K., and H. R. Bustard. 1976. A method to identify individual young Gharial (Gavialis gangeticus). British Journal of Herpetology 5:669-671.

Soberon, R., R. Ramos, W. McMahan, and R. Ross. 1996. Reintroduction of Cuban Crocodile on the Isle of Pines. Crocodile Specialist Group Newsletter 15:10-1.

Somaweera, R., J. K. Webb, and R. Shine. 2011. It's a dog-eat-croc world: dingo predation on the nests of freshwater crocodiles in tropical Australia. Ecological Research 26:957.

Staton, M. A. 1978. Distress calls of crocodylians--Whom do they benefit? American Naturalist. 112:327-332.

Swanepoel, D. G. J. 1996. Identification of the Nile Crocodile Crocodylus niloticus by the use of natural tail marks. Koedoe 39:113-115.

Terborgh, J., and J. A. Estes. 2012. Trophic Cascades. Natural Areas Journal 32:222-227. 
Thorbjarnarson, J. 1989. Ecology of the American Crocodile (Crocodylus acutus). Crocodiles: Their ecology, management, and conservation. Pp. 371-379. In Proceedings of the 7th Working Meeting of the Crocodile Specialist Group. Gland, Switzerland.

Thorbjarnarson, J. B. 1993. Fishing behavior of Spectacled Caiman in the Venezuelan Llanos. Copeia 1993:1166-1171.

Thorbjarnarson, J. B., H. Messel, F. W. King, and J. P. Ross. 1992. Crocodiles: An action plan for their conservation. IUCN, Gland, Switzerland.

Thorbjarnarson, J. B., and G. Hernández. 1993. Reproductive ecology of the Orinoco Crocodile (Crocodylus intermedius) in Venezuela. II. Reproductive and social behavior. Journal of Herpetology. pp. 371-379.

Thorbjarnarson, J. B., F. Mazzotti, E. Sanderson, F. Buitrago, M. Lazcano, K. Minkowski, M. Muñiz, P. Ponce, L. Sigler, R. Soberon, and A. M. Trelancia. 2006. Regional habitat conservation priorities for the American Crocodile. Biological Conservation 128:25-36.

Thorbjarnarson, J. B. 2010. American Crocodile Crocodylus acutus. Crocodiles. Status Survey and Conservation Action Plan. Crocodile Specialist Group IUCN-The World Conservation Union Publications. Switzerland.

Todd, N., and P. McAngus. 2006. Evidence for near-field hearing in crocodylian vocal communication: Intensity of the American Alligator (Alligator mississippiensis) vocal display. The Journal of the Acoustical Society of America 119:3433.

Van Tienhoven, A. M., J. E. Den Hartog, R. A. Reijns, and V. M. Peddemors. 2007. A computer - aided program for pattern - matching of natural marks on the spotted raggedtooth shark Carcharias taurus. Journal of Applied Ecology 44:273-280.

Vergne, A. L., A. S. Avril, S. Martin, and N. Mathevon. 2007. Parent-offspring communication in the Nile Crocodile Crocodylus niloticus: do newborns' calls show an individual signature?.Naturwissenschaften 94:49.

Vergne, A. L., M. B. Pritz, and N. Mathevon. 2009. Acoustic communication in crocodylians: from behavior to brain. Biological Reviews 84:391-411.

Vergne, A. L, T. Aubin, P. Taylor, and N. Mathevon. 2011. Acoustic signals of baby Black Caimans. Zoology 114:313-320.

Vergne, A. L., T. Aubin, S. Martin, and N. Mathevon. 2012. Acoustic communication in crocodylians: information encoding and species specificity of juvenile calls. Animal Cognition 15:1095-1109.

Vliet, K. A. 1989. Social displays of the American Alligator (Alligator mississippiensis). American Zoologist 29:1019-1031. 
Vliet, K. A. 2001. Courtship behaviour of American Alligators Alligator mississippiensis. Crocodylian Biology and Evolution. pp. 383-408.

Wang, X., D. Wang, X. Wu, R. Wang, and C. Wang. 2005. Congregative effect of Chinese Alligator's bellowing chorus in mating season and its function in reproduction. Dong wu xue bao. Acta zoologica Sinica 52:663-668.

Wang, X., D. Wang, X. Wu, R. Wang, and C. Wang. 2007. Acoustic signals of Chinese Alligators (Alligator sinensis): social communication. The Journal of the Acoustical Society of America 121:2984-2989.

Webb, G. J. W, P. G. Bayliss, and S. C. Manolis. 1989. Population research on crocodiles in the Northern Territory, 1984-86. Pp. 22-60. In Proceedings of the 8th Working Meeting of the Crocodile Specialist Group. Gland, Switzerland.

Wever, E.G. 1971. Hearing in the Crocodilia. Proceedings of the National Academy of Sciences 68:1498-1500.

Williams, T. M., J. A. Estes, D. F. Doak, and A. M. Springer. 2004. Killer appetites: assessing the role of predators in ecological communities. Ecology 85:3373-3384. 


\section{Figures}

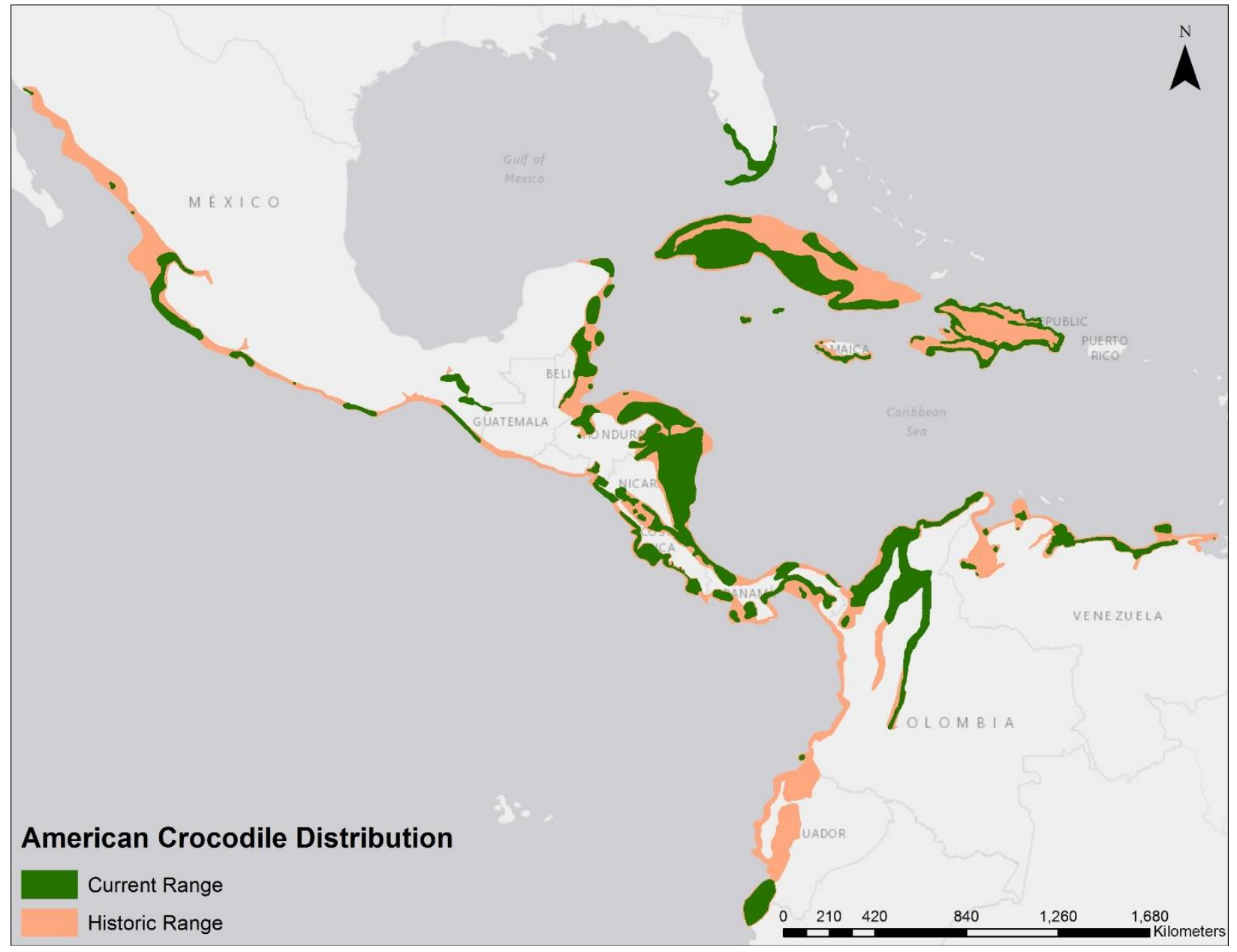

Figure 1. American Crocodiles geographical range. Green depicts the current range of American Crocodiles while orange represents the historic range. 


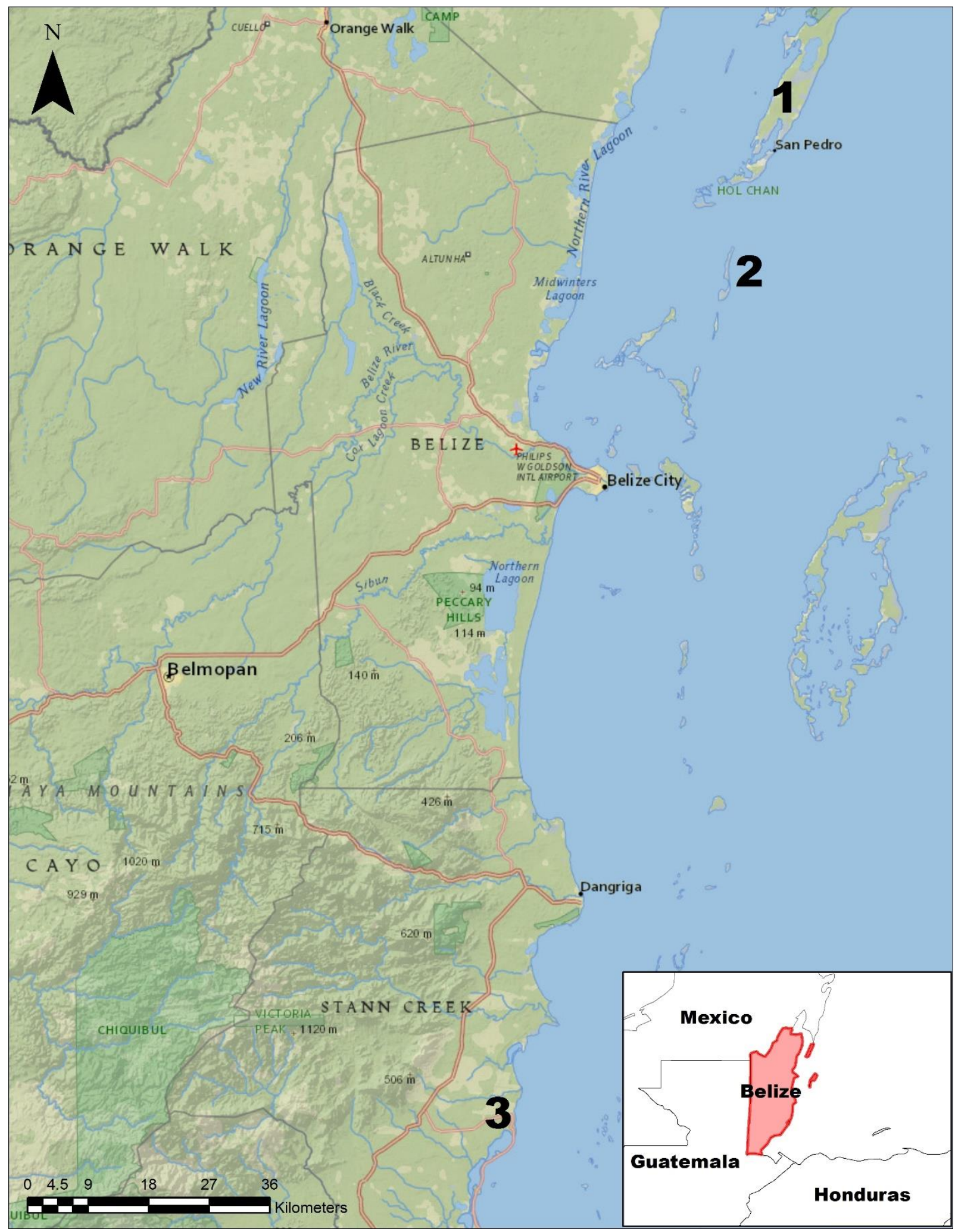

Figure 2. Belize, Central America. Numbers dictate study area location: (1) Ambergris Caye, (2) Caye Caulker, and (3) Belize Aquaculture Limited west of the Placencia Peninsula. 

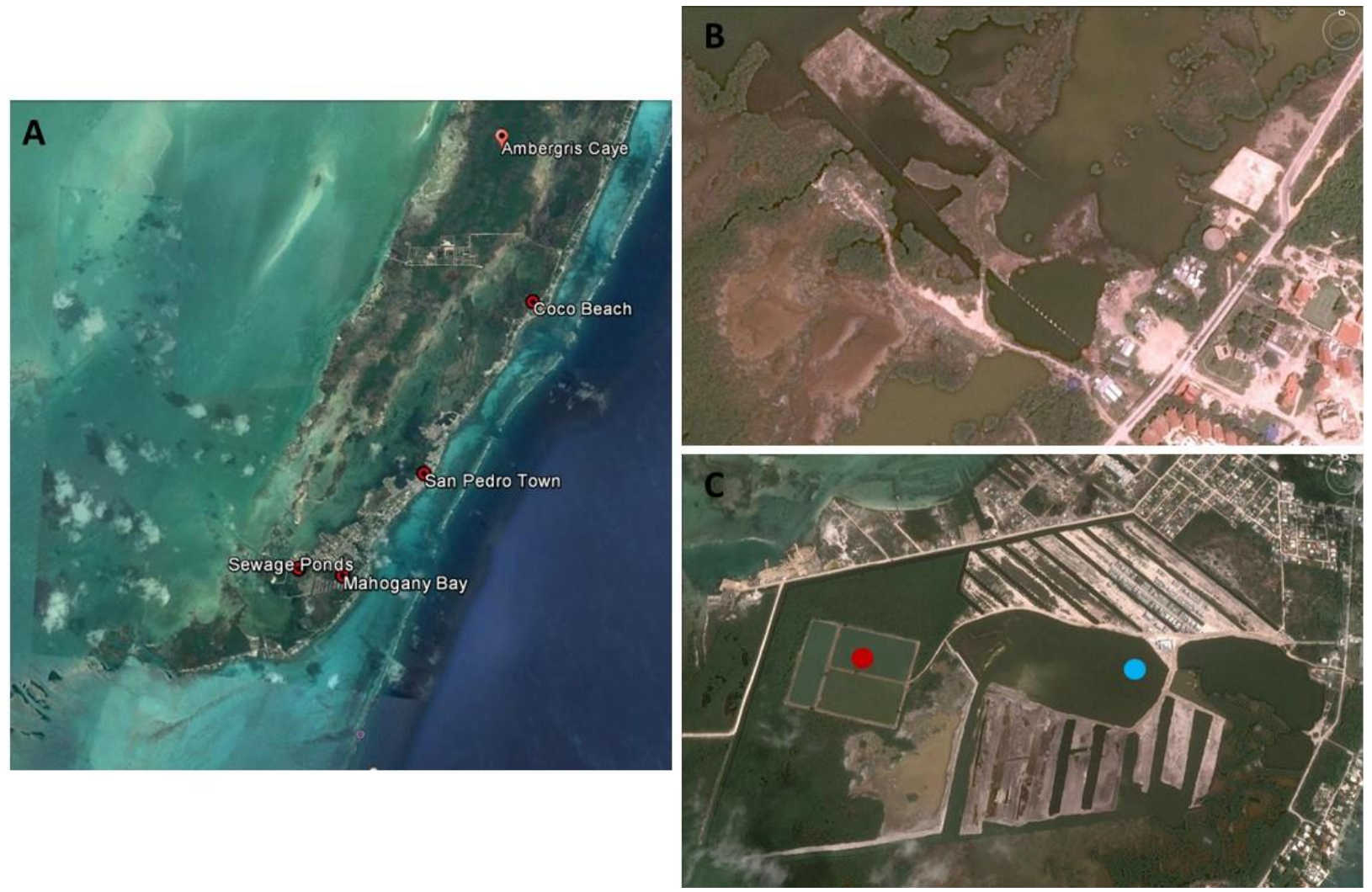

Figure 3. (A) American Crocodile study sites on Ambergris Caye in relation to San Pedro, Belize. (B) Coco Beach Resort (C) Sewage ponds (red circle) and Mahogany Bay Village development (blue circle). 


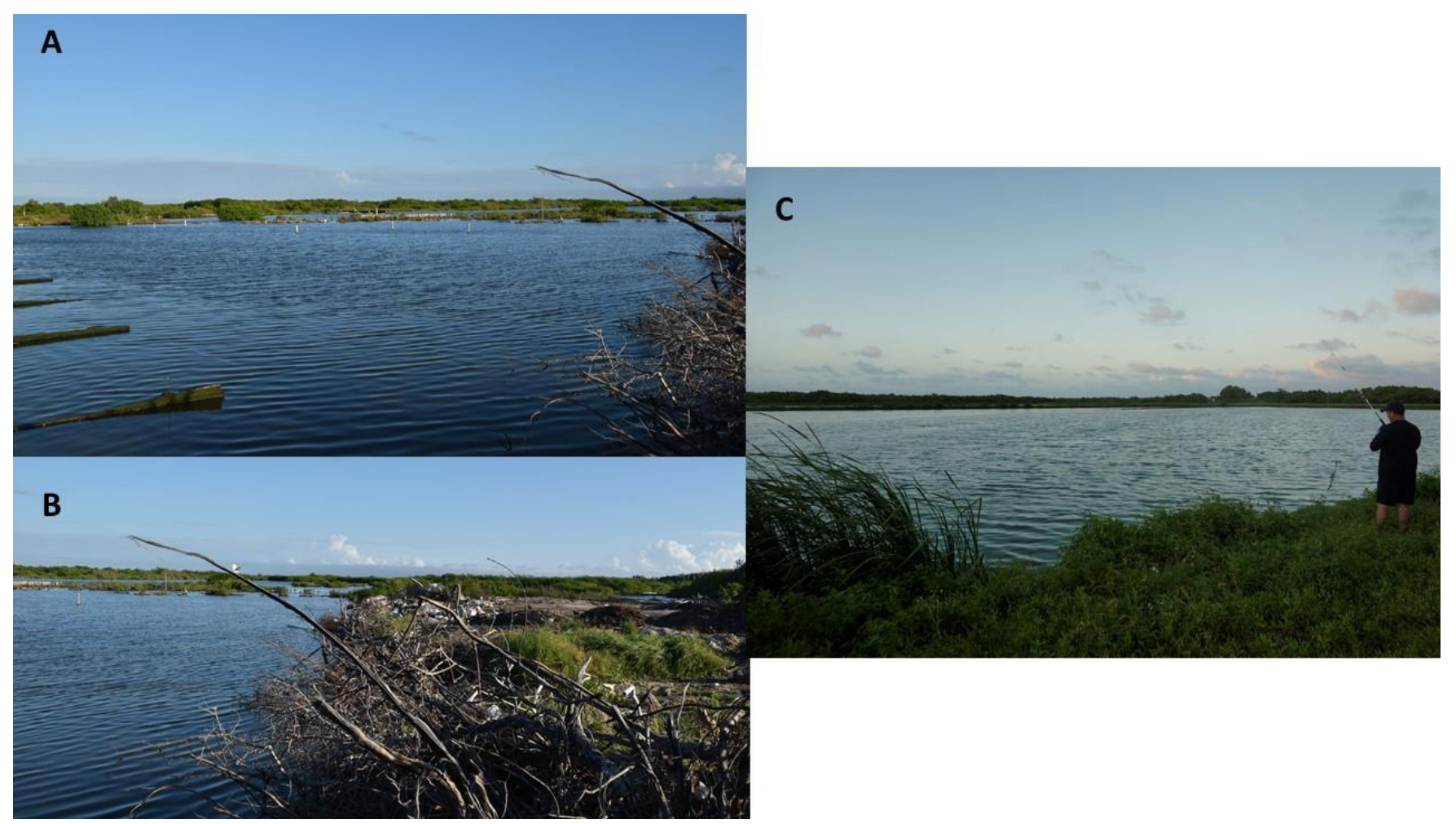

Figure 4. (A) Coco Beach study site showing sea wall to the left and dredged berms to the back of the lagoon. Main internal lagoon can be seen in the background ringed with mangroves. (B) Coco Beach showing shoreline being filled with industrial and household landfill. (C) San Pedro sewage ponds showing the left facultative lagoon. 


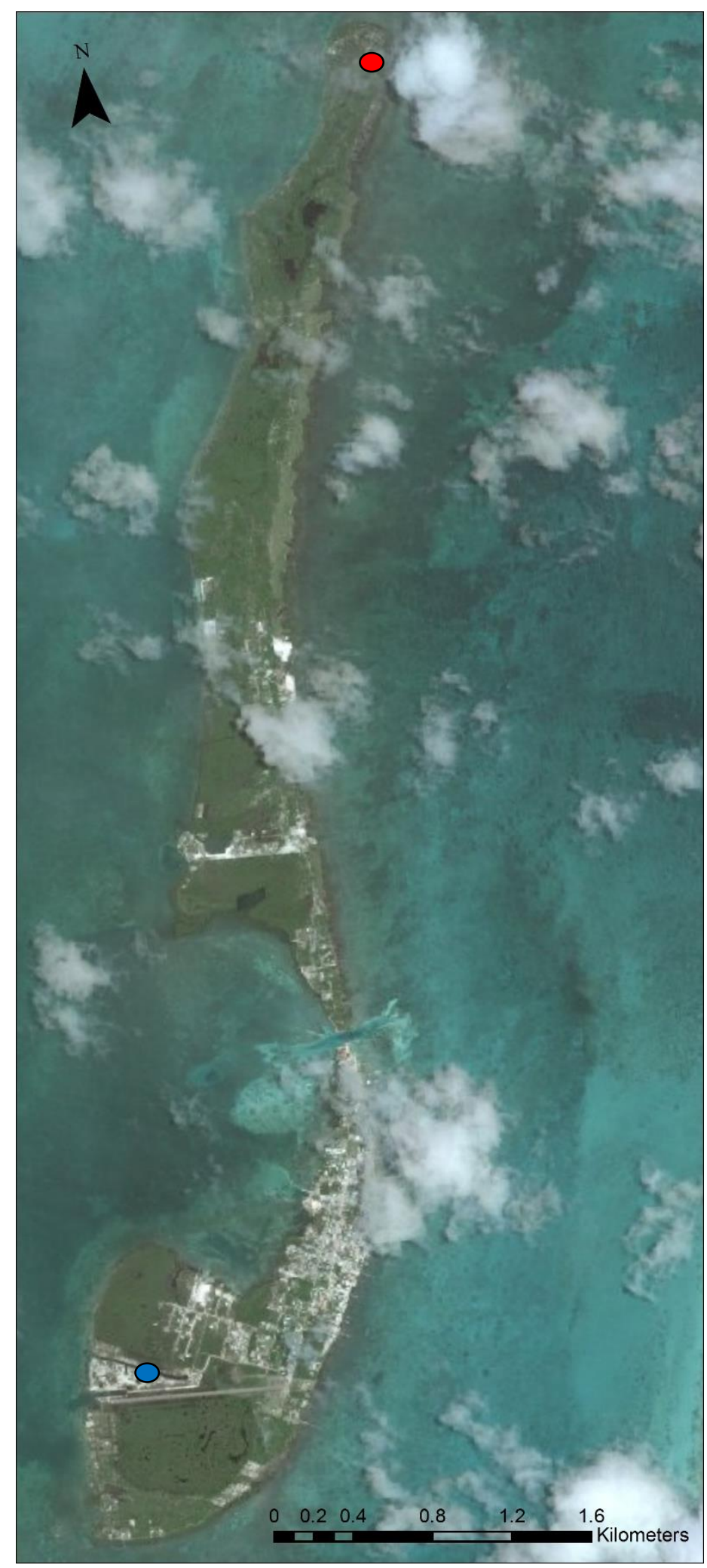

Figure 5. Caye Caulker study area. Behavioral observation sites are marked by colored circles; southern site (blue circle), and the northern site (red circle). 


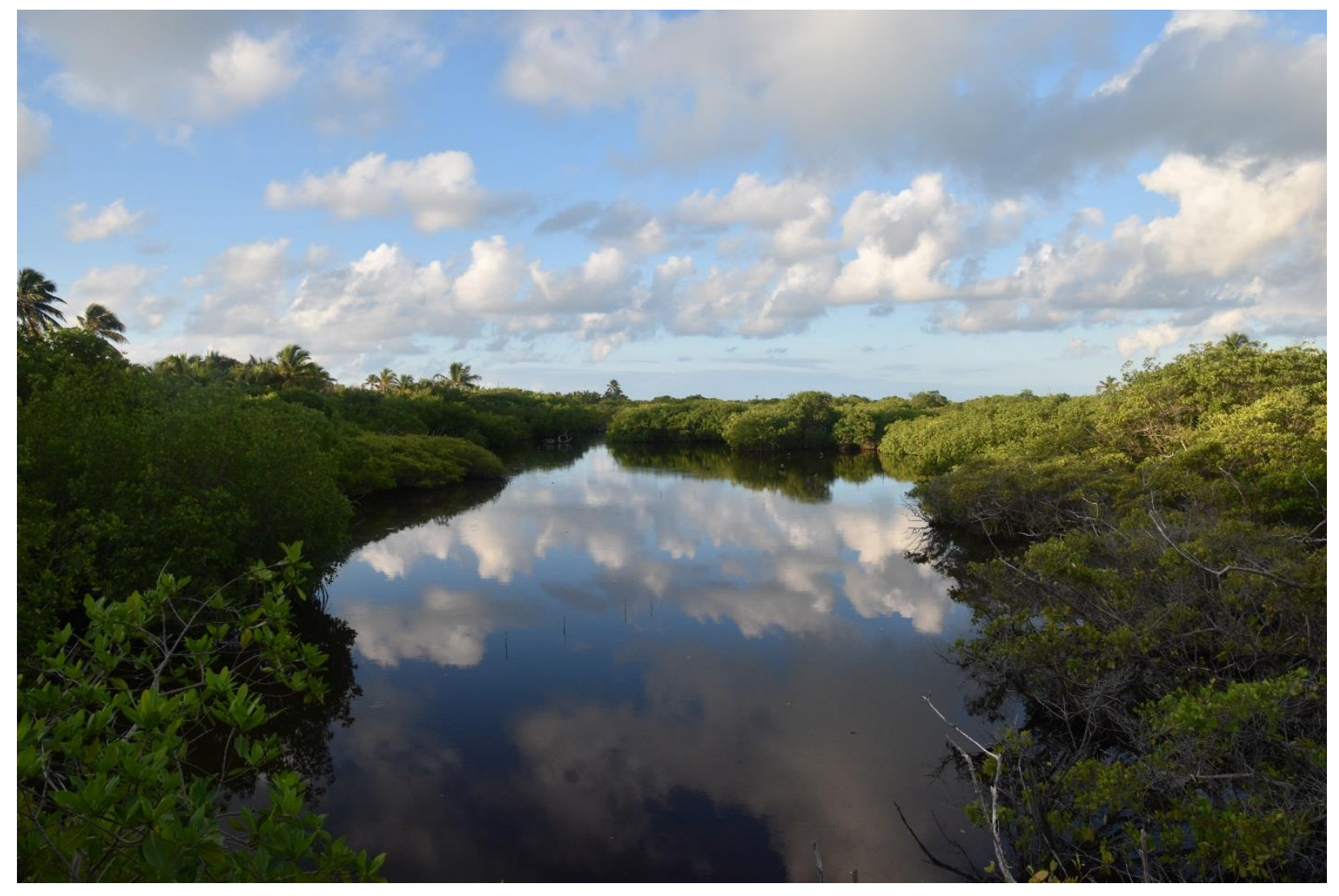

Figure 6. Northern behavioral observation site located in north Caye Caulker. 


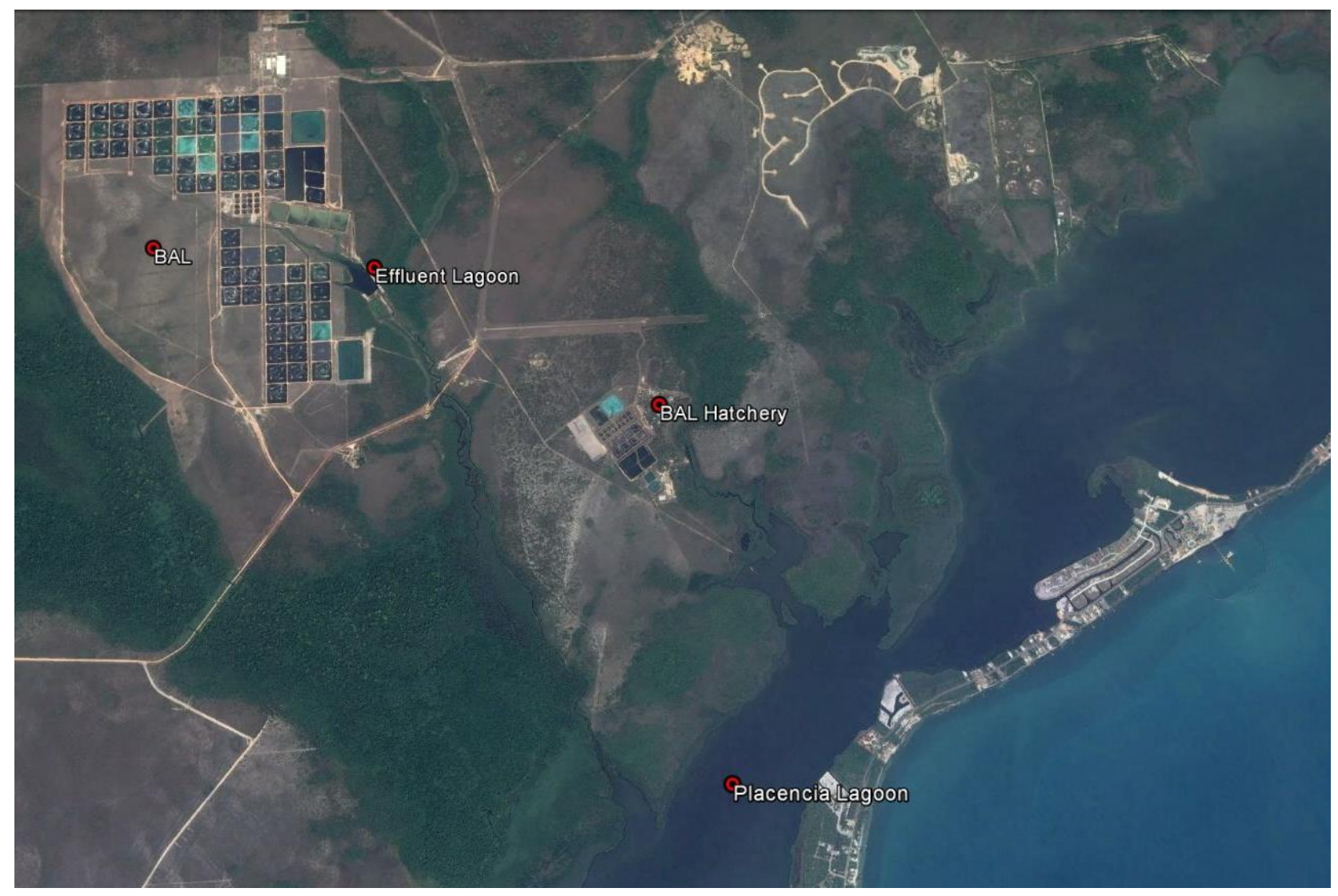

Figure 7. Belize Aquaculture Limited (BAL) property west of the Placencia Peninsula and lagoon. 


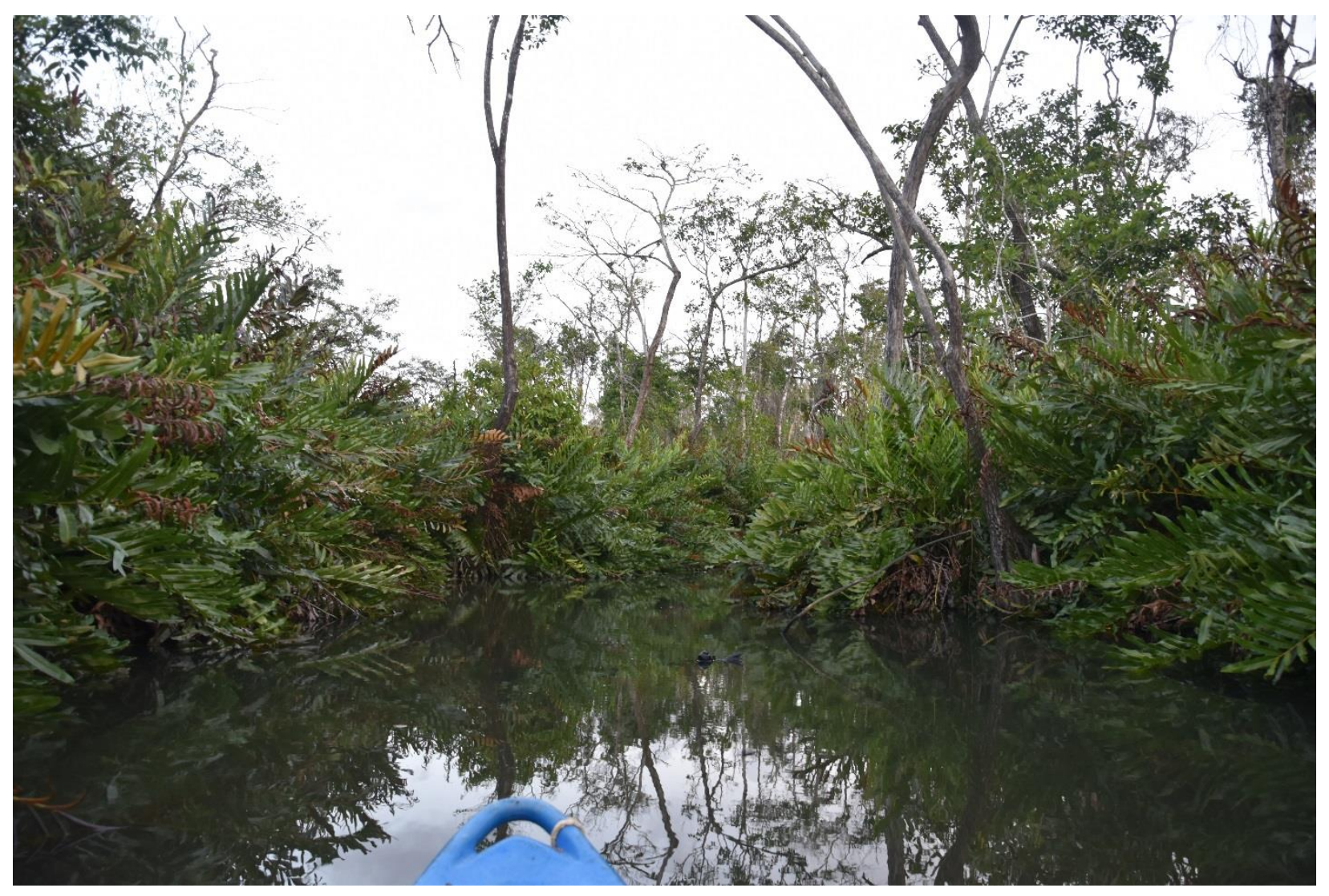

Figure 8. Tiger fern (Nephrolepis spp.) swamp and canal at Belize Aquaculture Limited North of the Placencia Peninsula. 
A B

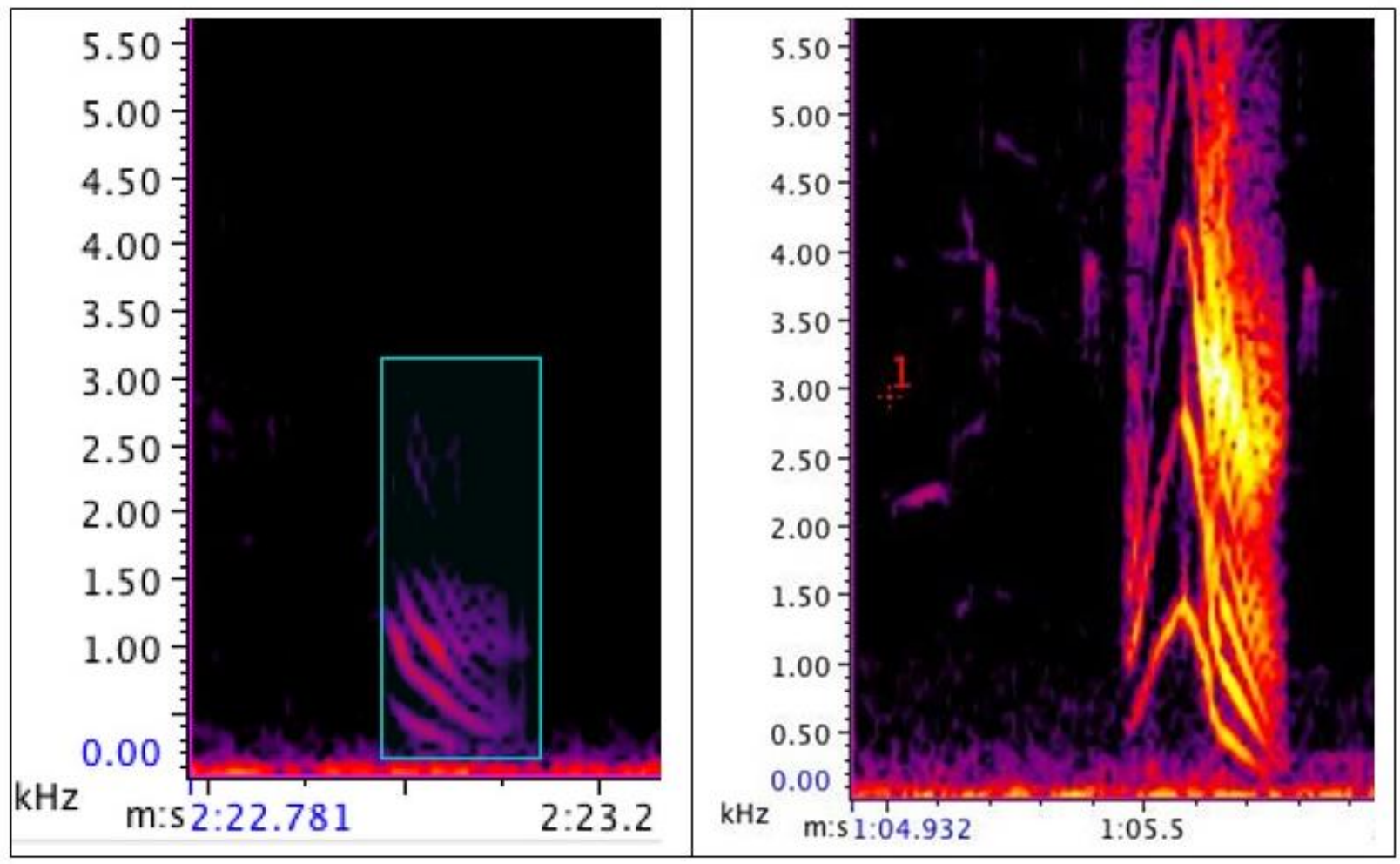

Figure 9. Acoustic structure of the principal vocalizations of juvenile American Crocodiles. (A) Spectrogram of a hatchling contact call recorded at approximately 2 weeks of age. (B) Spectrogram of a juvenile distress call $(30 \mathrm{~cm} 1$ month old) recorded during capture. 


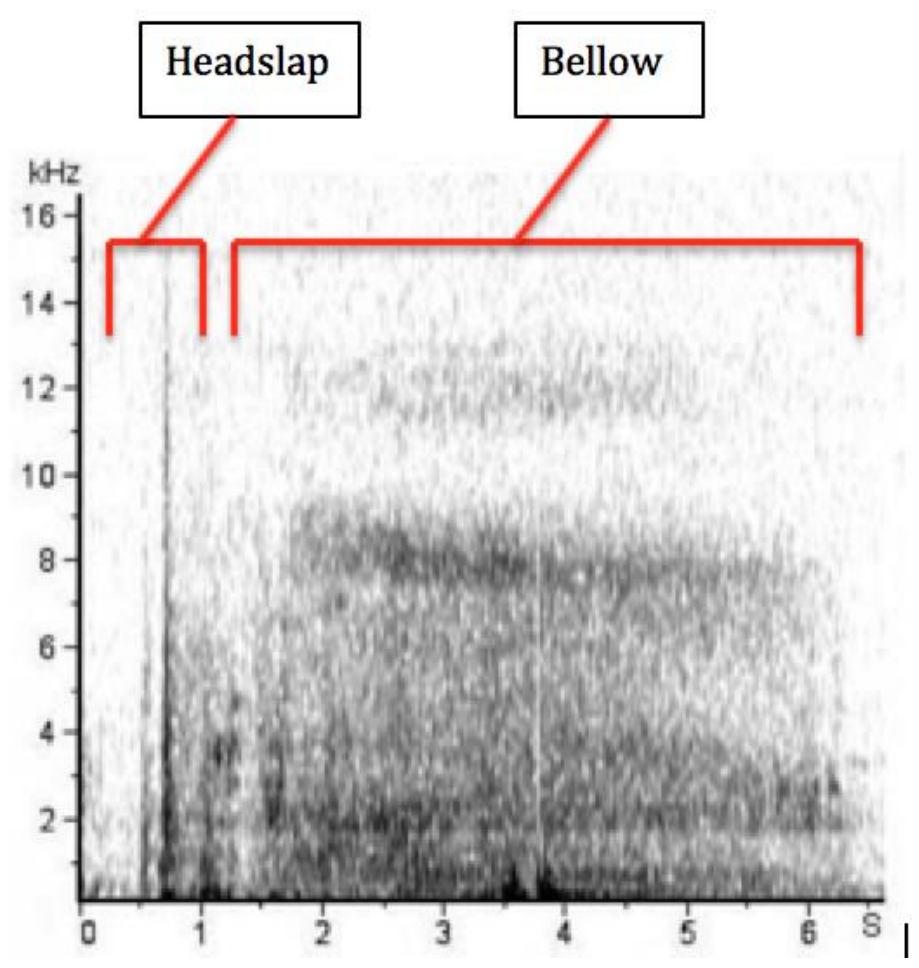

Figure 10. Spectrogram of American Crocodile headslap and roar recorded in Everglades National Park, Florida, USA (Dinets 2011). Sharp peak indicates headslap followed by roar. 


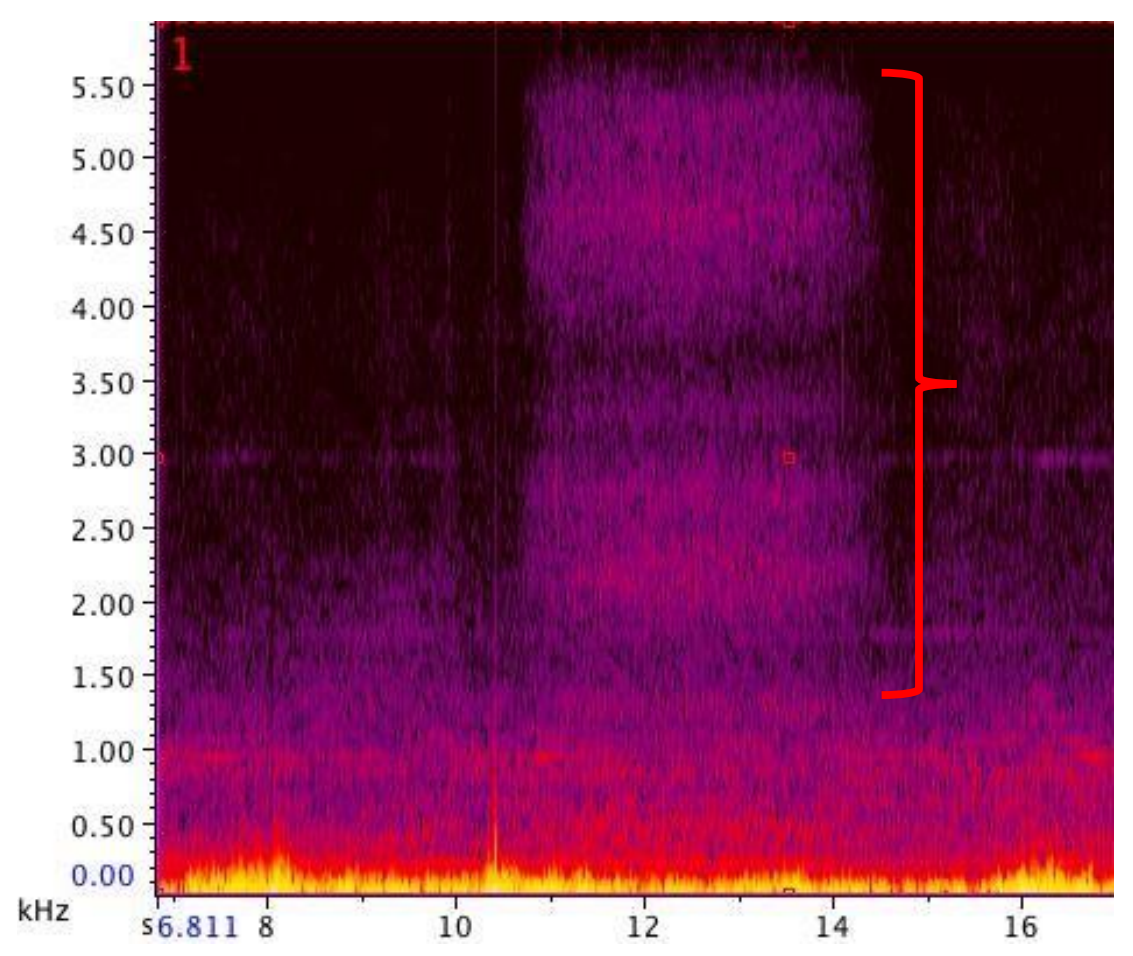

Figure 11. Adult American Crocodile hiss recorded during capture. Hiss is indicated by red bracket on the spectrogram and is characterized by low harmonic structure. 


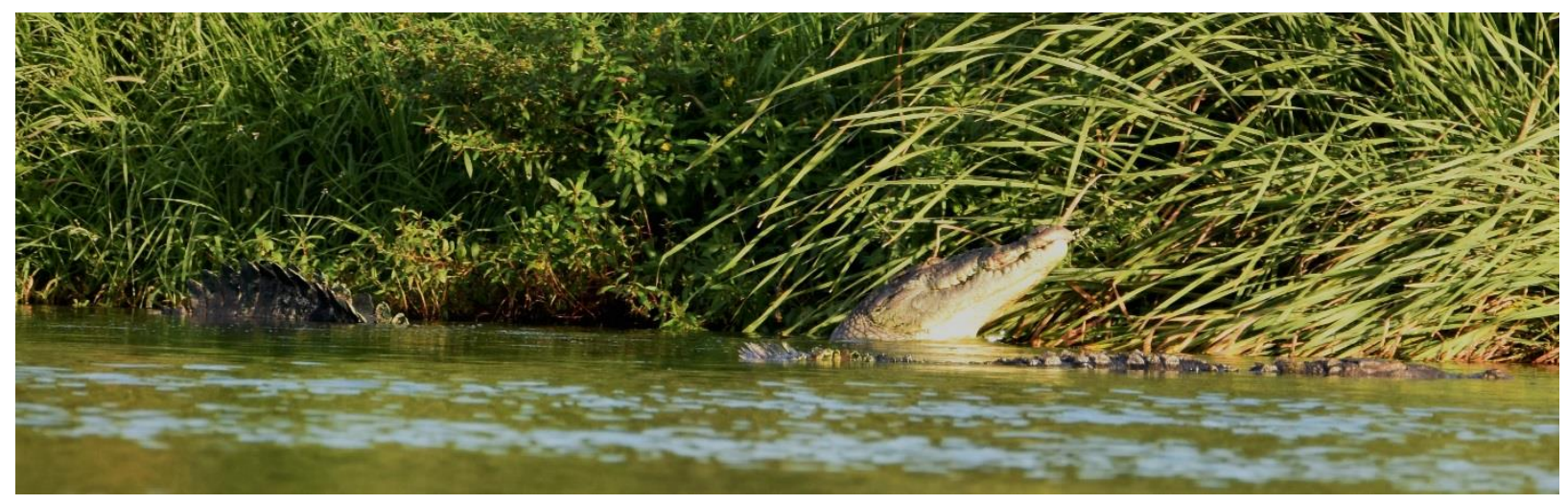

Figure 12. Head oblique tail arched (HOTA) position demonstrated by a large male American Crocodile in response to the proximity of another adult crocodile. 

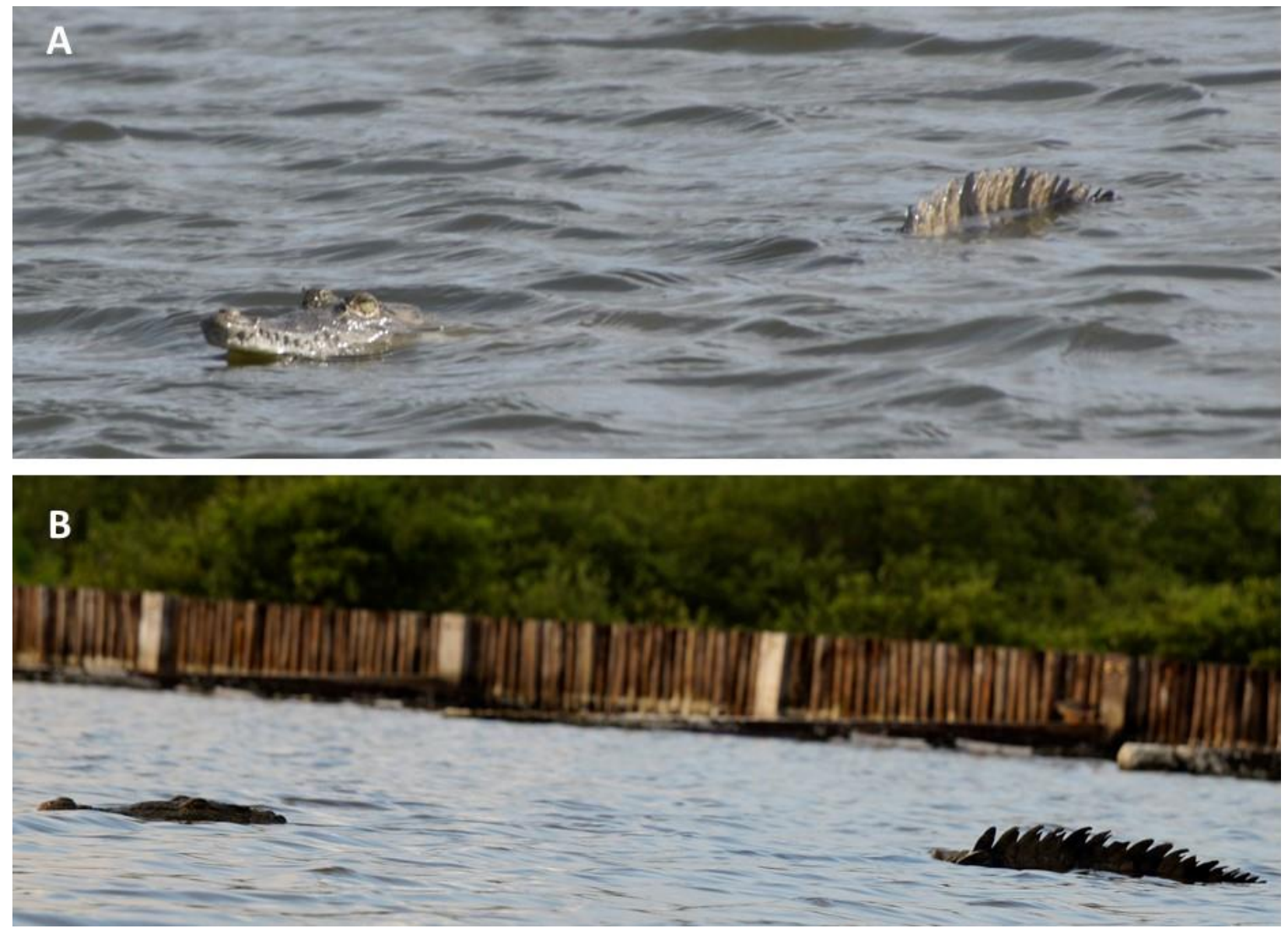

Figure 13. (A) Juvenile American Crocodile (1.2 $\mathrm{m}$ total length) displaying a raised tail in response to researcher presence on the shore. (B) Adult American Crocodile (2.5 m total length) displaying a raised tail to another crocodile (not shown) in close proximity as a possible warning to other crocodiles to stay away. 


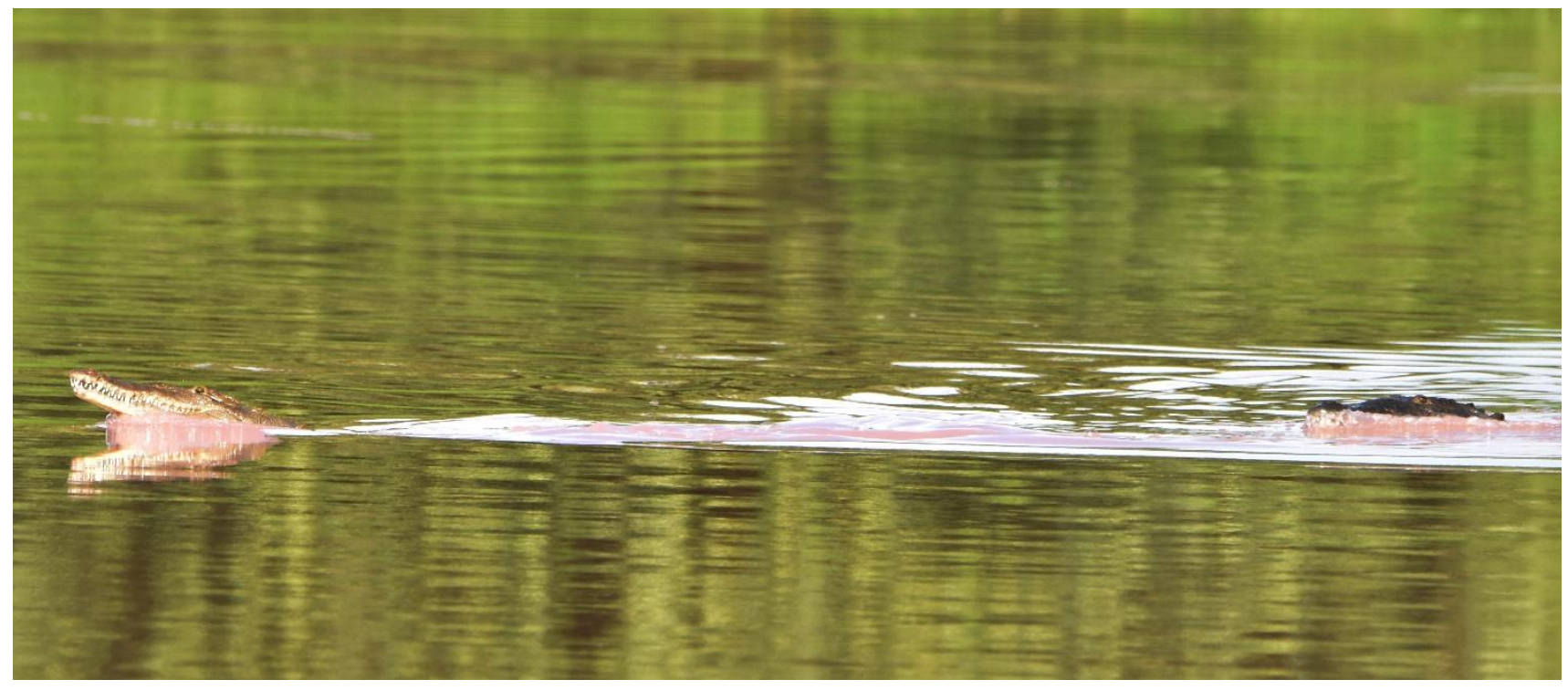

Figure 14. Snout lift by a submissive American Crocodile in response to being chased by a larger crocodile. 


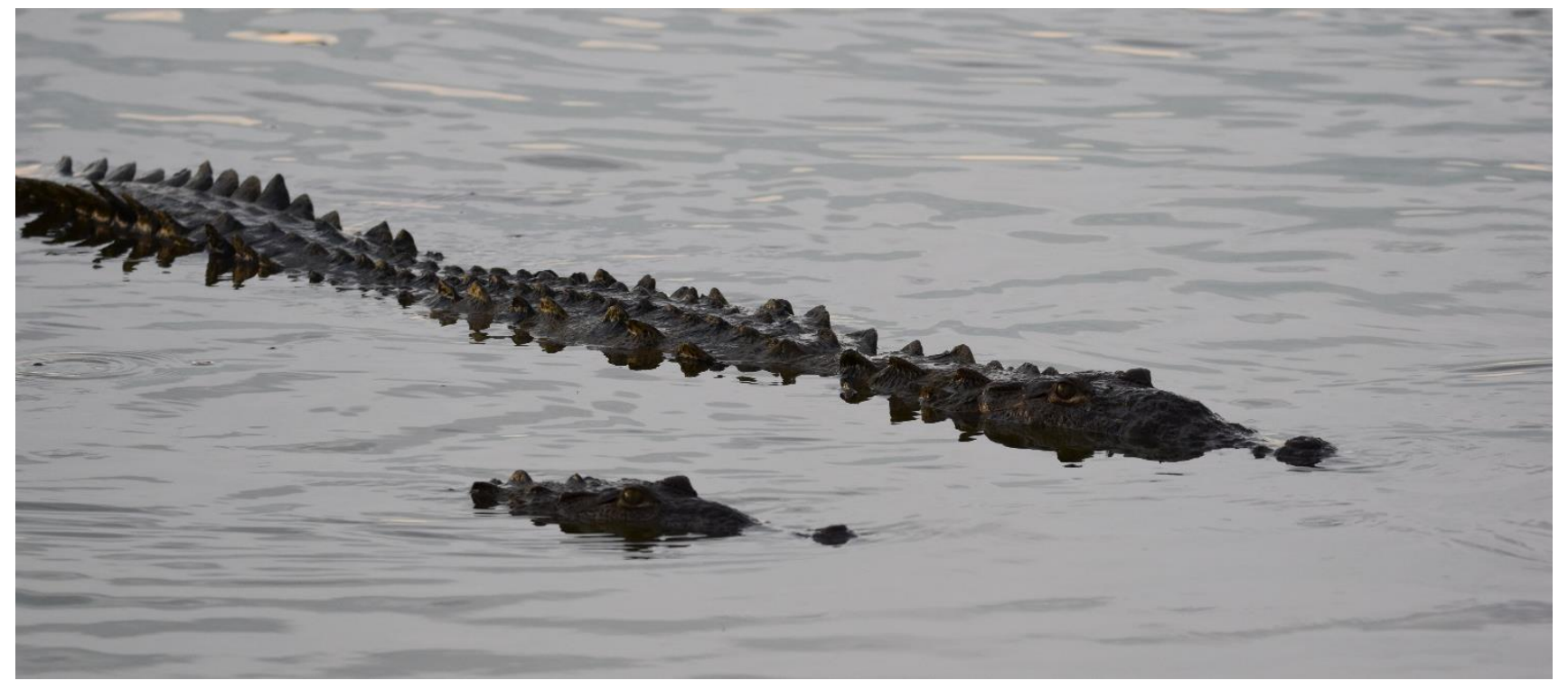

Figure 15. Adult American Crocodile adopting an inflated posture in response to human presence on the shoreline. 

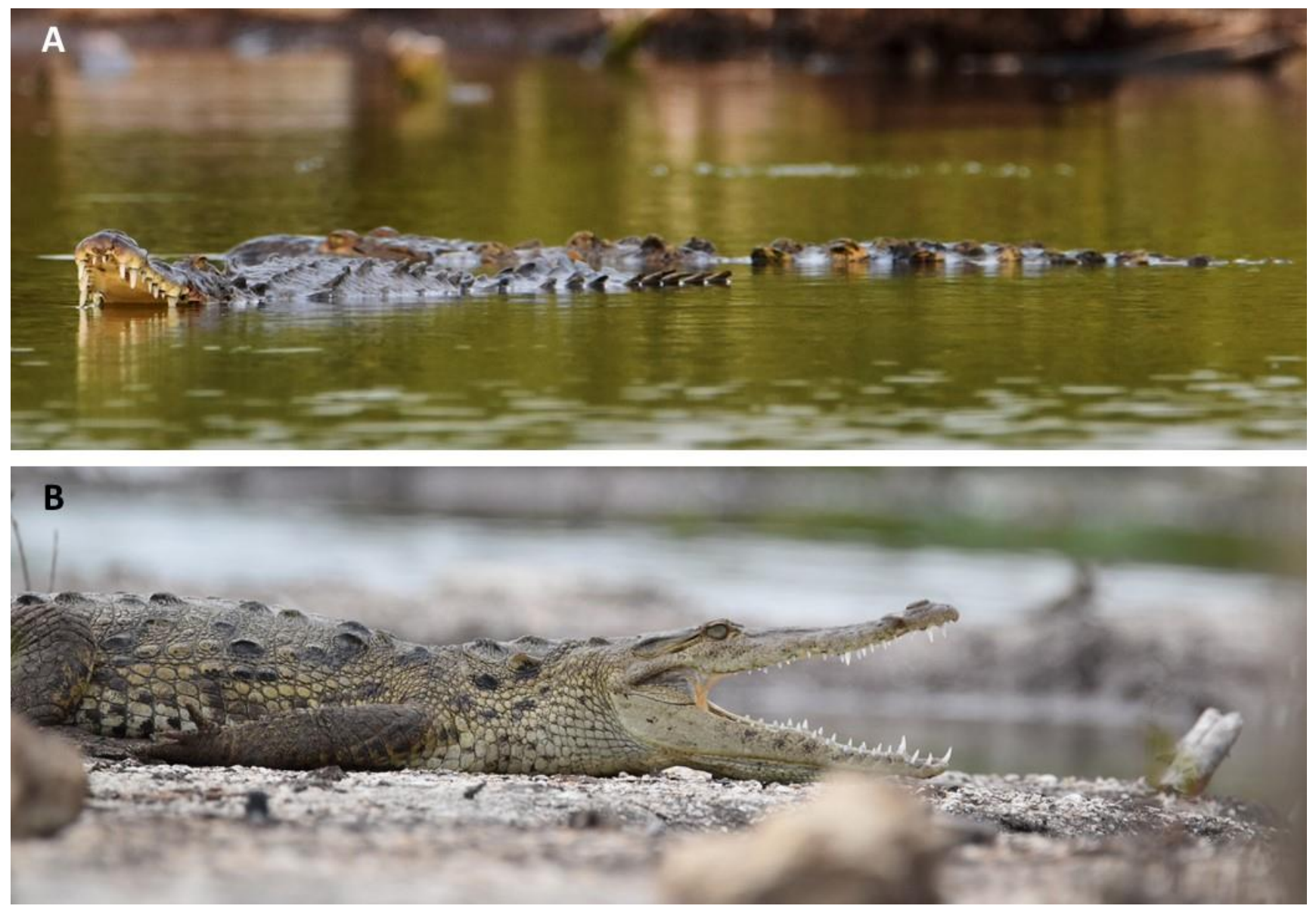

Figure 16. (A) An adult American Crocodile gapes as another larger crocodile passes in close proximity behind it in a threat display. (B) Gaping is most commonly associated with thermoregulation to prevent the brain from overheating during basking. 
A
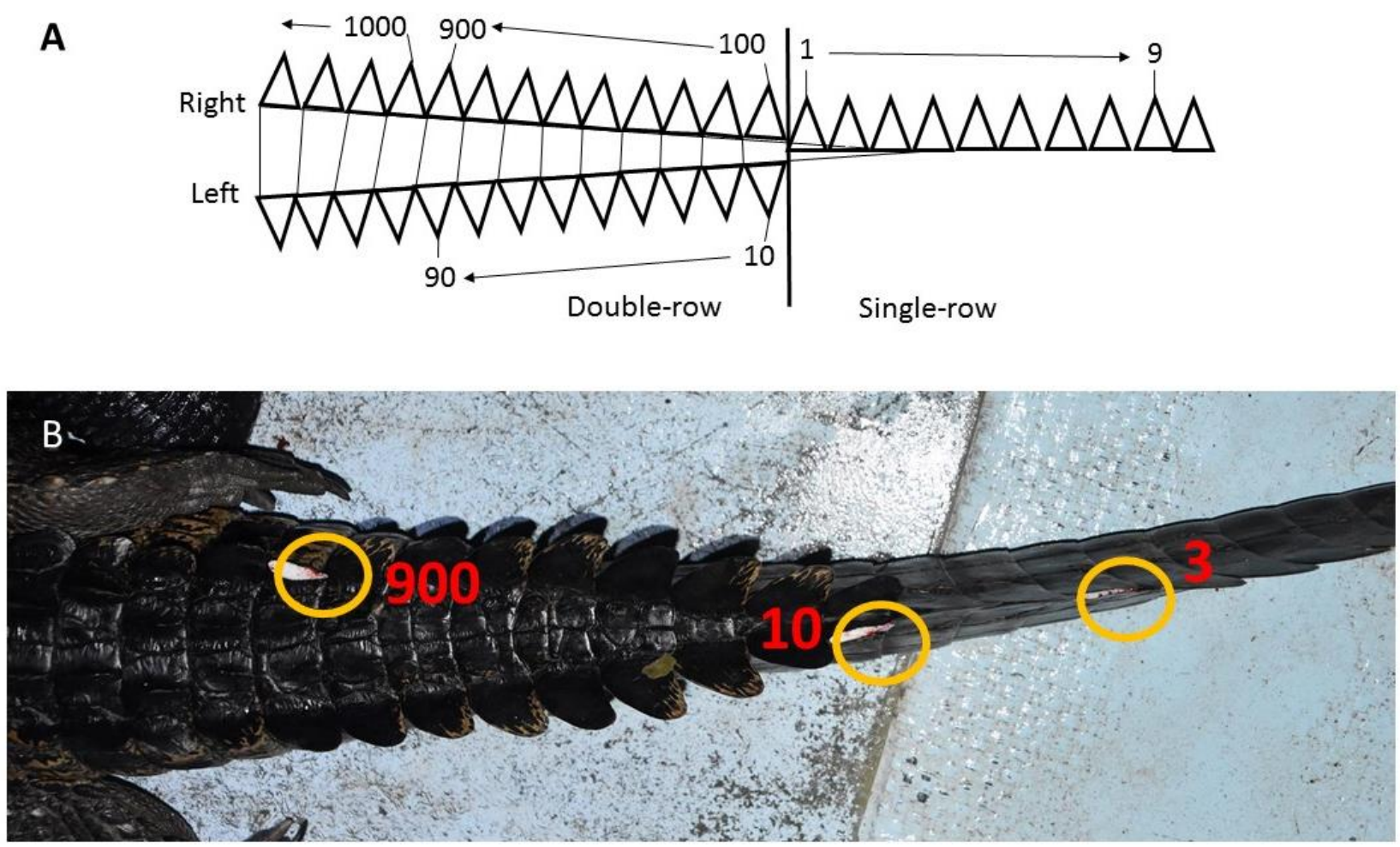

Figure 17. (A) Simplified numbering scheme for crocodile scute clipping in Belize. Caudal scutes are divided into a dorsolateral double row anteriorly and a single row extending medially to the posterior. (B) Example of scute clipping on a sub-adult American Crocodile illustrating the individual numerical code assigned through scute clipping. 

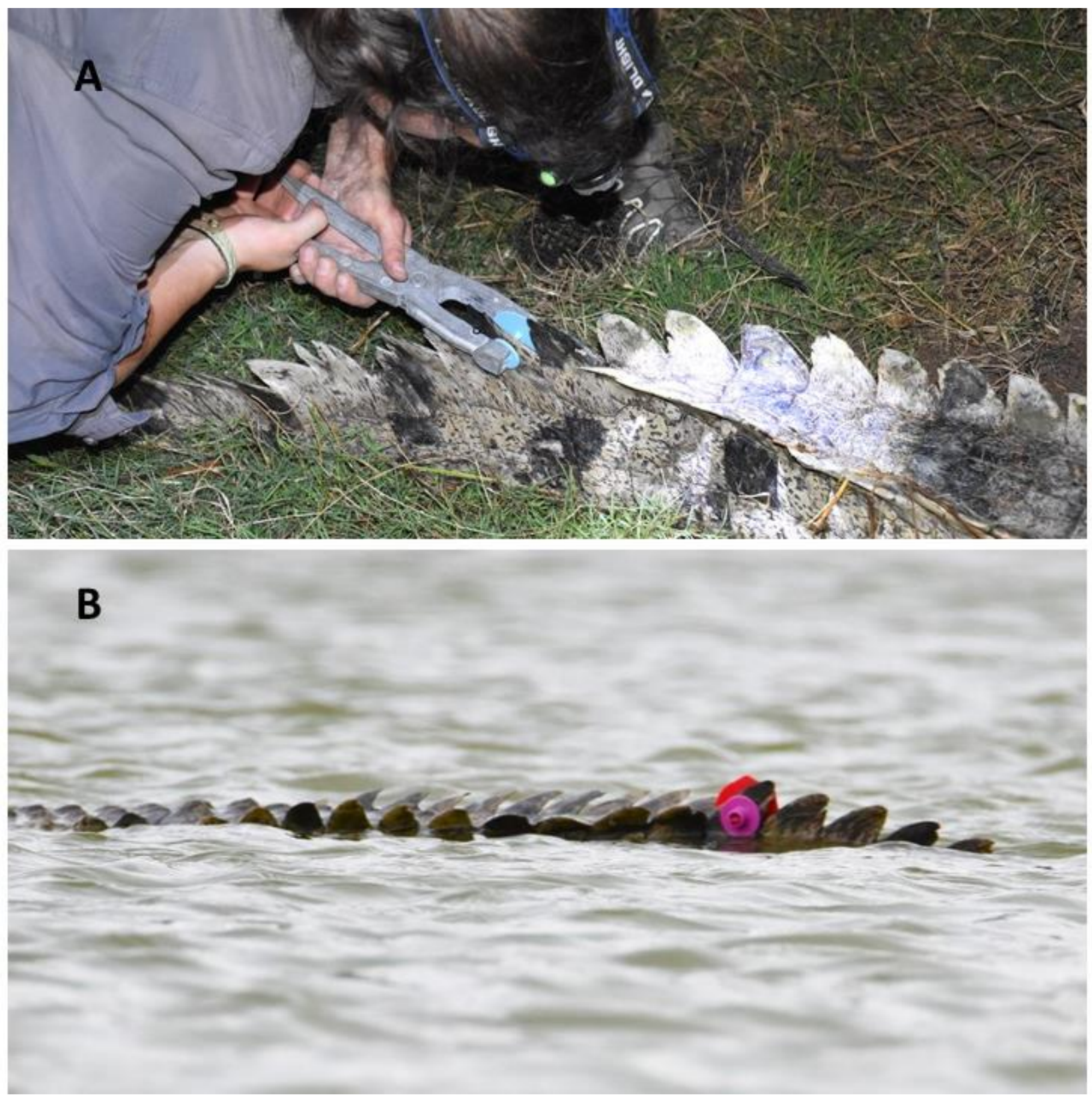

Figure 18. (A) Self-piercing plastic ear being applied to a captured American Crocodile in Belize. (B) Visual recapture of a tagged American Crocodile in Belize. Different tag color combinations are used to distinctly identify individual crocodiles in the field. 


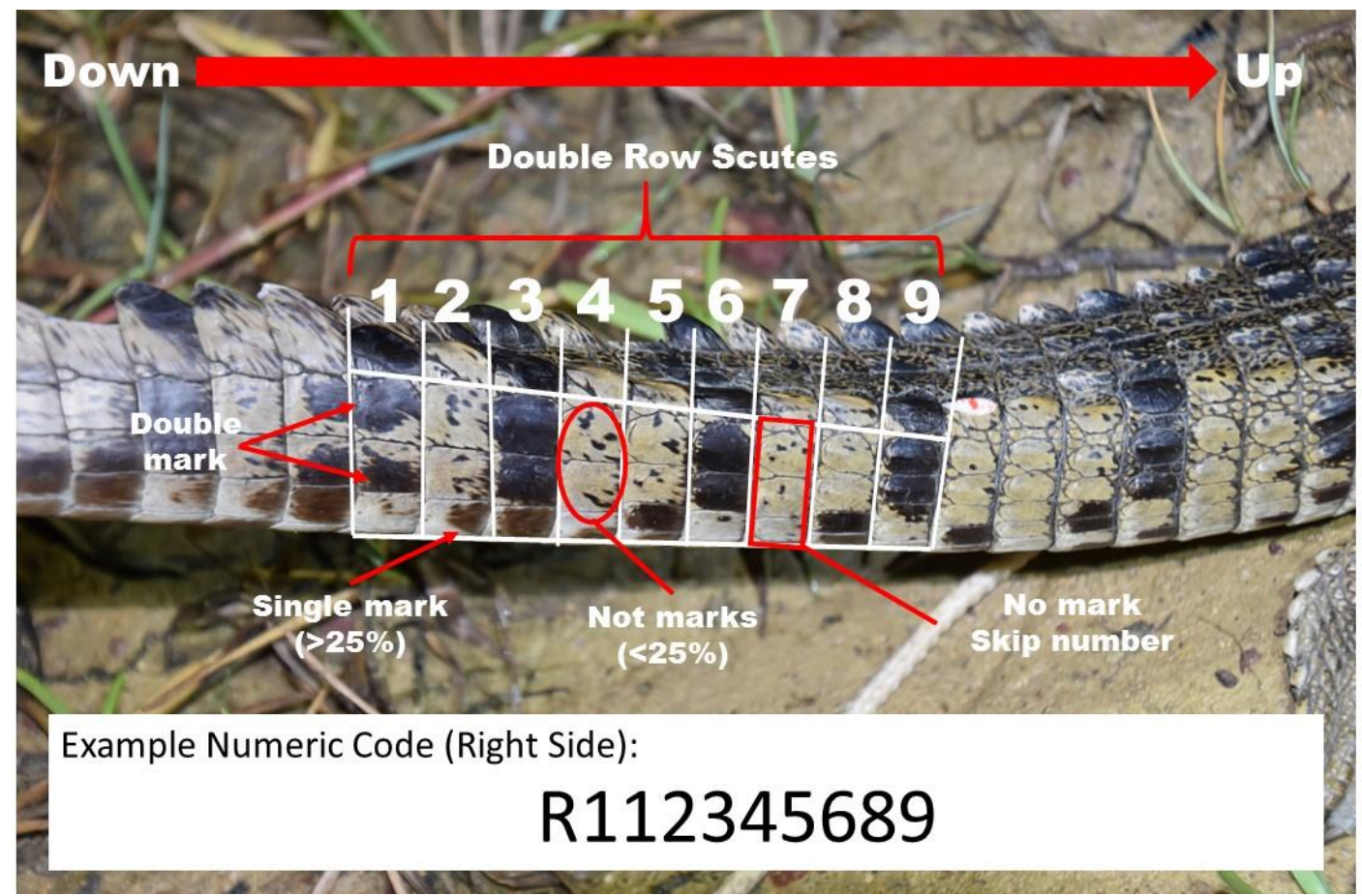

Figure 19. Example of a tail spot code generated for an American Crocodile using Swanepeol's (1996) method for numeric tail spot coding. Scute rows with markings are recorded and rows lacking markings are skipped. Rows with multiple markings are repeated in the sequence. 


\title{
CHAPTER 2
}

Activity Budget and Behavioral Patterns of American Crocodiles (Crocodylus acutus) in the Coastal Zone of Belize

\begin{abstract}
Miriam Boucher $^{1,2}$, Marisa Tellez ${ }^{3,4}$, and James T. Anderson ${ }^{1}$
\end{abstract}
${ }^{1}$ School of Natural Resources, West Virginia University, Morgantown, West Virginia, USA

${ }^{2}$ Corresponding author. E-mail: mnboucher01@gmail.com

${ }^{3}$ Crocodile Research Coalition, Maya Beach, Stann Creek, Belize

${ }^{4}$ Marine Science Institute, University of California Santa Barbara, Santa Barbara, California, USA

Written in the style of: Journal of Herpetology 
ABSTRACT.- American Crocodiles (Crocodylus acutus) are large-bodied crocodylians broadly distributed throughout coastal and lowland wetlands in the Americas. A vast majority of their habitat is threatened due to habitat destruction, and current management is limited in understanding anthropogenic impacts to crocodile behavior. Our study describes diurnal timeactivity budgets for American Crocodiles in Belize, and evaluated observed behavioral patterns in relation to a gradient of anthropogenic impact. We collected behavioral observations of wild crocodiles from multiple sites from May 2015 - August 2016, in conjunction with wetland impact assessments to quantify levels of anthropogenic disturbance. American Crocodiles allotted the greatest amount of time to performing maintenance activities fulfilling basic biological needs. We determined time allotment for other behaviors, particularly agonistic and social, to be proportionally greater at sites with greater anthropogenic disturbance, indicating human disturbance as a driver for altered activity patterns. Our research demonstrates that American Crocodile behavior and activity budgets are impacted by anthropogenic disturbance, and observed patterns of behavior indicate deleterious shifts towards unproductive and damaging activities.

Key Words: Conservation; Crocodylian; Ecology; Mesoamerica; Time-activity budget.

Wildlife are impacted by their environment, and documentation of behaviors, can serve as a metric for understanding interactions between wildlife and their respective ecosystems (Manning and Dawkins, 1998; Dwyer, 2004; Sumpter, 2010). Increasingly, anthropogenic activity is a factor that is changing and re-shaping wildlife behavior (Griffiths and Van Schaik, 1993; Luniak, 2004; Blickley and Patricelli, 2010; Hovick et al., 2014). Alteration of wildlife behavior in response to anthropogenic impacts can have deleterious effects on the biology and ecology of affected populations (Laiolo, 2010). Negative effects of anthropogenic activity are 
cause for concern, particularly for apex predators, which have strong, and sometimes cascading influence on ecosystems (Williams et al., 2004; Roemer et al., 2009; Nifong and Silliman, 2013; Heupel et al., 2014). Crocodylians are resilient predators that often live in close proximity to human settlement (Pooley et al., 1989). As ecosystem engineers and apex predators, they are keystone species in their respective habitats (Nifong and Silliman, 2013). Despite their importance within ecosystems, there still exists paucity of data regarding crocodylian behavior (Thorbjarnarson, 1989). In particular, there is need to further assess the behavior of wild crocodylians, and population response to anthropogenic activity and environmental change (Garrick and Lang, 1977; Thorbjarnarson, 1989; Vliet, 1989; Thorbjarnarson et al., 2006). To determine potential effects of human influence on crocodylians it is necessary to quantify behavior to monitor changes in response to anthropogenic driven environmental stressors.

Distributed from the southern tip of Florida, USA, to northern South America, American Crocodiles (Crocodylus acutus) have the widest distribution of the New World crocodylians (Ernst et al., 1999). Intense, unregulated exploitation for commercial harvest in the mid-1900s nearly extirpated this species in areas throughout its range (Thorbjarnarson, 1989; Thorbjarnarson et al., 2006). Still listed as Vulnerable by the International Union for the Conservation of Nature (IUCN, 2012), protection implemented through international and national laws has facilitated the recovery of some populations. Belize, once a stronghold of the American Crocodile, has experienced recovery of some offshore populations while mainland populations remain low and data deficient (Platt and Thorbjarnarson, 2000a). Although commercial hunting has ceased, pollution and habitat destruction have emerged as significant threats to current crocodile populations (Platt and Thorbjarnarson, 2000a; Tellez et al., 2016). As tourism and coastal development continues to expand it is reasonable to predict that there will be 
increases in conflict, both direct and indirect, between crocodiles and people. Previous behavioral studies in Belize have focused primarily on reproductive behavior (Platt and Thorbajarnarson, 2000b). There has been no dedicated study of American Crocodile behavior or activity budgets in Belize. Our study establishes the first time activity-budgets for American Crocodiles and assesses behavioral trends in relation to a gradient of human disturbance in Belize.

\section{MATERIALS AND METHODS}

Study Sites. - Belize is a small Central American country $\left(22,965 \mathrm{~km}^{2}\right)$ situated south of the Mexican Yucatan Peninsula and east of Guatemala (Fig. 1). We collected behavioral observations at three sites in Belize; Ambergris Caye, Caye Caulker, and Belize Aquaculture Limited in Stann Creek district.

Ambergris Caye is an extension of the Mexican Yucatan Peninsula separated by a small channel (Guderjan, 1995). We collected data from the Coco Beach Resort lagoon north of San Pedro town, and the San Pedro sewage ponds and Mahogany Bay Village development sites south of town. There are high relative densities of crocodiles at all sites ranging from $8-18$ crocodiles/km of lagoon and shoreline surveyed (Chenot-Rose, 2013; Boucher, pers. obs.).

Caye Caulker is an offshore island located $8 \mathrm{~km}$ south of Ambergris Caye. American Crocodiles are distributed along the entire island and recent population surveys have established a relative density of 2.4 crocodiles $/ \mathrm{km}$ of shoreline surveyed (Tellez et al., 2016). Due to the difficulty in accessing and locating resident crocodiles, we obtained observations opportunistically throughout the study area. Belize Aquaculture Limited (BAL) is a large commercial shrimp farm (3,642 ha) located $8.3 \mathrm{~km}$ east of the northern tip of the Placencia Peninsula. We observed crocodile behavior at the main effluent polishing lagoon, which has high relative crocodile density (11 crocodiles/km surveyed). 
Wetland Impact Assessment.- Concurrent to the collection of behavioral observations, we assessed sites using an adapted Human Disturbance Wetland Assessment. We ranked study sites using a 6-point scale (Table 1) to characterize human disturbance and identify environmental stressors (Maine Department of Environmental Protection, 2013). We assessed four categories of stressors; hydrologic modification to the wetland, vegetative modification to the wetland, evidence of pollutants, and acoustic disturbance and human contact. We used scores for the sites to determine an overall level of human disturbance for each study site.

Behavioral Observations. - We observed American Crocodiles on Ambergris Caye from May - August 2015, December 2015 - January 2016, and March of 2016. Caye Caulker observations were conducted January, March, and August 2016, and BAL observations were completed June - August 2016. The lead author conducted observations to reduce observer bias and the amount of human interaction with crocodiles during observation periods. We observed crocodiles during crepuscular hours as crocodile wariness and behavior was greatly influenced by human presence and artificial lighting at night (Marioni et al., 2008). This may be due in part to poaching pressure and response to past and concurrent trapping efforts. We did observe crocodiles nocturnally with the use of a night vision scope, but could not accurately observe or discern crocodiles in the water at night. Thus, our observations focused on hours of peak activity in the early morning and evening (Thorbjarnarson and Hernández, 1993; Dinets, 2011).

We conducted observations using focal animal sampling following the protocol of Altmann (1974). We conducted sampling for four hour periods, not including time for equipment set up and seasonal discrepancies in sunrise and sunset. Morning observation periods began predawn $0530 \mathrm{~h} \pm 1$ and concluded at $0930 \mathrm{~h} \pm 1$. We conducted evening observations beginning $1400 \mathrm{~h} \pm 1$ and terminating at full dark, approximately $1800 \mathrm{~h} \pm 1$. We recorded 
observations for all individual crocodiles visible at the observation site and added or removed crocodiles from the observation record as they entered or left the field of view of the observer. We estimated approximate total length for each focal animal to determine size class. As the focus for this study was adult behavior, we observed either sub-adult (TL $90-180 \mathrm{~cm}$ ) or adult (TL > $180 \mathrm{~cm}$ ) American Crocodiles (Platt and Thorbjarnarson, 2000a). We determined size classes by comparing individual crocodiles to known objects at the study site (Nair et al., 2012). Additionally some crocodiles observed at the study sites had been measured and marked as part of concurrent population tagging and monitoring program. We were able to use the known length of the marked individuals to determine size class during observations and comparatively determine size estimate for unmarked crocodiles. We recorded all (inter)actions for focal individuals in detail as well as behaviors directed at an individual by others. As time is a crucial factor for the determination of time-activity budgets, we recorded the duration of each observed behavior. We classified recorded behaviors into three categories: Maintenance, Social, and Agonistic (Table 2).

Statistical Analysis. — We compared proportion of crocodile time spent on activities among sites, and between morning and evening observation periods using a test of equal proportion $\left(\chi^{2}\right)$ with the Yate's continuity correction at a $95 \%$ confidence interval. We repeated the same analyses to perform pairwise comparisons of activities between sites and between activities following significant $\chi^{2}$ test $(P<0.05)$. Our data did not meet the assumptions of normality or homogeneity of variance, therefore we used non-parametric Kruskal-Wallis (H) test to compare mean duration among locations for categorized behaviors and individual activities. We followed significant Kruskal-Wallis tests $(P<0.05)$, with Mann-Whitney post-hoc testing and Bonferroni correction to determine differences between sites and activities. Statistical 
analyses were performed using RStudio version 0.99.902 (RStudio Team, 2015). We performed analyses assuming observed populations are independent of one another and that observed behaviors have equal likelihood of being performed across sites.

\section{RESULTS}

Wetland Impact Assessment.- Our wetland assessment at all three sites on Ambergris Caye indicated moderate to high human disturbance (rank $=3-4 ; X=3.7 ; \mathrm{SE}=0.19$ ) due to extensive habitat modification, pollution, and contact with humans. Moreover, Ambergris sites had nearly constant anthropogenic sound present from development, road, boat, and air traffic. Scores for Caye Caulker varied with location and human impact in the study area ranged from high $($ rank $=4)$ to no disturbance (rank $=0)$. Collectively, we determined Caye Caulker to be a site of low-moderate (rank $=2-3 ; X=2.5 ; \mathrm{SE}=0.30$ ) disturbance with few sources of constant sound production. Despite being a commercial aquaculture farm, The BAL site had minimal human impact. The effluent lagoon is located on the margins of the farm and received low chronic anthropogenic sound production in concomitance to low direct contact with people, and minimal pollution. Through assessment of the wetland, and associated habitat, we determined the study site to have low overall human impact (rank $=1-2 ; X=1.8 ; \mathrm{SE}=0.15)$.

Behavioral Observations.-During observations from May 2015 - August 2016 we recorded 13,975 minutes of American Crocodile behavior which produced 815 activity records across all three study areas. We recorded a mean of 7.0 ( $\mathrm{SE}=1.14$; range $=1-18)$ American Crocodiles per observation period. Totals of observed hours and animals differed across sites due to crocodile densities, sampling effort, and ability to effectively observe focal animals.

Overall, American Crocodiles in Belize spent the largest proportion of crepuscular time at the surface $40.3 \%$, followed by $31.3 \%$ basking, $16 \%$ submerged, and $4.1 \%$ swimming. 
Foraging (3.8\%), aggression (2.5\%), and social signaling contributed to the smallest overall proportions of crocodile activity. We determined that crocodiles spent the highest overall proportion of time performing maintenance activities (94.8\%) followed by $3.2 \%$ of time performing agonistic behaviors, and $2 \%$ on social interactions. Overall, we observed American Crocodiles to be more active during the morning observation periods. Maintenance activities accounted for a proportionally greater amount of crocodile time during the morning observation block (96\%) as compared to the evening (93\%; Table 3). We observed American Crocodiles spending proportionally more time engaging in social behavior during the morning activity period. In contrast to social behavior, we observed American Crocodiles to engage more in agonistic interactions during evening hours. Crocodiles foraged more during morning hours, and spent more time basking during the evening (Table 3).

Proportion of time spent on all activities differed among sites $(P<0.001)$ with the exception of basking (Table 4). American Crocodiles at Ambergris Caye spent proportionally greater time performing agonistic activities compared to Caye Caulker and BAL $\left(\chi^{2}{ }_{1,5213}=\right.$ 497.31; $P<0.001)$. Correspondingly, we determined the proportion of social behavior to be greater on Ambergris Caye in relation to Caye Caulker and BAL $\left(\chi_{1,5213}^{2}=87.54 ; P<0.001\right)$. We also observed that crocodiles at Caye Caulker and BAL spent greater time loafing at surface as compared to Ambergris Caye $\left(\chi^{2}{ }_{1,7006}=68.70 ; P<0.001\right)$.

Mean duration (minutes) of categorized behaviors differed significantly among sites $\left(\mathrm{H}_{2}\right.$ $=17.02 ; P<0.001)$ as did mean duration of individual activities $\left(\mathrm{H}_{2}=17.64 ; P<0.001\right)($ Table 5). However, our pairwise comparisons of categorized behaviors and observed activities among sites yielded fewer significant results. We found that mean duration of maintenance behavior varied among all sites $\left(\mathrm{H}_{2}=10.13 ; P=0.006\right)$. Agonistic and social behavior means did not 
significantly differ among sites $(P>0.05)$. Of the behaviors we observed, mean duration of time spent at the surface $\left(\mathrm{H}_{2}=12.05 ; P=0.002\right)$, and time spent submerged varied among sites $\left(\mathrm{H}_{2}=\right.$ 8.12; $P=0.017$ ). All other behavior and activity means (aggression, basking, foraging, swimming, social signaling) did not differ significantly among study sites $(P>0.05)$. Overall mean durations of activities on Ambergris $\left(\mathrm{H}_{6}=88.53 ; P<0.001\right)$, Caye Caulker $\left(\mathrm{H}_{5}=15.85 ; P\right.$ $=0.007)$, and BAL $\left(\mathrm{H}_{6}=87.40 ; P<0.001\right)$ varied $($ Table 5$)$.

\section{DISCUSSION}

Our results are the first to detail variation of activity levels for wild sub-adult and adult American Crocodiles during diurnal hours. Although nocturnal activity likely varies from our results, diurnal activity is important to record as it is the most easily observed occurs at times when people and crocodiles are most likely to interact. As such, diurnal activity-budgets allow for effective long-term monitoring and provide information on crocodile behavior to inform human use of crocodile habitat during diurnal hours. Population dynamics across sites differed and we did not analyze activity budgets or patterns between sub-adults and adults as samples sizes for sub-adults are not sufficient. However, it is noted that microhabitat use for sub-adults and adults are similar (Thorbjarnarson, 1989) and we did not observe overt discrepancies in behavior between the two size classes. Our data are the first to the detail activity budgets of American Crocodiles, and further research could facilitate robust comparison of activity variance between size classes.

Maintenance behaviors that include activity to sustain daily function and survival dominated crocodile behavior during crepuscular hours, particularly during the morning hours. We found that American Crocodiles dedicated a greater proportion of their time to maintenance behaviors at study sites with lower human impact rankings, such as Caye Caulker and BAL. 
Overall, mean duration of maintenance behaviors differed significantly across sites. Of the maintenance behaviors observed, foraging accounted for the smallest proportion of activity. We did not readily observe American Crocodiles foraging during diurnal hours; foraging is likely a nocturnal activity (Alvarez del Toro, 1974, Thorbjarnarson, 1989). Evidence from our study supports this as crocodiles foraged most frequently in the pre-dawn morning hours. We commonly observed juvenile crocodiles foraging and eating, small fish along shorelines during nocturnal surveys. Our observations confirmed that fish and crab are the primary prey items consumed by American Crocodiles in our study sites; and despite prolific abundance of shorebirds and wading birds at Ambergris Caye and BAL study sites, we rarely observed depredation of these birds. However, two separate observations were made of crocodiles feeding on a Double-crested Cormorant (Phalacrocorax auritus) and a Cattle Egret (Bubulcus ibis). We noted halfhearted attempts by adult crocodiles to prey on shorebirds, and we often sighted birds within one meter of crocodiles both in and out of the water. It is likely that the predation of birds is opportunistic or more frequent during nocturnal feeding times when crocodiles are less conspicuous.

Basking is the most conspicuous of the observed behaviors. Crocodiles bask as the primary means for thermoregulation and observed basking behavior occurred more during afternoon hours and higher daytime temperatures. Lack of significance among locations indicates that activity allotment for thermoregulation is consistent across sites. Temperature relations for adult and sub-adult American Crocodiles are not well defined (Thorbjarnarson, 1989). However, observations in Belize demonstrate that thermal requirements are likely similar for crocodiles throughout the coastal zone of Belize. 
Idling at the surface, another proportionally dominant behavior, differed among sites, which may be a reflection of environmental stressors. Overall, we observed crocodiles spending proportionally greater time at the surface during the morning observation period. Crocodiles on Caye Caulker spent the greatest time at the surface. Our observation of crocodile behavior on Caye Caulker, during population monitoring, noted crocodiles less wary and reactionary to approach by people during surveys and capture (Tellez et al., 2016). This behavioral tendency may be attributed to lessened human impact in the area and little illegal hunting or harassment pressure. Increased human activity and harvest pressure has been noted to cause increased wariness in crocodylians (Webb and Messel, 1979; Verdade, 1996). Conversely, we observed crocodiles at Ambergris Caye spending the smallest overall proportion of time at the surface in relation to the other two sites. This site also has the highest amount of disturbance and there is more direct human interaction with crocodiles through relocations and conflict with local communities (Boucher, pers. obs.). Compared to observations at Caye Caulker and BAL, Ambergris Caye crocodiles spent more time at the surface posturing and engaging in agonistic activities as opposed to resting at the surface. Moreover agonistic behavior on Ambergris Caye appeared to have less contextual relevance than at other sites.

We observed agonistic behavior observed at Caye Caulker and BAL performed in direct response to interactions between crocodiles or to human presence at the observation site. Conversely, on Ambergris Caye, we recorded crocodiles spending extended periods of time posturing and showing aggression outside of interactions with other crocodiles and people. Despite greater overall observations and relative crocodile density at BAL, we observed less agonistic behavior both proportionally and as a reflection of total time. As territorial and dominance behaviors are density-dependent, it is counterintuitive that BAL, with the highest 
crocodile densities, demonstrated a significantly lower proportion of agonistic behavior (Lang, 1989). The observation sites at BAL are also those with the least severe human impact for the entire study area. Therefore, data suggests that agonistic and aggressive behavior is more predominant at the site with greater anthropogenic disturbance. Determination of agonistic behavior patterns for Caye Caulker cannot be inferred as we recorded only one observation of agonistic behavior. This is likely due to the difference in population dynamics of crocodiles on Caye Caulker as the population is less concentrated and more widely distributed among suitable habitats (Tellez et al., 2016). Additionally, crocodiles observed on Caye Caulker had little agonistic response to other conspecifics and people which may be attributed to less human impact and exploitation (illegal hunting).

In compliment to agonistic behavior patterns, we observed social behaviors to be proportionally higher at Ambergris Caye sites. Our difficulty in observing crocodiles on Caye limited observations of social behavior. This may also be another reflection of the population dynamic of the island as crocodiles are less gregarious and social interaction is limited. Despite greater number of observations and higher crocodile densities, we observed proportionally less social behavior at BAL as compared to Ambergris Caye. However, we did observe different social dynamics between Ambergris Caye and BAL. We observed crocodiles at BAL to frequently be in close proximity to one another without engaging socially. Despite increased density there appeared to be less direct social interaction than on Ambergris Caye. Moreover, the hierarchal structure appeared better defined in the BAL population. Dominance hierarchies are common in crocodylian populations, and larger size and aggressive temperament are characteristic of dominant crocodiles (Lang, 1989). We frequently observed the largest observed crocodile at BAL $(\mathrm{TL}<4 \mathrm{~m})$ patrolling the study site and recorded this individual recurrently 
engaging in social interaction. Among the rest of the BAL population, we observed that smaller individuals generally moved away from larger crocodiles and did not engage in social or agonistic exchanges. This differed greatly from our observations at Ambergris Caye, particularly at the Coco Beach study site, where there appeared to be no dominance hierarchy and crocodiles frequently engaged in social interactions and agonistic behavior. Dominance did not follow general protocol at Ambergris sites and we frequently observed smaller crocodiles hassling larger animals during social interactions. We observed these behaviors outside of the natural cycle of increased interaction (i.e. breeding season), which indicates behavioral shifts may be due to increased stress in highly impacted habitats as opposed to natural processes.

Although proportionally significant, we did not observe swimming to have a distinct pattern across sites. We observed crocodiles swimming at all sites and dominant crocodiles patrolled territories at Ambergris and BAL. Habitat structure may play a role in increased swimming activity at BAL as the lagoon is linear in shape and crocodiles moved along the shoreline to access basking areas and to forage. Despite variable habitat on Ambergris Caye we observed slightly less swimming behavior than at the BAL site. We could not consistently observe crocodiles swimming at Caye Caulker as dense mangroves along the shoreline obstructed observations. Crocodiles submerging also appeared to have less behavioral context. We observed marked increases in crocodiles submerging and time spent submerged as daytime temperatures increased. Records of American Crocodile behavior in Mexico also note that adult crocodiles conceal themselves in deep water during periods of high daytime temperature (Alvarez del Toro, 1974). Additionally, it is likely that frequency and proportion of time spent submerged differed across sites as a result of environmental factors such as canopy cover, and air and water temperature as opposed to crocodile density or human impact. This study did not 
investigate the relationship between environmental factors and crocodile activity, but there does appear to be a relation between these factors and crocodile submersion.

Conclusions. - This project is the first dedicated behavioral study of American Crocodiles in Belize. Proportion of time allotted for recorded activities differed greatly across the study areas and observed trends indicate anthropogenic influence as a driver for behavioral differences. In particular, we observed agonistic and social behaviors more by total time and proportion at highly disturbed sites. We observed this trend in spite of higher population density and observation numbers at the site with the least human impact. The effects of human presence in, and modification of, crocodylian habitat must be further explored and should be considered in management planning. There is increasing evidence of physical and physiological ramifications from pollution and degradation of American Crocodile habitat (Tellez, unpublish.). As such the impact of these stressors is being integrated into management and conservation planning. However, anthropogenic degradation of crocodile habitat has broader consequence for overall crocodile ecology apart from diminished health. Our results indicate that crocodiles modify behavior and activity budgets in areas with high human disturbance. This may have overarching influence on foraging, courtship and breeding, social behavior, and general fitness that may be compromised through increased conflict between crocodiles or insufficient time allocation for maintenance activities. As such, consideration for anthropogenic impact on crocodile behavior and activity should be integrated into conservation measures to mitigate further disruption of crocodile ecology and fitness. 
Acknowledgments. - We thank the Belize Forest Department for their support of this project (permit CD/60/3/15(45)) and the Crocodile Research Coalition for logistic assistance. Fieldwork in Belize was assisted by many individuals including S. Heflick, H. Sung, K. Kolhman, D. Brianne, and A. Austin. Statistical support was provided by L. Stiffler. Financial support of this study was provided by the Explorer's Club, the IUCN/SSC-Crocodile Specialist Group Student Research Assistance Scheme, the West Virginia University Davis College Dr. David E. Samuel Faculty Excellence Award, the West Virginia University Natural History Museum, and The James. T. Anderson lab. This is Scientific Article XXXX of the West Virginia Agricultural and Forestry Experiment Station, Morgantown. Protocol approved by the West Virginia Institutional Animal Care and Use Committee (Protocol \# 15-0703). 


\section{LITERATURE CITED}

Altmann, J. 1974. Observational study of behavior: sampling methods. Behavior 49:227-266.

Alvarez del Toro, M. 1974. Los Crocodylia de Mexico, estudio comparativo. Instituto Mexicano de Recursos Naturales Renovables, México.

Blickley, J. L., and G. L. Patricelli. 2010. Impacts of anthropogenic noise on wildlife: research priorities for the development of standards and mitigation. Journal of International Wildlife Law and Policy 13:274-292.

Chenot-Rose, C. R. 2013. American Crocodile, Crocodylus acutus, population census in Ambergris Caye, Belize, Central America. Report to Belize Forest Department.

Dinets, V. 2011. The role of habitat in crocodylian communication. Ph.D. Dissertation, University of Miami, USA.

Dwyer, C. M. 2004. How has the risk of predation shaped the behavioral responses of sheep to fear and distress? Animal Welfare 13:269-281.

Ernst, C. H., F. D. Ross, and C. A. Ross. 1999. Crocodylus acutus (Cuvier) American Crocodile. Catalogue of American Amphibians and Reptiles 700:1-17.

Garrick, L. D., and J. L. Lang. 1977. Social signals and behaviors of adult alligators and crocodiles. American Zoologist 17:225-239.

Griffiths, M., and C. P. Van Schaik. 1993. The impact of human traffic on the abundance and activity periods of Sumatran rain forest wildlife. Conservation Biology 7:623-626.

Guderjan, T. H. 1995. Maya settlement and trade on Ambergris Caye, Belize. Ancient Mesoamerica 6:147-159.

Heupel, M. R., D. M. Knip, C. A. Simpfendorfer, and N. K. Dulvy. 2014. Sizing up the ecological role of sharks as predators. Marine Ecology Progress Series 495:291-298. 
Hovick, T. J., R. D. Elmore, D. K. Dahlgren, S. D. Fuhlendorf, and D. M. Engle. 2014. Evidence of negative effects of anthropogenic structures on wildlife: a review of grouse survival and behaviour. Journal of Applied Ecology 51:1680-1689.

IUCN. 2012. IUCN Red List of Threatened Species (ver. 2012.2). http://www.iucnredlist.org.

Laiolo, P. 2010. The emerging significance of bioacoustics in animal species conservation. Biological Conservation 143:1635-1645.

Lang, J. W. 1989. Social behavior. Pp. 102-117 in G. J. Webb, S.C. Manolis, and P.J. Whitehead (Eds.), Crocodiles and Alligators. Surrey Beatty and Sons, Australia.

Luniak, M. 2004. Synurbization-adaptation of animal wildlife to urban development. Pp. 50-55 in W. W. Shaw, L. K. Harris, and L. Vandruff (Eds.), Proceedings 4th International Symposium of Urban Wildlife Conservation, USA.

Maine Department of Environmental Protection. 2013. Protocol for wetland human disturbance assessment. Division of Environmental Assessment Biological Monitoring Program. http://www.maine.gov/dep/water/monitoring/biomonitoring/materials/sop_whda_manual. pdf. Archived by WebCite at http://www.webcitation.org/6qLOA6YfY on 9 May 2017. Manning, A., and M. S. Dawkins. 1998. An Introduction to Animal Behavior. $5^{\text {th }}$ ed., Cambridge University Press, UK.

Marioni, B., R. Da Silveira, W. E. Magnusson, and J. Thorbjarnarson. 2008. Feeding behavior of two sympatric caiman species, Melanosuchus niger and Caiman crocodilus, in the Brazilian Amazon. Journal of Herpetology 42:768-772. 
Nair, T., J. B. Thorbjarnarson, P. Aust, and J. Krishnaswamy. 2012. Rigorous gharial population estimation in the Chambal: implications for conservation and management of a globally threatened crocodilian. Journal of Applied Ecology 49: 1046-1054.

Nifong, J. C., and B. R. Silliman. 2013. Impacts of a large-bodied, apex predator (Alligator mississippiensis Daudin 1801) on salt marsh food webs. Journal of Experimental Marine Biology and Ecology 440:185-191.

Platt, S. G., and J. B. Thorbjarnarson. 2000a. Status and conservation of the American Crocodile, Crocodylus acutus, in Belize. Biological Conservation 96:13-20.

Platt, S. G., and J. B. Thorbjarnarson. 2000b. Nesting ecology of the American Crocodile in the coastal zone of Belize. Copeia 2000:869-873.

Pooley, A. C., T. C. Hines, and J. Shield. 1989. Attacks on humans. Pp. 172-189 in G. J. Webb, S.C. Manolis, and P.J. Whitehead (Eds.), Crocodiles and Alligators. Surrey Beatty and Sons, Australia.

Roemer, G. W., M. E. Gompper, and B. Van Valkengurgh. 2009. The ecological role of the mammalian mesocarnivore. BioScience 59:165-173.

RStudio Team. 2015. RStudio: Integrated Development for R. RStudio, Inc., Boston, MA, USA. Sumpter, D. J. 2010. Collective Animal Behavior. Princeton University Press, USA.

Tellez, M., M. Boucher, and K. Kohlman. 2016. Population status of the American Crocodile (Crocodylus acutus) in Caye Caulker, Belize. Mesoamerican Herpetology 3:450-460.

Thorbjarnarson, J. 1989. Ecology of the American Crocodile (Crocodylus acutus). Pp. 228-258 in P. Hall and R. Bryant (Eds.), Crocodiles: Their Ecology, Management, and Conservation. IUCN The World Conservation Union Publications, Switzerland. 
Thorbjarnarson, J. B., and G. Hernández. 1993. Reproductive ecology of the Orinoco Crocodile (Crocodylus intermedius) in Venezuela. II. Reproductive and social behavior. Journal of Herpetology 27:371-379.

Thorbjarnarson, J. B., F. Mazzotti, E. Sanderson, F. Buitrago, M. Lazcano, K. Minkowski, M. Muñiz, P. Ponce, L. Sigler, R. Soberon, and A. M. Trelancia. 2006. Regional habitat conservation priorities for the American Crocodile. Biological Conservation 128:25-36.

Verdade, L. M. 1996. The influence of hunting pressure on the social behavior of vertebrates. Revista Brasileira de Biologia 56:1-13.

Vliet, K. A. 1989. Social displays of the American Alligator (Alligator mississippiensis). American Zoologist 29:1019-1031.

Webb, G. J. W., and H. Messel. 1979. Wariness in Crocodylus porosus (Reptilia: Crocodilidae). Wildlife Research 6:227-234.

Williams, T. M., J. A. Estes, D. F. Doak, and A. M. Springer. 2004. Killer appetites: assessing the role of predators in ecological communities. Ecology 85:3373-3384. 


\section{TABLES}

TABLE 1.- Description of stressor severity ranks for wetland human disturbance assessment (Maine Department of Environmental Protection 2013).

\begin{tabular}{llc}
\hline Severity of stressor & \multicolumn{1}{c}{ Severity description } & Rank \\
\hline Not observed or unknown & Stressor is not observed or has no detrimental impact. & 0 \\
Observed; minimal & Stressor is present and appears to have negligible impacts on & 1 \\
disturbance & wetland. & 2 \\
Low disturbance & Stressor is present and appears to have minor impacts on & 3 \\
& wetland condition. & \\
Moderate disturbance & Stressor is present and appears to moderately impact wetland \\
condition. & Stressor is present and appears to significantly impact \\
High disturbance & wetland condition. \\
& Stressor is present and appears to have major impacts on \\
& wetland condition.
\end{tabular}


TABLE 2.- List of characterized behavior and description of activities observed for American Crocodiles in Belize, Central America.

\begin{tabular}{lll}
\hline $\begin{array}{l}\text { Characterized } \\
\text { behavior }\end{array}$ & $\begin{array}{l}\text { General categories } \\
\text { of activities }\end{array}$ & Description of activities \\
\hline A &
\end{tabular}

Agonistic Negative behavior (competition for non-food items)

Aggression Chasing with aggressive intent

Physical altercation

Aggressive threat display (jaw clap, tail wag, head oblique tail arched (HOTA), gaping)

Social

Social signaling Courtship (pair bonding, circling, dorsal rubbing)

Submissive posturing (snout lift)

Alertness indicator (tail lift, back bob, inflated posture)

Maintenance
Basking
On land, whole body exposed
Partially withdrawn from water, dorsal area exposed
In water, prolonged exposure of full dorsal surface
Foraging Stalking prey
Lifting head to consume prey
Striking out to capture prey
Submerging Entire body concealed below water's surface
Surface Head or body exposed and floating stationary at surface
Swimming Locomotion in the water 
TABLE 3.- Time-activity budgets of American Crocodiles during morning ( $0530 \mathrm{~h}-0930 \mathrm{~h} \pm 1)$ and evening $(1400 \mathrm{~h}-1800 \mathrm{~h} \pm 1)$ observation periods in Belize, $2015-2016$.

\begin{tabular}{ccccc}
\hline $\begin{array}{c}\text { Category } \\
\text { Activity }\end{array}$ & Morning & Evening & $\chi^{2}$ & $P$ \\
\cline { 2 - 3 } Agonistic & 1.4 & 6.2 & 246.02 & $<0.001$ \\
Aggression & 1.4 & 6.2 & 298.95 & $<0.001$ \\
Maintenance & 96.2 & 93.0 & 69.73 & $<0.001$ \\
Basking & 23.0 & 45.2 & 1189.50 & $<0.001$ \\
Foraging & 4.6 & 0.9 & 119.88 & $<0.001$ \\
Submerging & 17.7 & 13.6 & 12.62 & 0.0004 \\
Surface & 43.4 & 28.9 & 741.41 & $<0.001$ \\
Swimming & 5.5 & 2.1 & 72.94 & $<0.001$ \\
Social & 2.4 & 0.8 & 51.95 & $<0.001$ \\
Social Signaling & 2.9 & 2.9 & 61.16 & $<0.001$ \\
\hline
\end{tabular}


TABLE 4.- Time-activity budgets of American Crocodile behaviors across three study areas in Belize, 2015 - 2016. Percent followed by the same uppercase letter are not significantly different among sites within a category or activity $(\mathrm{P}>0.05)$. Proportions followed by the same lowercase letter are not significantly different among categories or activities within a site (P > $0.05)$.

\begin{tabular}{|c|c|c|c|c|c|}
\hline \multirow{2}{*}{$\begin{array}{l}\text { Category } \\
\text { Activity }\end{array}$} & \multicolumn{3}{|c|}{ Percent time } & \multirow[b]{2}{*}{$\chi^{2}$} & \multirow[b]{2}{*}{$P$} \\
\hline & Ambergris Caye & Caye Caulker & $\begin{array}{c}\text { Belize Aquaculture } \\
\text { Limited }\end{array}$ & & \\
\hline Agonistic & $7.5 \mathrm{Ab}$ & $0.1 \mathrm{Cb}$ & $0.7 \mathrm{Bc}$ & 497.310 & $<0.001$ \\
\hline Aggression & 5.7Ad & $0.1 \mathrm{Cde}$ & $0.7 \mathrm{Bf}$ & 343.270 & $<0.001$ \\
\hline Maintenance & $89.5 \mathrm{Ca}$ & 99.7Aa & $98.1 \mathrm{Ba}$ & 561.760 & $<0.001$ \\
\hline Basking & 31.0Aa & $33.0 \mathrm{Ab}$ & $31.0 \mathrm{Ab}$ & 2.963 & 0.227 \\
\hline Foraging & 8.9Ac & - & $0.8 \mathrm{Bf}$ & 614.910 & $<0.001$ \\
\hline Submerging & $15.0 \mathrm{Bb}$ & $8.6 \mathrm{Cc}$ & $20.1 \mathrm{Ac}$ & 338.790 & $<0.001$ \\
\hline Surface & $32.7 \mathrm{Ca}$ & 63.0Aa & $40.5 \mathrm{Ba}$ & 68.704 & $<0.001$ \\
\hline Swimming & $3.6 \mathrm{Be}$ & $1.5 \mathrm{Cd}$ & $5.2 \mathrm{Ad}$ & 492.740 & $<0.001$ \\
\hline Social & 3.0Ac & $0.2 \mathrm{Cb}$ & $1.2 \mathrm{Bb}$ & 87.544 & $<0.001$ \\
\hline Social Signaling & $3.2 \mathrm{Ae}$ & $0.2 \mathrm{Cde}$ & $1.6 \mathrm{Be}$ & 68.704 & $<0.001$ \\
\hline
\end{tabular}


TABLE 5.- Comparisons among sites (sample size, mean duration (minutes), and standard error) of observed behaviors for American Crocodiles in Belize, 2015 - 2016. Means followed by the same uppercase letter are not significantly different among sites within a category or activity (P $>0.05)$. Means followed by the same lowercase letter are not significantly different among categories or activities within a site $(\mathrm{P}>0.05)$.

\begin{tabular}{|c|c|c|c|c|c|c|c|c|c|}
\hline \multirow{2}{*}{$\begin{array}{l}\text { Category } \\
\text { Activity }\end{array}$} & \multicolumn{3}{|c|}{ Ambergris Caye } & \multicolumn{3}{|c|}{ Caye Caulker } & \multicolumn{3}{|c|}{$\begin{array}{c}\text { Belize Aquaculture } \\
\text { Limited }\end{array}$} \\
\hline & $n$ & $X$ & $\mathrm{SE}$ & $n$ & $X$ & $\mathrm{SE}$ & $n$ & $X$ & SE \\
\hline Agonistic & 78 & $5.0 \mathrm{Ab}$ & 1.2 & 1 & $1.0 \mathrm{Ab}$ & 0 & 19 & $2.7 \mathrm{Ab}$ & 0.9 \\
\hline Aggression & 75 & 4.0Ad & 1.0 & 1 & $1.0 \mathrm{Ac}$ & 0 & 19 & 2.7Ac & 0.9 \\
\hline Maintenance & 213 & $23.0 \mathrm{ABa}$ & 2.1 & 34 & 48.6Aa & 11.1 & 416 & $16.4 \mathrm{Ba}$ & 1.2 \\
\hline Basking & 34 & 49.0Aa & 6.1 & 9 & 60.9Aa & 20.8 & 51 & 42.4Aa & 5.2 \\
\hline Foraging & 28 & $17.0 \mathrm{Abc}$ & 3.1 & 0 & - & - & 4 & 14.0Aabc & 10.1 \\
\hline Submerging & 49 & $16.5 \mathrm{Ab}$ & 3.0 & 2 & $15.5 \mathrm{ABab}$ & 5.5 & 130 & $10.8 \mathrm{Bcd}$ & 1.3 \\
\hline Surface & 68 & $25.8 \mathrm{Bb}$ & 4.6 & 16 & $65.5 \mathrm{Aa}$ & 18.9 & 183 & $15.4 \mathrm{Bb}$ & 1.6 \\
\hline Swimming & 36 & 5.3Acd & 1.0 & 6 & 4.2Abc & 1.9 & 47 & 7.7Abde & 1.3 \\
\hline Social & 33 & $5.0 \mathrm{Ab}$ & 1.8 & 1 & $3.0 \mathrm{Ab}$ & 0 & 23 & 4.9Ab & 1.5 \\
\hline Social Signaling & 33 & 5.0Acd & 2.4 & 1 & $3.0 \mathrm{Ac}$ & 0 & 23 & 4.9Ace & 1.5 \\
\hline
\end{tabular}




\section{FIGURE LEGENDS}

FIG 1.- Belize, Central America, located on the eastern Caribbean seaboard. Letters dictate study area location; (A) Ambergris Caye, (B) Caye Caulker, (C) Belize Aquaculture Limited. 


\section{FIGURES}

FIG 1.-

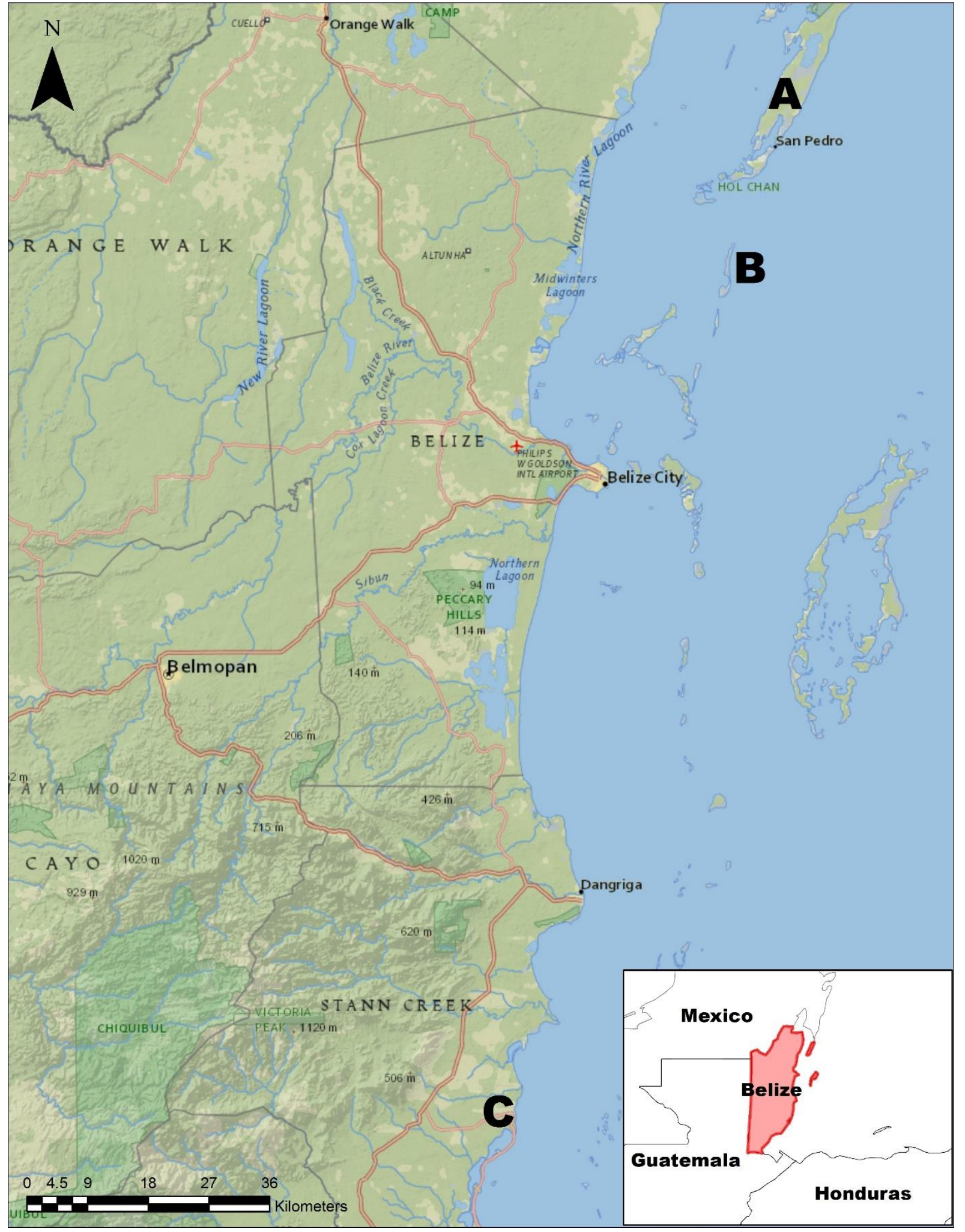




\section{CHAPTER 3}

Differences in Distress: Variance and Production of American Crocodile (Crocodylus acutus)

Distress Calls in Belize

Miriam BoucheR ${ }^{1,2}$, MARISA TELlez ${ }^{3,4}$, KYLE HARTMAN $^{1}$, AND JAMES T. ANDERSON ${ }^{1}$

${ }^{1}$ School of Natural Resources, West Virginia University, Morgantown, West Virginia, USA

${ }^{2}$ Corresponding author. E-mail: mnboucher01@gmail.com

${ }^{3}$ Crocodile Research Coalition, Maya Beach, Stann Creek, Belize

${ }^{4}$ Marine Science Institute, University of California Santa Barbara, Santa Barbara, California, USA

Written in the style of: Journal of Herpetology 
ABSTRACT.- Acoustic communication of American Crocodiles (Crocodylus acutus) is relatively understudied. Our overall aim was to determine the acoustic structure of wild American Crocodile distress calls, distinguish call differences among size classes (hatchling, juvenile, sub-adult, and adult), and investigate call production on a gradient of human disturbance. American Crocodile distress calls have strong frequency modulation and are comprised of multiple harmonics in a downsweeping pattern. Measured parameters (total duration, first quartile duration, maximal frequency, first quartile frequency, end frequency, slope of first quartile, slope of last quartiles) differed significantly among size classes $(P<0.05)$. Hatchling distress calls are higher in frequency and strongly modulated, whereas calls produced by sub-adults and adults showed little modulation, are lower in frequency, and have greater overall duration. Proportion of crocodiles that produced distress calls during capture differed by size class and sampling location, particularly adult distress calls which are reported here to be produced with undocumented frequency. American Crocodiles, of all size classes, produced distress calls at varying rates among study sites. American Crocodiles produced distress calls more frequently at sites with higher anthropogenic activity. Measured call parameters of juveniles and hatchling American Crocodiles also varied among sites in relation to human disturbance. Calls recorded at sites of high anthropogenic impact have increased duration and less modulation, which may adversely affect response to emitted distress calls. Proportional and call parameter variation suggest anthropogenic activity as a driver for increased call production and alteration of call parameters at high human-impacted sites.

Key Words: American Crocodile; Belize; Bioacoustics; Crocodylian; Sound

Social interactions between crocodylians are facilitated through a variety of acoustic and physical signals. Of the acoustic signals produced, distress calls are perhaps the most frequently 
recorded call. Distress calls are repetitive chirps with multiple harmonics and frequency modulation (Garrick and Lang, 1977; Vergne et al., 2009). The distress call is commonly produced by juveniles as a warning to other crocodylians and also elicits a defense response from conspecifics (Campbell, 1973; Garrick and Lang, 1977; Herzog and Burghardt, 1977; Britton, 2001; Vergne et al., 2009; 2011). Production of this behaviorally significant call decreases as the size of the crocodylian increases in conjunction with reduced risk of predation (Staton, 1978). Although reported, production of distress calls by sub-adult and adult crocodylians is rare (Staton, 1978). There is a paucity of data in regards to the structure, production, and significance of distress calls among crocodylians, such as the American Crocodile (Crocodylus acutus), and the exploration is still in its infancy.

American Crocodiles are the most widely distributed crocodylian in the New World, inhabiting coastal and lowland wetlands from southern Florida, USA to northern South America (Ernst et al., 1999; Platt and Thorbjarnarson, 2000). Although now a protected species in all of its range, previous exploitation in the mid-1900s led to extirpation and declines of the American Crocodile in many areas. Populations drastically decreased in Belize, between 1930 and 1970 (Platt and Thorbjarnarson, 2000; Rainwater and Platt, 2009). Although the commercial hunting that caused population declines has ceased, new threats have emerged putting recovering populations at risk. Degradation and diminishment of habitat as a result of widespread pollution and coastal development are significant threats to American Crocodiles in Belize (Platt and Thorbjarnarson, 2000; Platt et al., 2004; Rainwater, 2008; Tellez et al., 2016). Ongoing research in highly impacted habitats of Belize is collecting increasing evidence of the physical effects of environmental toxicity in American Crocodiles (Tellez, unpubl. data). It is likely however, that there are also ecological consequences of human influence on American Crocodiles in Belize. 
Additionally, there has been little dedicated study of American Crocodile bioacoustics anywhere in its range. Increasingly, anthropogenic noise and impact in wildlife habitat is demonstrated to have deleterious effects on wildlife acoustics and ecology (Hildebrand, 2005; Blickley and Patricelli, 2010; Laiolo, 2010). As an acoustically communicative species, it is feasible that American Crocodile sound production may be affected by anthropogenic disturbance. Herein we describe the acoustic structure of American Crocodile distress calls and explore a possible link between distress call production and anthropogenic impact.

\section{MATERIALS AND METHODS}

Study Areas. - Belize is a small Mesoamerican nation $\left(22,965 \mathrm{~km}^{2}\right)$ paralleled by the Mesoamerican Barrier Reef and located south of Mexico on the eastern seaboard (Fig. 1). We collected acoustic recordings in the coastal zone of Belize at Ambergris Caye, Caye Caulker, and Belize Aquaculture Limited west of the Placencia Peninsula.

Ambergris Caye is the southern extension of the Mexican Yucatan Peninsula separated from Mexico by a small channel. We collected American Crocodile recordings throughout the southern portion of the island in proximity to the highly developed San Pedro town center. We recorded captured crocodiles throughout the study area and in particular from the Coco Beach Resort lagoon, San Pedro sewage treatment ponds, and the Mahogany Bay Village development site.

Our second study area, Caye Caulker, is an offshore island located $8 \mathrm{~km}$ south of Ambergris Caye. American Crocodiles are distributed along the entire island and we collected recordings opportunistically throughout the study area during concurrent population surveys.

Belize Aquaculture Limited (BAL), our final study area, is a large commercial shrimp farm (3,642 ha) located approximately $8.3 \mathrm{~km}$ east of the northern tip of the Placencia peninsula. 
We recorded crocodiles captured in the effluent polishing lagoon and canal system located on the margins of the farming operation.

Wetland Impact Assessment.- Concurrent to the collection of behavioral observations, we assessed study sites using a 6-point scale (Table 1) to characterize human disturbance in the wetlands (Maine Department of Environmental Protection, 2013). Our assessments scored presence and severity of hydrologic modifications to the wetland, vegetative modifications to the wetland, evidence of pollutants, and acoustic disturbance and human contact. We used rankings of each category of stressor to determine an overall level of human disturbance for each study site.

Capture Techniques. - As distress calls are produced when crocodiles are under duress or perceived threat, we collected recordings during capture of wild American Crocodiles. We captured crocodiles as part of ongoing behavioral research and population surveys. The West Virginia University Animal Care and Use Committee (Protocol \# 15-0703) and the Belize Forest Department (BFD) approved our capture protocol. The lead author acquired research permits from the BFD prior to initiating any capture or recording (Ref. No. CD/60/3/15(45)). We captured and restrained crocodiles using conventional techniques detailed by Webb and Messel (1977). We captured smaller crocodiles by hand and larger animals by noosing or a treble hook. We did not secure the snout of crocodiles prior to recording to avoid altering distress call emission. Following the collection of recordings, or if the crocodile ceased to vocalize, we secured the jaws using electrical tape and applied eye coverings to reduce capture stress. We collected morphometric measurements from all captured crocodiles following the protocol of Webb and Messel (1978). We used the total length (TL) to classify captured crocodiles as; hatchlings $(\mathrm{TL}<35 \mathrm{~cm})$, juveniles $(\mathrm{TL}=36-90 \mathrm{~cm})$, sub-adults $(\mathrm{TL}=91-180 \mathrm{~cm})$, or adults 
$(\mathrm{TL}>181 \mathrm{~cm})$. Following the completion of health assessment and morphometric measurements, we released crocodiles at site of capture.

Acoustic Recording. - We recorded American Crocodiles on Ambergris Caye from May - August 2015, December 2015 - January 2016, and March of 2016. Concurrent with ongoing population surveys, we collected recordings on Caye Caulker in January, March, and August 2016. We collected acoustic recordings from BAL June - August 2016. We recorded distress calls ad libitum in the field during capture events as recording conditions and difficulty of capture determined the actual number of recordings collected. Independent of acoustic recording, we noted incidence of call production for each individual capture as not all captures resulted in call production or successful recording. We collected distress call recordings from May 2015 January 2016 using a Marantz PDM661 or Roland R-26 digital recorder coupled with a Senheiser ME67 shotgun directional microphone. During the March-August 2016 field seasons, we employed a Sony Zoom H5 digital recorder with an XY modular microphone capsule. We recorded all calls in .wav format at a sampling rate of $44.1 \mathrm{kHz}$ and 24 bits per sample. Although equipment differed, sampling protocol remained consistent. We held hatchling and juvenile crocodiles in hand and collected recordings approximately $50 \mathrm{~cm}$ from the microphone. We recorded sub-adult and adult crocodiles from 1-2 $\mathrm{m}$ from the microphone to ensure safety of personnel.

Sound Analysis. - We performed acoustic analysis to determine the structure of distress calls for each size class. We analyzed five calls per individual, in one case only three calls were analyzed due to heavy background noise, and measured seven acoustic variables, two temporal and five spectral, using Raven Pro 1.5 acoustic analysis software (Bioacoustics Research Program, 2014). We used spectrographic analysis (window size 1024, overlap 80\%) of the fundamental frequency to determine maximal frequency $\left(\mathrm{F}_{\max }, \mathrm{Hz}\right)$, frequency at end of first quartile $\left(\mathrm{F}_{1 / 4}, \mathrm{~Hz}\right)$, 
and final frequency ( $F_{\text {end }}, \mathrm{Hz} ;$ Fig. 2A). Using call oscillograms, we measured temporal properties for total duration (DT, s) and duration of the first quartile ( $\mathrm{D}_{1 / 4}, \mathrm{~s} ;$ Fig. 2B). Measurement windows were drawn around the fundamental frequency and the maximal frequency values at the beginning, end, and first quartile were recorded. We used frequency and temporal measurements to calculate call modulation of the first temporal quartile slope (Slope 1, Hz/s, calculated as $\left.\left(\mathrm{F}_{1 / 4}-\mathrm{F}_{\max }\right) / \mathrm{D}_{1 / 4}\right)$, and the slope of the remaining three temporal quartiles (Slope 2, Hz/s, calculated as $\left(\mathrm{F}_{\text {end }}-\mathrm{F}_{1 / 4}\right) /($ DT- $\left.\mathrm{D}_{1 / 4}\right)$ ) (Vergne et al. 2012). Concurrent to call measurements, we recorded number of calls produced by each individual for 10,20 , and 30 second intervals as total recording time varied between individual crocodiles. We began call counts at the first recorded call for each individual. We used size designation to organize and analyze distress call recordings by overall size class.

We performed statistical analyses using RStudio version 0.99 .902 (RStudio Team, 2015). Our call parameter data did not meet the assumptions of normality or homogeneity of variance $(\mathrm{P}$ $<0.05$ )(Appendix I). Thus, we analyzed call parameter means (DT, $\mathrm{D}_{1 / 4}, \mathrm{~F}_{\max }, \mathrm{F}_{1 / 4}$, Fend, Slope 1, Slope 2) among size classes (hatchling, juvenile, sub-adult, adult) by performing nonparametric Kruskal-Wallis $(H)$ tests. We used Mann-Whitney post-hoc testing with Bonferroni correction to determine pairwise variance of call parameters between size classes following a significant Krukal-Wallis test $(P<0.05)$. We tested size class differentiation by call parameters using a principal component analysis cross-validated by discriminant function analysis which assigned each recorded individual to a size class based on call parameters. To determine variance in number of calls produced $(10,20,30$ second intervals) we performed one-way analysis of variance (ANOVA) tests as these data met assumptions of normality $(P>0.05)$ and equality of variance $(P>0.05)$. 
We analyzed differences in call production by determining the total number of American Crocodiles captured throughout the study for each location and compared them by size class. To account for small sample size, we aggregated data for Caye Caulker and BAL sites. We performed a 2-sample test for equality of proportions with continuity correction (Newcombe, 2008) on total call production proportions among size classes. Designed for small sample sizes $(<5)$, we performed Fisher's Exact Test (Agresti, 2002) to determine inequality in call production by size classes between Ambergris Caye, and the combined Caye Caulker and BAL sites. As a compliment to proportional tests, we performed Mann-Whitney tests to determine variance of spectral parameters of hatchling and juvenile calls between Ambergris Caye and aggregated Caye Caulker and BAL sites.

\section{RESULTS}

Wetland Impact Assessment. - Ambergris Caye had the highest degree of human disturbance (rank $=3-4 ; X=3.7 ; \mathrm{SE}=0.19)$ due to extensive habitat modification, pollution, and contact with humans. Moreover, all Ambergris sites had nearly constant anthropogenic sound present from development, and road, boat, and air traffic. Anthropogenic impact on Caye Caulker varied in the study area and ranged from high $($ rank $=4)$ to no disturbance $($ rank $=0)$. We determined Caye Caulker to be a site of low-moderate (rank $=2-3 ; X=2.5 ; \mathrm{SE}=0.30)$ disturbance with few sources of constant sound production. Our wetland assessments of the BAL effluent lagoon and surrounding areas determined the study site to have low overall human impact $($ rank $=1-2 ; X=1.8 ; \mathrm{SE}=0.15)$. Despite being a commercial aquaculture facility the effluent lagoon is located on the margins of the farm and received little chronic anthropogenic sound production, had minimal pollution, and the crocodiles rarely came into direct contact with people. 
Call Structure.- We captured and recorded 33 American Crocodiles from May 2015 August 2016; 17 hatchlings, 12 juveniles, 2 sub-adults, and 2 adults (Appendix II). In total, we analyzed 153 distress calls, a combined 7 calls from 2 individuals were excluded from the analyses as measurements could not be attained due to background noise. American Crocodiles produced multiple distress calls during each recording event but mean number of calls produced by size class did not differ for $10 \operatorname{second}\left(F_{3,29}=1.36 ; P<0.001\right), 20$ second $\left(F_{3,29}=1.16 ; P<\right.$ $0.001)$, and 30 second $\left(F_{3,29}=0.92 ; P<0.001\right)$ time intervals (Appendix III). Number of calls across all size classes averaged 7.10 $(\mathrm{SE}=0.24)$ for 10 second, $11.70(\mathrm{SE}=0.32)$ for 20 second, and $15.39(\mathrm{SE}=0.39)$ for 30 second intervals.

American Crocodile distress calls in Belize had strong frequency modulation and were comprised of multiple harmonics with downsweeping frequencies (Fig. 2A). Call structure was consistent across size classes; however, measured call parameters differed. Measured variables differed among all size classes (Wilks, $\alpha=0.05 ; F_{3,149}=16.86, P<0.001$ ). All acoustic variables differed significantly among size classes for total duration and duration of the first quartile $\left(H_{3}=\right.$ 91.73; $P<0.001)$, maximal frequency of the fundamental $\left(H_{3}=64.39 ; P<0.001\right)$, frequency at first quartile $\left(H_{3}=49.46 ; P<0.001\right)$, ending frequency $\left(H_{3}=32.10 ; P<0.001\right)$, first quartile slope $\left(H_{3}=78.75 ; P<0.001\right)$, and slope of the last three quartiles $\left(H_{3}=78.49 ; P<0.001\right)$ (Table 2). Hatchling calls had the highest frequencies $\left(F_{\max }, F_{1 / 4}, F_{\text {end }}\right)$ and greatest call modulation (Slope 1, Slope 2), but the shortest total durations. Conversely, adult distress calls exhibited longer total duration, and had the lowest frequencies and call modulation. Call parameters allowed for successful discrimination of individuals among size classes, but not all parameters had equal success. Temporal variables (DT, $\mathrm{D}_{1 / 4}$ ) differentiated all size classes; however, frequency modulation (Slope 1, Slope 2) differed less and was not effective in discriminating 
between sub-adults and adults (Table 2). Frequency parameters had mixed effectiveness of differentiating size classes by acoustic parameters. Results from our principal components analysis complimented result of the one-way analyses demonstrating separation and grouping of size classes from the measured variables (Fig. 3). Cross-validation through discriminant function analysis demonstrated $82.4 \%$ overall success in appropriate size class classification of individuals. We achieved greatest classification accuracy for hatchlings (89.7\%), followed by juveniles (81.8\%), sub-adults (70.0\%), and adults (40.0\%).

Site Variance.- Call parameters of hatchlings and juveniles varied between Ambergris Caye and aggregated Caye Caulker and BAL sites for hatchling and juvenile American Crocodile distress calls (Table 3). At high impact (rank $=3-4)$ Ambergris Caye sites, hatchling calls had greater durations $\left(\mathrm{DT}, \mathrm{D}_{1 / 4}\right)\left(H_{l}=5.75 ; P=0.02\right)$ and call modulation for the first slope (Slope 1) $\left(H_{l}=5.78 ; P=0.02\right)$, but less modulation for the slope of the last three quartiles (Slope 2) $\left(H_{1}=13.04 ; P<0.001\right)$. Spectral parameters $\left(\mathrm{F}_{\mathrm{max}}, \mathrm{F}_{1 / 4}, \mathrm{~F}_{\mathrm{end}}\right)$ did not differ for hatchling calls between sites $(P>0.05)$.

Juvenile American Crocodile distress calls differed for all parameters with the exception of Slope $1\left(H_{1}=0.001 ; P=0.98\right)$. Juvenile distress calls produced at Ambergris sites had greater call durations $\left(H_{l}=5.29 ; P=0.02\right)$. However, we found that juvenile call spectral parameters for $\mathrm{F}_{\max }\left(H_{1}=4.63 ; P=0.03\right), \mathrm{F}_{1 / 4}\left(H_{1}=17.05 ; P<0.001\right)$, and $\mathrm{F}_{\text {end }}\left(H_{1}=4.52 ; P=0.03\right)$ to be greater at the aggregated low - moderate impact (rank $=1-3)$ Caye Caulker and BAL sites. We also determined frequency modulation of Slope $2\left(H_{l}=23.49 ; P<0.001\right)$ to be greater for the combined Caye Caulker and BAL sites. Total length (TL) of recorded individuals also differed between sites. Hatchlings captured at Ambergris Caye had greater total lengths than those 
captured at aggregated Caye Caulker and BAL sites $\left(H_{1}=29.47 ; P<0.001\right)$, but we found juvenile TL to be greater for aggregated Caye Caulker and BAL sites $\left(H_{1}=4.84 ; P<0.03\right)$.

Call Production. - We captured 89 American Crocodiles during the entirety of this project. Of the 89 captured individuals only 46 (51.7\%) produced distress calls. Differences in overall distress call production existed among size classes with hatchlings calling the most and sub-adults calling the least $\left(\chi_{3,89}^{2}=20.44 ; P<0.001\right)$. We determined that size class call production varied between sites (Fig. 4). However, only hatchlings $(P=0.001)$ and adults $(P=$ 0.03) called more often at Ambergris Caye than at the combined Caye Caulker and BAL sites (Table 4).

\section{DISCUSSION}

Call Structure. - American Crocodile calls were acoustically complex with multiple harmonics. General call structure is the same for all size classes, but call parameters differed among size classes and allowed for successful differentiation of individual's calls to their respective size class. Individually, the measured parameters achieved successful differentiation of larger size classes (sub-adult and adult) from the smaller size classes (juveniles and hatchlings). When applied together, measured call parameters separated recorded crocodiles into homogeneous groups of their respective size classes. Hatchlings and juveniles emitted calls with higher overall frequencies and call modulation. Adult and sub-adult American Crocodiles produced longer distress calls at significantly lower frequencies and had reduced call modulation.

Total call duration increased incrementally with body size. This increase in call duration and decrease in call frequency has also been noted for Indian Gharial (Gavialis gangeticus) (Bonke et al., 2015). Animal sound production changes as body size increases. Larger 
crocodiles generate lower frequencies as the call production mechanisms are larger and produce longer wavelengths (Britton, 2001). Crocodylians use low frequency sound production to communicate long-distances, particularly during courtship (Vliet, 1989; Vergne et al., 2009; Dinets, 2013). Hatchling distress calls are higher in frequency and have limited range as high frequencies do not travel long-distances as effectively. Post-hatching American Crocodile hatchlings remain in cohesive groups monitored closely by the maternal female (Thorbjarnarson, 1989). Call production likely does not need to travel long-distance to elicit appropriate defense response. However, microhabitat use by juveniles and sub-adult and adult American Crocodiles differ from hatchlings and yearlings (Thorbjarnarson, 1989). The production of juvenile distress calls at lower frequencies may be beneficial in garnering response from conspecifics that have greater dispersion within a given habitat. Also, larger American Crocodiles occupy more open microhabitats and long-distance signals can travel unimpeded by the dense shoreline cover that hatchlings prefer.

Differences in call parameters among size classes may be a reflection of differences in behavioral responses. Investigation of distress call information coding demonstrated that crocodylian distress calls produced at higher pitch, with higher frequencies elicit greater behavioral response from other crocodylians (Staton, 1978; Vergne et al. 2011). Hatchling American Crocodiles produce distress calls at significantly higher frequencies and have greater modulation. During collection of distress calls we noted that nearby conspecifics reacted more intensely to distress calls from hatchlings compared to the other size classes. Size of hatchlings also differed between nest sites and capture of smaller hatchlings from other pods elicited greater response from non-related females. Hatchlings also produced distress calls more frequently than the other size classes which may be another reflection of the significant behavioral response the 
call elicits. It is likely that the increased behavioral response to hatchling distress calls aids in juvenile survivorship by decreasing predation risk. However, if response to distress calls decreases as frequency and signal modulation decreases it is counterintuitive that sub-adult and adult American Crocodiles produce distress calls with frequency. Distress calls do not appear to have intrinsic value to individual survivorship as sub-adult and adult crocodiles have few natural predators (Staton, 1978; Pooley and Ross, 1989). We observed that sub-adult and adult distress calls did not receive the same behavioral response from conspecifics. As such, it makes little sense for crocodiles to produce calls that have no perceived benefit. Adult crocodile distress calls, to our best knowledge, have never been reported in such high incidence rates and are noted to be rarely produced, even during capture (Staton, 1978). It may be that the production of distress calls by larger American Crocodiles is indeed the result of anthropogenic activity as opposed to evolutionary or behavioral drivers.

Call Production.- Our study is the first to document the frequency of distress call production of American Crocodiles in response to capture. Furthermore, this is the first record of adult American Crocodiles producing distress calls with such regularity. Adult production of distress calls has been reported but described to be a rarity (Staton, 1978). Our results show that a high proportion (36\%) of adult American Crocodiles in Belize produce distress calls. This is markedly higher than the production of distress calls for sub-adults (22\%). In particular, we found that the highest proportion of distress calls produced by both adults and sub-adults came from crocodiles captured on Ambergris Caye. Ambergris Caye also had the highest proportion of juvenile and hatchling call production. With the exception of hatchlings, we did not find the proportion of call production to be statistically significant for size classes between study sites. This result may be somewhat underestimated as sample size for each size class is low for all 
sites. However, we noted ecological significance in distress call production. Higher distress call production for hatchlings and adults occurred at the study area with high human impact (rank= 3-4). We found, for juveniles and sub-adults, lower distress call production at Caye Caulker $($ rank $=2-3)$ and BAL (rank $=1-2)$. Greater call production may be a result of anthropogenic impact in crocodile habitat. As such, production of distress calls could be a metric to determine increased stress levels in American Crocodiles. Moreover, anthropogenic impact has been demonstrated to cause deleterious shifts in wildlife behavior and sound production (Laiolo, 2010).

Anthropogenic sound production causes temporal and frequency shifts in wildlife sound production (Barber et al., 2010; Laiolo, 2010). Our analyses of call parameters of hatchling and juvenile American Crocodiles demonstrated marked temporal and spectral variances between our sites. Spectral parameters $\left(\mathrm{F}_{\max }, \mathrm{F}_{1 / 4}, \mathrm{~F}_{\mathrm{end}}\right)$ of hatchling distress calls did not differ between sites, but call duration and modulation (Slope 1, Slope 2) did differ. We found call duration (DT, $\left.\mathrm{D}_{1 / 4}\right)$ to be greater for hatchling calls recorded at Ambergris Caye. However, it is likely that this variance is a result of increased body size (TL) of hatchlings recorded at Ambergris Caye $(X=$ 31.06; $\mathrm{SE}=0.17)$ compared to Caye Caulker and BAL $(X=29.23 ; \mathrm{SE}=0.08)$. Hatchling distress calls recorded at Ambergris Caye had higher modulation of Slope 1 and Caye Caulker and BAL sites had higher modulation of Slope 2. Juvenile call parameters varied between sites with the exception of Slope 1. Juvenile American Crocodiles at Ambergris Caye were smaller overall $(X=73.57 ; \mathrm{SE}=2.25)$ than those at the other sites, but produced calls of longer duration. Our results contradict a previous study that demonstrated increased body size resulted in increased call duration (Bonke et al. 2015). We found maximal frequency, $F_{1 / 4}, F_{\text {end }}$, and call modulation of Slope 2 higher at Caye Caulker and BAL sites, which is also contradictory of 
previous research in which larger crocodiles produce sound at lower frequencies due to increased size of the sound production apparatus (Britton, 2001). Further research and replication of these results is needed to truly determine if our results truly reflect call parameter shifts due to anthropogenic impact at sites or, perhaps, differences in dialect between separate populations.

Our results for variance of call parameters between sites complement those of our analysis of distress call production. We observed that the behavioral response of American Crocodiles to distress calls decreased as frequency and modulation decreased, and duration increased. Specifically, American Crocodiles, particularly adults, responded much more intensely in defense of hatchlings than the other size classes sampled. Moreover, previous research on information encoding of juvenile crocodylian calls determined that frequency modulation is the key parameter for behavioral response (Vergne et al., 2012). Higher modulation of the call slope elicited stronger behavioral response from juvenile crocodylians. Slope 2 had greater modulation at our sites of lower anthropogenic impact. We found call duration to be longer and modulation of Slope 2 to be less for hatchlings on Ambergris Caye. Ambergris Caye juvenile calls had greater duration, despite smaller body size, and decreased call frequency and modulation (Fig. 4). This may indicate that distress calls for hatchling and juvenile American Crocodiles at high impact sites may be structured to be less effective at eliciting a behavioral response. Further research is required to determine if the differences in call parameters shown here is truly a reflection of anthropogenic impact in the environment. However, in conjunction with increased call production, it is plausible that American Crocodiles may be demonstrating temporal and frequency shifts of distress calls as a result of anthropogenic disturbance. 
Conclusions. - Our results indicate that anthropogenic disturbance may be altering American Crocodile sound production. This could have overarching effects on the behavioral response to distress calls impacting juvenile and hatchling survivorship if defense response is lessened by altered call production. American Crocodiles also use a variety of other acoustic signals to communicate, particularly during courtship, and it is feasible that other calls produced may also be impacted by anthropogenic disturbance. There is ever increasing evidence of human activity and sound production affecting avian, terrestrial, and aquatic wildlife sound production and mitigation of bioacoustic conflict between people and wildlife is emerging. The study of crocodylian bioacoustics is still in its infancy, but steps should be taken to further study crocodylian acoustic communication, particularly in response to environmental and acoustic stressors.

Acknowledgments. - We thank the Belize Forest Department for their support of this project and the Crocodile Research Coalition for logistic assistance. We express our gratitude to the Cornell Lab of Ornithology for their assistance with field equipment loans and acoustic analysis expertise. Thank you to K. Kohlman, S. Heflick, H. Sung, and D. Brianne, for their assistance in the field, and L. Stiffler for her statistical support. Financial support of this study was provided by the Explorer's Club, the IUCN/SSC-Crocodile Specialist Group Student Research Assistance Scheme, the West Virginia University Davis College Dr. David E. Samuel Faculty Excellence Award, the West Virginia University Natural History Museum, the James. T. Anderson lab, C. and K. Bellingham, C. and T. Polanic, D. Seiffert, and J. C. Lucas. This is Scientific Article XXXX of the West Virginia Agricultural and Forestry Experiment Station, Morgantown. 


\section{LITERATURE CITED}

Agresti, A. 2002. Categorical Data Analysis. Second ed., John Wiley and Sons, Inc. New Jersey, USA.

Barber, J. R., K. R. Crooks, and K. M. Fristrup. 2010. The costs of chronic noise exposure for terrestrial organisms. Trends in Ecology and Evolution 25:180-189.

Bioacoustics Research Program. 2014. Raven Pro: Interactive Sound Analysis Software. The Cornell Lab of Ornithology, New York, USA.

Blickley, J. L., and G. L. Patricelli. 2010. Impacts of anthropogenic noise on wildlife: research priorities for the development of standards and mitigation. Journal of International Wildlife Law and Policy 13:274-292.

Bonke, R., N. Whitaker, D. Rodder, and W. Bohme. 2015. Vocalizations in two rare crocodylian species: A comparative analysis of distress calls of Tomistoma schlegelii (Müller, 1838) and Gavialis gangeticus (Gmelin, 1789). North-Western Journal of Zoology 11:51-62.

Boucher, M., M. Tellez, and J. T. Anderson. 2017. Activity budget and behavioral patterns of American Crocodiles (Crocodylus acutus) in the coastal zone of Belize. Unpublished thesis, West Virginia University, Morgantown, West Virginia, USA.

Britton, A. 2001. Review and classification of call types of juvenile crocodylians and factors affecting distress calls. Pp. 364-377 in G. C. Grigg, F. Seebacher, and C. F. Franklin (Eds), Crocodylian Biology and Evolution. Surrey Beatty and Sons, New South Wales, Australia.

Campbell, H. W. 1973. Observations on the acoustic behavior of crocodylians. Zoologica 58:111.

Dinets, V. 2013. Long-distance signaling in crocodylia. Copeia 2013:517-526. 
Ernst, C. H., F. D. Ross, and C. A. Ross. 1999. Crocodylus acutus (Cuvier) American Crocodile. Catalogue of American Amphibians and Reptiles 700:1-17.

Garrick, L. D., and J. L. Lang. 1977. Social signals and behaviors of adult alligators and crocodiles. American Zoologist 17:225-239.

Herzog, H. A., and G. M. Burghardt. 1977. Vocalization in juvenile crocodylians. Zeitschrift für Tierpsychologie 44:294-304.

Hildebrand, J. A. 2005. Impacts of anthropogenic sound. Pp. 101-124 in J. E. Reynolds III, W. F. Perrin, R. R. Reeves, S. Montgomery, and T. J. Ragen (Eds), Marine Mammal Research: Conservation Beyond Crisis. The Johns Hopkins University Press, Maryland, USA.

Laiolo, P. 2010. The emerging significance of bioacoustics in animal species conservation. Biological Conservation 143:1635-1645.

Maine Department of Environmental Protection. 2013. Protocol for wetland human disturbance assessment. Division of Environmental Assessment Biological Monitoring Program. http://www.maine.gov/dep/water/monitoring/biomonitoring/materials/sop_whda_manual. pdf. Archived by WebCite at http://www.webcitation.org/6qLOA6YfY on 9 May 2017.

Newcombe, R. G. 2008. Interval estimation for the difference between independent proportions: comparison of eleven methods. Statistics in Medicine 17:873-890.

Platt, S. G., T. R. Rainwater, and S. Nichols. 2004. A recent population assessment of the American Crocodile (Crocodylus acutus) in Turneffe Atoll, Belize. Herpetology Bulletin $89: 26-32$.

Platt, S. G., and J. B. Thorbjarnarson. 2000. Status and conservation of the American Crocodile, Crocodylus acutus, in Belize. Biological Conservation 96:13-20. 
Pooley, A. C, and C. A. Ross. 1989. Mortality and Predators. Pp. 92-101 in G. J. Webb, S. C. Manolis, and P. J. Whitehead. (Eds.), Crocodiles and Alligators. Surrey Beatty and Sons, New South Wales, Australia.

Rainwater, T. R. 2008. Population assessment of American Crocodiles (Crocodylus acutus) in Turneffe Atoll, Belize, 2008. Report to Oceanic Society, San Francisco, CA.

Rainwater, T.R., and S.G. Platt. 2009. Possible decline of an American Crocodile (Crocodylus acutus) population on Turneffe Atoll, Belize. Herpetological Bulletin 107:3-11.

RStudio Team. 2015. RStudio: Integrated Development for R. RStudio, Inc., Boston, USA.

Staton, M. A. 1978. Distress calls of crocodylians--Whom do they benefit? American Naturalist $112: 327-332$.

Thorbjarnarson, J. 1989. Ecology of the American Crocodile (Crocodylus acutus). Pp. 228-258 in P. Hall and R. Bryant (Eds.), Crocodiles: Their Ecology, Management, and Conservation. IUCN The World Conservation Union Publications, Gland, Switzerland.

Vergne, A. L., M. B. Pritz, and N. Mathevon. 2009. Acoustic communication in crocodylians: from behavior to brain. Biological Reviews 84:391-411.

Vergne, A. L, T. Aubin, P. Taylor, and N. Mathevon. 2011. Acoustic signals of baby Black Caimans. Zoology 114:313-320.

Vergne, A. L., T. Aubin, S. Martin, and N. Mathevon. 2012. Acoustic communication in crocodylians: information encoding and species specificity of juvenile calls. Animal Cognition 15:1095-1109.

Vliet, K. A. 1989. Social displays of the American Alligator (Alligator mississippiensis). American Zoologist 29:1019-1031. 
Webb, G. J., and H. Messel. 1977. Crocodile capture techniques. The Journal of Wildlife Management 41:572-575.

Webb, G. J. W., and H. Messel. 1978. Morphometric analysis of Crocodylus porosus from the north coast of Arnhem Land, northern Australia. Australian Journal of Zoology 26:1-27. 


\section{TABLES}

TABLE 1.- Description of stressor severity ranks for wetland human disturbance assessment (Maine Department of Environmental Protection, 2013).

\begin{tabular}{|c|c|c|}
\hline Severity of stressor & Severity description & Rank \\
\hline Not observed or unknown & Stressor is not observed or has no detrimental impact. & 0 \\
\hline Observed; minimal & Stressor is present and appears to have negligible impacts on & 1 \\
\hline disturbance & wetland. & \\
\hline Low disturbance & $\begin{array}{l}\text { Stressor is present and appears to have minor impacts on } \\
\text { wetland condition. }\end{array}$ & 2 \\
\hline Moderate disturbance & $\begin{array}{l}\text { Stressor is present and appears to moderately impact wetland } \\
\text { condition. }\end{array}$ & 3 \\
\hline High disturbance & $\begin{array}{l}\text { Stressor is present and appears to significantly impact } \\
\text { wetland condition. }\end{array}$ & 4 \\
\hline Severe disturbance & $\begin{array}{l}\text { Stressor is present and appears to have major impacts on } \\
\text { wetland condition. }\end{array}$ & 5 \\
\hline
\end{tabular}


TABLE 2.- Mean and standard error for total duration (DT), duration at first quartile ( $\left.\mathrm{D}_{1 / 4}\right)$, maximal frequency $\left(\mathrm{F}_{\max }\right)$, frequency at first quartile duration $\left(\mathrm{F}_{1 / 4}\right)$, end frequency $\left(\mathrm{F}_{\text {end }}\right)$, slope of the first quartile (Slope 1), and slope of the last three quartiles (Slope 2) for American Crocodile distress calls by size classes, Belize, 2015 - 2016. Means within a row, followed by the same uppercase letter are not significantly different between ages $(P>0.05)$.

\begin{tabular}{|c|c|c|c|c|c|c|c|c|}
\hline \multirow{3}{*}{ Variable } & \multicolumn{6}{|c|}{ Age } & & \\
\hline & \multicolumn{2}{|c|}{ Hatchling } & \multicolumn{2}{|c|}{ Juvenile } & \multicolumn{2}{|c|}{ Sub-adult } & \multicolumn{2}{|c|}{ Adult } \\
\hline & $X$ & SE & $X$ & $\mathrm{SE}$ & $X$ & $\mathrm{SE}$ & $X$ & $\mathrm{SE}$ \\
\hline $\mathrm{DT}(\mathrm{s})$ & $0.15 \mathrm{C}$ & 0.002 & $0.21 \mathrm{~B}$ & 0.01 & $0.36 \mathrm{~A}$ & 0.01 & $0.46 \mathrm{~A}$ & 0.09 \\
\hline $\mathrm{D}_{1 / 4}(\mathrm{~s})$ & $0.04 \mathrm{C}$ & 0.001 & $0.05 \mathrm{~B}$ & 0.002 & $0.09 \mathrm{~A}$ & 0.002 & $0.11 \mathrm{~A}$ & 0.02 \\
\hline $\mathrm{F}_{\max }(\mathrm{Hz})$ & $1,043.36 \mathrm{~A}$ & 23.41 & $823.09 \mathrm{~B}$ & 36.83 & $527.40 \mathrm{C}$ & 57.06 & $287.70 \mathrm{D}$ & 15.24 \\
\hline $\mathrm{F}_{1 / 4}(\mathrm{~Hz})$ & $674.11 \mathrm{~A}$ & 19.12 & $572.70 \mathrm{~B}$ & 23.61 & $436.00 \mathrm{~B}$ & 40.65 & $211.50 \mathrm{C}$ & 15.39 \\
\hline $\mathrm{F}_{\text {end }}(\mathrm{Hz})$ & $185.76 \mathrm{~A}$ & 7.44 & $166.91 \mathrm{~A}$ & 5.49 & $117.56 \mathrm{~B}$ & 11.31 & $107.90 \mathrm{~B}$ & 6.22 \\
\hline Slope $1(\mathrm{~Hz} / \mathrm{s})$ & $9,661.22 \mathrm{~A}$ & 419.65 & 4,958.91 B & 578.54 & $1,083.85 \mathrm{C}$ & 310.30 & $624.77 \mathrm{C}$ & 104.05 \\
\hline Slope $2(\mathrm{~Hz} / \mathrm{s})$ & $4,443.30 \mathrm{~A}$ & 175.63 & $2,693.41 \mathrm{~B}$ & 183.17 & $1,242.05 \mathrm{C}$ & 222.40 & $470.55 \mathrm{C}$ & 105.94 \\
\hline
\end{tabular}


TABLE 3.- Mean and standard error of total duration (DT), duration at first quartile (D), maximal frequency $\left(\mathrm{F}_{\mathrm{max}}\right)$, frequency at first quartile duration $\left(\mathrm{F}_{1 / 4}\right)$, end frequency $\left(\mathrm{F}_{\text {end }}\right)$, slope of the first quartile (S1), slope of the last three quartiles (S2), and total length (TL) of hatchling and juvenile American Crocodiles by location, Belize, 2015 - 2016. Mean of measured variables, between hatchling columns and between juvenile columns, followed by the same uppercase letter are not significantly different between locations $(P>0.05)$.

\begin{tabular}{|c|c|c|c|c|c|c|c|c|}
\hline \multirow{3}{*}{ Variable } & \multicolumn{4}{|c|}{ Hatchling } & \multicolumn{4}{|c|}{ Juvenile } \\
\hline & \multicolumn{2}{|c|}{ Ambergris } & \multicolumn{2}{|c|}{ BAL/Caulker } & \multicolumn{2}{|c|}{ Ambergris } & \multicolumn{2}{|c|}{ BAL/Caulker } \\
\hline & $X$ & $\mathrm{SE}$ & $X$ & $\mathrm{SE}$ & $X$ & $\mathrm{SE}$ & $X$ & $\mathrm{SE}$ \\
\hline $\mathrm{DT}(\mathrm{s})$ & $0.15 \mathrm{~A}$ & 0.003 & $0.14 \mathrm{~B}$ & 0.00 & $0.23 \mathrm{a}$ & 0.01 & $0.19 \mathrm{~b}$ & 0.01 \\
\hline $\mathrm{D}_{1 / 4}(\mathrm{~s})$ & $0.04 \mathrm{~A}$ & 0.001 & $0.03 \mathrm{~B}$ & 0.00 & $0.06 \mathrm{a}$ & 0.002 & $0.05 \mathrm{~b}$ & 0.01 \\
\hline $\mathrm{F}_{\max }(\mathrm{Hz})$ & $1,044.73 \mathrm{~A}$ & 23.66 & $1,035.00 \mathrm{~A}$ & 86.22 & $778.37 \mathrm{~b}$ & 48.35 & $901.35 \mathrm{a}$ & 52.68 \\
\hline $\mathrm{F}_{1 / 4}(\mathrm{~Hz})$ & $655.66 \mathrm{~A}$ & 19.09 & $786.45 \mathrm{~A}$ & 61.93 & $499.59 \mathrm{~b}$ & 18.09 & $700.65 \mathrm{a}$ & 44.49 \\
\hline $\mathrm{F}_{\text {end }}(\mathrm{Hz})$ & $189.21 \mathrm{~A}$ & 8.38 & $164.73 \mathrm{~A}$ & 12.11 & $158.69 \mathrm{~b}$ & 6.04 & $181.30 \mathrm{a}$ & 10.23 \\
\hline Slope $1(\mathrm{~Hz} / \mathrm{s})$ & $-10,088.64 \mathrm{~A}$ & 452.88 & $-7,057.84 \mathrm{~B}$ & 762.51 & $-5,187.05 \mathrm{a}$ & 819.04 & $-4,559.67 \mathrm{a}$ & 708.56 \\
\hline Slope $2(\mathrm{~Hz} / \mathrm{s})$ & $-4,198.74 \mathrm{~B}$ & 180.36 & $-5,932.86 \mathrm{~A}$ & 343.74 & $-2,014.86 \mathrm{~b}$ & 104.94 & $-3,880.87 \mathrm{a}$ & 333.33 \\
\hline TL (cm) & $31.06 \mathrm{~A}$ & 0.17 & $29.23 \mathrm{~B}$ & 0.08 & $73.57 \mathrm{~b}$ & 2.25 & $83.00 \mathrm{a}$ & 1.67 \\
\hline
\end{tabular}


TABLE 4.- Number of American Crocodiles captured by size class, and proportion (\% Call) of captured crocodiles that produced distress calls at Ambergris Caye, Belize Aquaculture Limited (BAL), and Caye Caulker, Belize, 2015 - 2016. Caye Caulker and BAL data were combined to account for low sample size and facilitate analysis. Proportion of overall calls, within the overall column and between the Ambergris Caye and Caye Caulker/BAL columns, followed by the same uppercase letter are not significantly different between sizes $(P>0.05)$.

\begin{tabular}{|c|c|c|c|c|c|c|c|c|c|c|}
\hline \multirow{3}{*}{ Size class } & \multirow{2}{*}{\multicolumn{2}{|c|}{ Overall }} & \multicolumn{8}{|c|}{ Location } \\
\hline & & & & $\begin{array}{l}\text { bergris } \\
\text { Caye }\end{array}$ & & ulker & \multicolumn{2}{|c|}{ BAL } & $\mathrm{Cau}$ & $\begin{array}{l}\text { rye } \\
\text { r/BAL }\end{array}$ \\
\hline & $n$ & $\%$ Call & $n$ & $\%$ Call & $n$ & $\%$ Call & $n$ & $\%$ Call & $n$ & $\%$ Call \\
\hline Hatchling & 22 & $86.4 \mathrm{~A}$ & 17 & $100.0 \mathrm{a}$ & - & - & 5 & 40.0 & 5 & $40.0 \mathrm{~b}$ \\
\hline Juvenile & 24 & $62.5 \mathrm{AB}$ & 14 & $71.4 \mathrm{a}$ & 7 & 42.9 & 3 & 66.7 & 10 & $50.0 \mathrm{a}$ \\
\hline Sub-adult & 18 & $22.2 \mathrm{C}$ & 3 & $66.7 \mathrm{a}$ & 12 & 8.3 & 3 & 33.3 & 15 & $13.3 \mathrm{a}$ \\
\hline Adult & 25 & 36.0BC & 15 & $53.3 \mathrm{a}$ & 6 & 0.0 & 4 & 25.0 & 10 & $10.0 \mathrm{~b}$ \\
\hline
\end{tabular}




\section{FIGURE LEGENDS}

FIG 1.- Belize, Central America, located on the eastern Caribbean seaboard. Letters dictate study area location; (A) Ambergris Caye, (B) Caye Caulker, and (C) Belize Aquaculture Limited.

FIG 2.- Spectrogram (A) and oscillogram (B) of a hatchling American Crocodile distress call, Ambergris Caye, Belize, 2016. Frequency parameter measurements; maximal fundamental frequency $\left(\mathrm{F}_{\max }\right)$, fundamental frequency at one-quarter duration $\left(\mathrm{F}_{1 / 4}\right)$, and frequency of the fundamental at the call end $\left(\mathrm{F}_{\text {end }}\right)$ shown as derived from spectrographic analysis. Temporal properties; total duration (DT), and duration of first quartile $\left(\mathrm{D}_{1 / 4}\right)$ shown from the measurement of distress call oscillogram.

FIG 3.- Principal component analysis of parameters for total duration (DT), duration at first quartile $(D)$, maximal frequency $\left(F_{\max }\right)$, frequency at first quartile duration $\left(F_{1 / 4}\right)$, end frequency ( $\left.\mathrm{F}_{\mathrm{end}}\right)$, slope of the first quartile (S1), slope of the last three quartiles (S2), and individual size class of American Crocodile distress calls in Belize, 2015- 2016. Ordinal ellipse illustrates core size class groupings in relation to call parameters. Call variables on the principal component axes indicate the measured variables driving the separation of individuals by size class. 
FIG 4.- Variance of juvenile American Crocodiles call parameters between Ambergris Caye and aggregated Caye Caulker and BAL sites. (A) Total duration variance of juvenile distress calls in relation to total length, longer calls being produced by crocodiles at Ambe5gris Caye site. (B) Maximal frequency of juvenile distress calls plotted against total length. Ambergris Caye distress calls are produced at lower frequencies. (C) Slope of last three quartiles plotted against total length. Distress calls produced at Ambergris Caye site are less modulated.

FIG 5.- Proportion of American Crocodiles, by size class and location that produced distress calls during capture in Belize, 2015 - 2016. 


\section{FIGURES}

FIG 1.

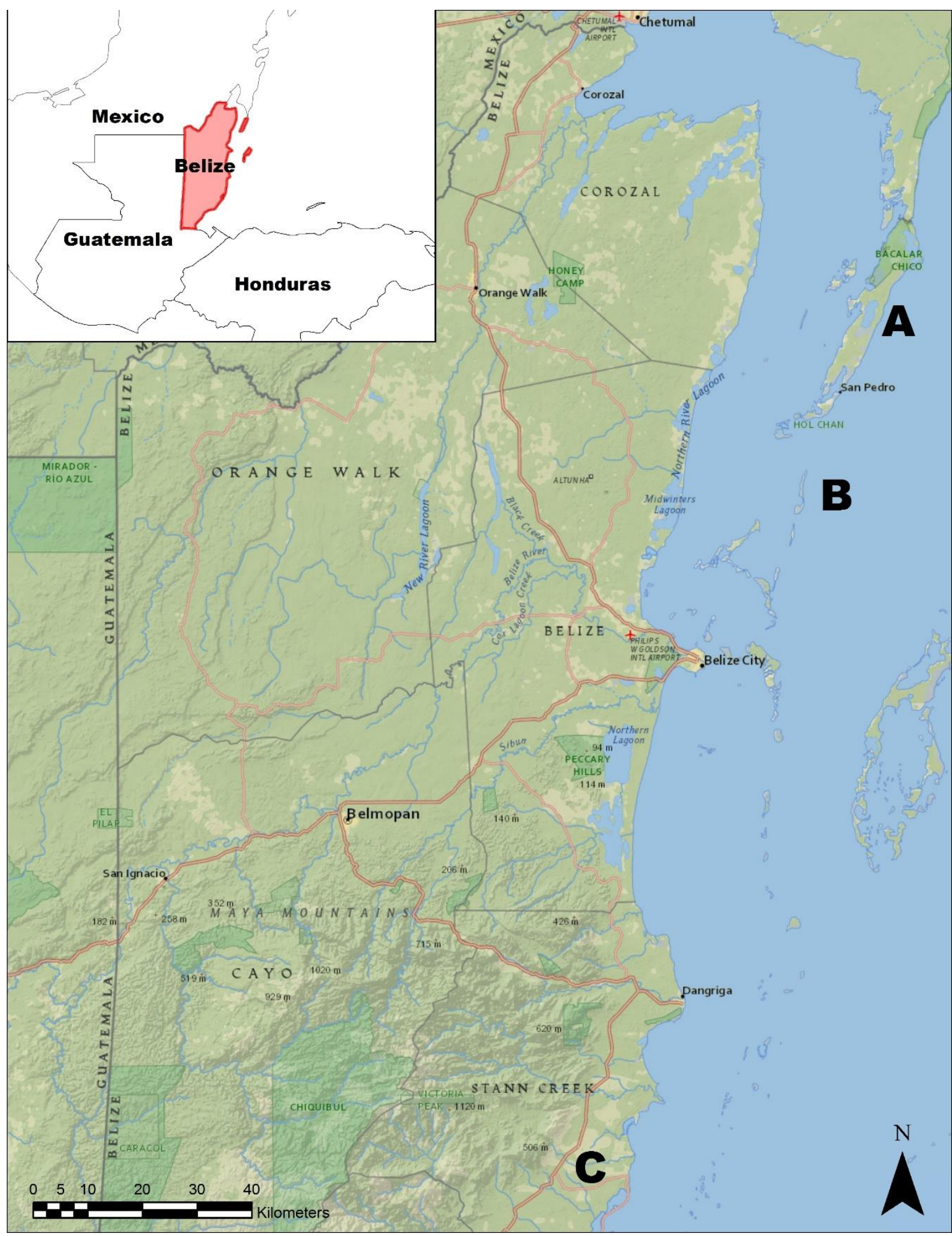


FIG 2.

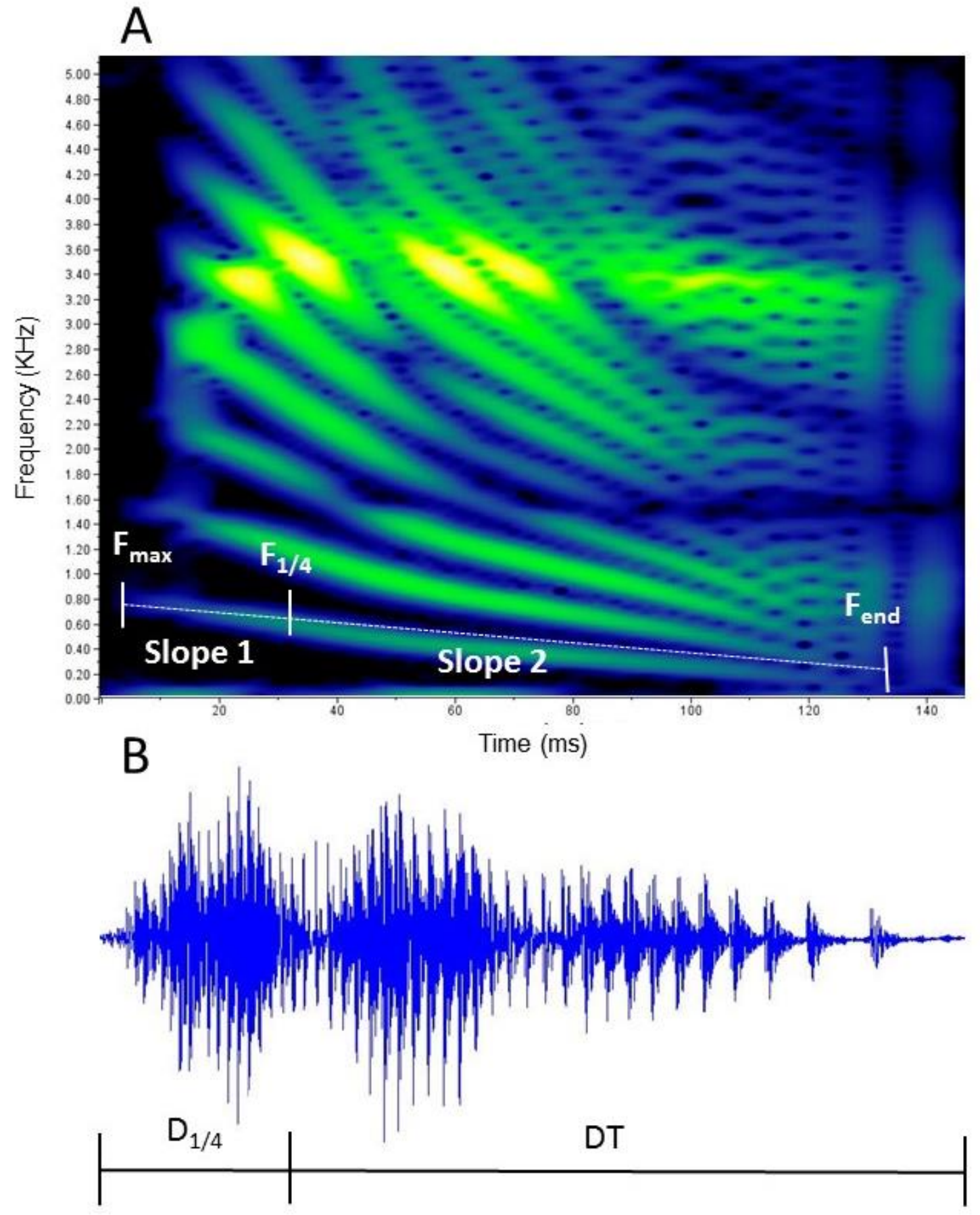


FIG 3.

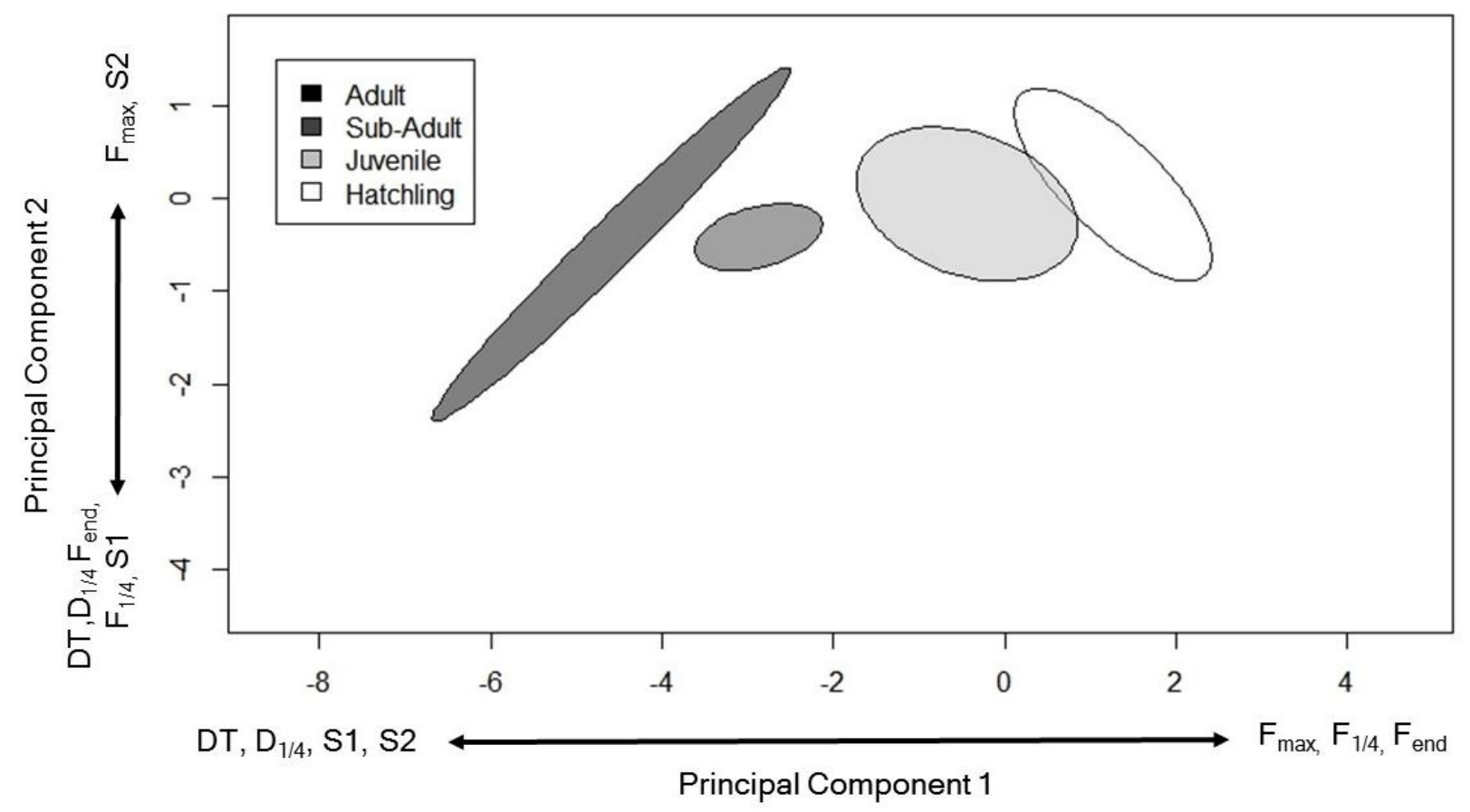


FIG 4
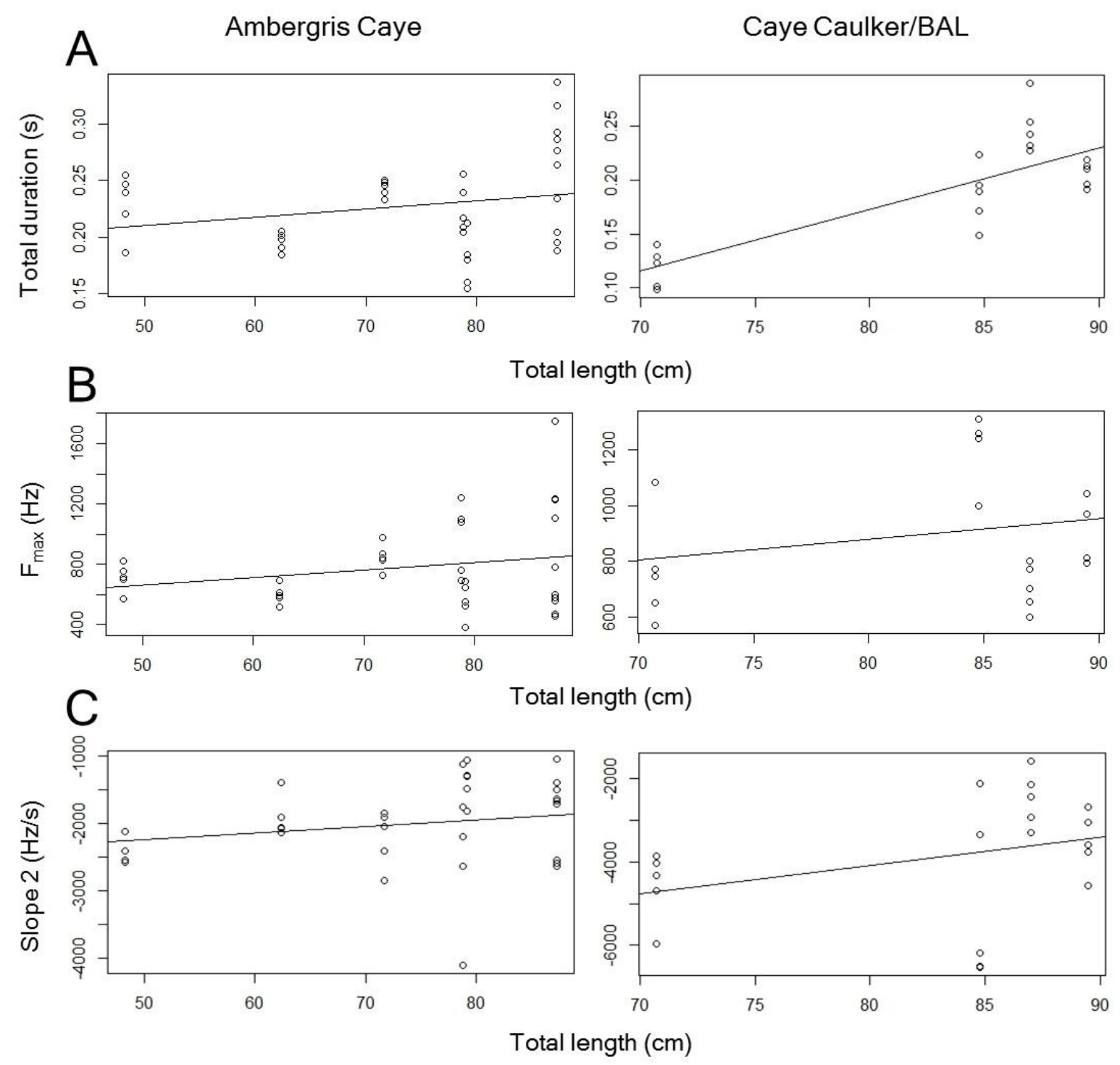
FIG 5.

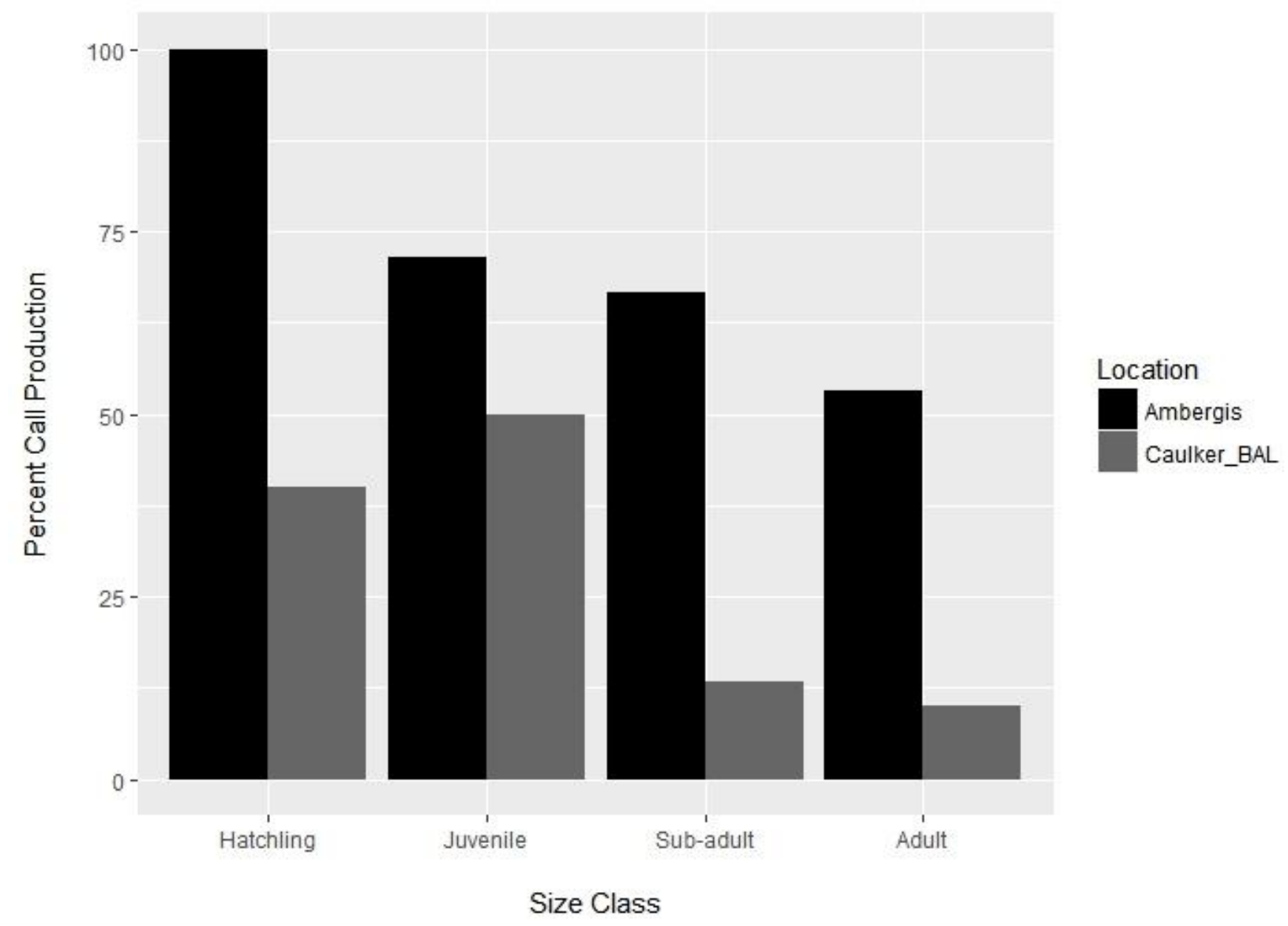




\section{CHAPTER 4}

A tail of two crocs: Individual identification of American (Crocodylus acutus) and Morelet's (Crocodylus moreletii) crocodiles by tail-spot patterns

\section{MIRIAM BOUCHER ${ }^{1 *}$, MARISA TELLEZ ${ }^{2,3}$, AND JAMES T. ANDERSON ${ }^{1}$}

${ }^{1}$ School of Natural Resources, West Virginia University, Morgantown, West Virginia, USA

${ }^{2}$ Crocodile Research Coalition, Maya Beach, Stann Creek, Belize

${ }^{3}$ Marine Science Institute, University of California Santa Barbara, Santa Barbara, California, USA

*Corresponding author. E-mail: mnboucher01@gmail.com

Written in the style of: Mesoamerican Herpetology 
ABSTRACT: Marking of wildlife is an effective tool for the conservation and management of many species. Crocodylian management and conservation uses a range of marking techniques, predominantly involving the alteration of caudal scutes and application of tags. Here we present the methods and application of two natural pattern identification techniques used concurrently with research and monitoring of the American (Crocodylus acutus) and Morelet's (Crocodylus moreletii) crocodile in Belize. We collected and analyzed 547 photographs of observed and captured crocodiles, identifying individuals by coding of spot patterns on the lateral tail sides. We investigated the efficacy of an established spot pattern coding protocol for crocodylians, and modified the original coding procedure by integrating vertical caudal scutes and irregular scale groups. We generated a total of 191 tail codes for 105 individual crocodiles $(C$. moreletii, $\mathrm{N}=$ 27; C. acutus, $\mathrm{N}=78$ ). The established methodology demonstrated $84 \%$ successfulness in differentiating individuals, compared to our novel method which showed $99 \%$ effectiveness at differentiating individuals and species. Using the spot pattern protocols, we identified no individuals with fully repeated codes (both tail sides). The proposed techniques are a costeffective and simple tool easily used by managers and communities alike to facilitate long-term demographic monitoring and encourage active participation in crocodile conservation via citizen science. Results from this project demonstrate that tail-spot patterns are distinct and coding of spot patterns is an effective way to passively identify individuals across species.

Key Words: Conservation management, individual identification, mark-recapture, population monitoring. 


\section{INTRODUCTION}

Conservation and management of wildlife relies on the ability to effectively monitor populations. Of the methods to assess and monitor populations, mark-recapture studies remain a staple for the collection of direct quantitative data regarding population dynamics (Twigg, 1975; Krebs, 1989; Powell and Proulx, 2003; Skalski and Robson, 2012). Advances in technology have led to new dimensions for marking individuals including; genetic mark-recapture, visual detection through game cameras, telemetry and satellite tracking, and implanted tags (Fuller, 1987; Fancy et al., 1988; Bailey et al., 1998; Pearse et al., 2001; Miller et al., 2005; Aarts et al., 2008; Heard et al., 2009). Despite increased use of these techniques in wildlife management and conservation, they are not easily implemented in resource deficient areas (Kellert, 1985). Much of terrestrial biodiversity exists in the tropics and sub-tropics; however, human and technological resources for wildlife management remain limited (Barrett et al., 2001; Janzen, 2004; Brooks et al., 2006; Bradshaw et al., 2009). As such, this is an associated challenge of assessing wildlife populations in developing nations where necessary funding for management programs may be restricted. There are obvious advantages to employing more technologically advanced methods for assessing wildlife populations; however, resource limitations may be circumvented through the application of simple, cost-effective marking techniques, particularly for large predators which are difficult to capture and handle.

Crocodylians are long-lived, large bodied predators that are keystone species in their respective habitats and offer a variety of ecosystem services that benefit ecological and human communities alike (Nifong and Silliman, 2013). Population survey methods generally use nocturnal point counts using light reflected from internal ocular structures to locate individuals 
(Webb et al., 1987). However, this method has inherent levels of error from possible failed or repeat detections (Webb et al., 1987). Advances in modeling and statistical techniques can mitigate some of this error, but there remain challenges to observing or recapturing marked individuals, particularly during diurnal periods.

Physical alterations of crocodylians by the clipping of caudal scutes and toe tagging are common means to mark individual animals (Bustard and Choudhury, 1981; Chabreck, 1963; Webb et al., 1989; Jennings et al., 1991; Soberon et al., 1996; Platt et al., 2002; Richardson et al., 2002; Elsey et al., 2004). Plastic tags may also be affixed to tail scutes to create a more effective visual identifier. Tail tags have been used to monitor Gavialis gangetus (Lang and Whitaker, 2010), Crocodylus niloticus (Swanepoel, 1996; Calverley and Downs, 2014), and Crocodylus porosus (Bayliss, 1987). At a distance physical alterations can be difficult to discern, and tags may not last the life of the animal (Bayliss et al., 1986; Swanepoel, 1996). Similarly, tracking equipment and data loggers have limited lifespans and effectiveness when deployed on crocodylians (Franklin et al., 2009).

One alternative to physical marking is the use of natural spot patterns on the lateral tail sides. Noted not to change over the life of the crocodylian, these patterns are a means to accurately distinguish individuals (Nair et al., 2012; Bouwman and Cronje, 2016). Spot pattern comparisons have been used to discern G. gangeticus (Singh and Bustard, 1976; Nair, 2010; Nair et al., 2012) and spot pattern coding, creating unique individual identification codes, for $C$. niloticus (Swanepoel, 1996; Bouwman and Cronje, 2016). Despite previous successes of individual identification through natural spot patterns, this technique has not been applied for American (Crocodylus acutus) and Morelet's crocodiles (Crocodylus moreletii). Here, we applied an established spot pattern identification technique and developed new methodology to 
assess the effectiveness of spot pattern coding in the visual identification and monitoring of $C$. acutus and C. moreletii in Belize.

\section{MATERIAL AND METHODS}

\section{Study area}

Belize is a small $\left(22,965 \mathrm{~km}^{2}\right)$ Caribbean country located on the eastern seaboard south of Mexico and east of Guatemala (Fig. 1). Crocodile identification took place at five areas throughout Belize; Ambergris Caye, Caye Caulker, Stann Creek District, Corozal District (Rio Hondo), and Chiquibul National Park.

Ambergris Caye is an extension of the Mexican Yucatan peninsula and paralleled by the Mesoamerican Barrier Reef. Development is centered on San Pedro, and undeveloped areas are largely littoral forest, mangrove swamp, and shallow lagoons. We collected C. acutus tail patterns from crocodiles captured throughout the island, but largely in proximity to San Pedro where they exist in higher densities.

Caye Caulker is an offshore island located $8 \mathrm{~km}$ south of Ambergris Caye. A deep channel splits the island with high development south of the split and the northern portion sporadically settled. We collected tail patterns from $C$. acutus captured the length of the island.

We collected tail patterns from both $C$. moreletii and $C$. acutus captured on a commercial shrimp farm located west of the Placencia Peninsula in Stann Creek District. We sampled $C$. moreletii from Chiquibul National Park, Belize's largest national park located in Cayo District, and the Rio Hondo River in Corozal District. We captured C. moreletii along the Raspaculo and Macal River branches in Chiquibul National Park, and from Four Mile Lagoon located on the Rio Hondo, Corozal District 


\section{Capture Methods}

We captured crocodiles concomitant to ongoing behavioral research and population surveys from September 2014 to September of 2016, and data collection is still ongoing by resident collaborators and management agencies. The West Virginia University Animal Care and Use Committee (Protocol \# 15-0703) and the Belize Forest Department (BFD) approved our capture protocol prior to fieldwork. We acquired research permits from the BFD prior to initiating any visual identification or tagging (Ref. No. CD/60/3/15(45)). We captured and restrained crocodiles using conventional techniques detailed by Webb and Messel (1977), such as hand-capture $(\mathrm{TL}<1.2 \mathrm{~m})$, noose or treble hook $(\mathrm{TL}>1.2 \mathrm{~m})(1977)$. We collected morphometric measurements and performed a health assessment of all captured crocodiles following the protocol of Webb and Messel (1978) and Sánchez-Herrera et al. (2011). Lastly, we applied visual tags to adult C. acutus at Ambergris, Caye Caulker, and Stann Creek District study sites, and tail pattern photos collected from all individuals.

\section{Tail Pattern Collection and Coding}

During crocodile processing and passive observation, we collected photographs of the lateral tail sides. We organized photographs by date and recorded relevant metadata of location, species, approximate size, and, if known, sex. To analyze tail-spot patterns, we used two marking systems to record the presence of distinct markings on lateral caudal scales to generate a code representative of the observed pattern and determine the efficacy of such methods for crocodiles in Belize. The first system, hereinafter referred to as the numeric code, followed the protocol from Swanepoel (1996) to assign a numeric value per the presence or absence of dark markings on caudal scales. The second coding method, hereinafter referred to as the additive 
code, is a novel method we adapted from Swanepoel's numeric code system and integrated dark vertical scutes and irregular scales groups.

\section{Numeric Code}

We assessed tail patterns by working up the body of the animal commencing at the single row of caudal scutes and counting forward to double scute row 9. We denoted tail side with a capitalized character; "L" for the left, and "R" for the right side. Solid dark markings were counted if they occupied at least $25 \%$ of the scale on which they were observed. We did not count markings on vertical scutes or irregular scales. We counted markings that spanned multiple scales across rows separately on each row. After the alphabetic character, we recorded scute row numbers if dark markings were present. We repeated the scute row number in the code if multiple markings were present, or skipped if no markings were present (Table 1). As they would not be visible from a distance, we did not record markings occurring on the ventral tail (Fig 2).

\section{Additive Code:}

Although the numeric code is a simple and effective way to create distinct identifiers for crocodiles it may not adequately account for individual variances. Thus, we created the additive code to incorporate markings on vertical scutes and irregular scale groups, which assists in the distinction of the two sympatric species in Belize (Table 2). We integrated vertical tail scutes from double rows 1-9 where, at a minimum, $90 \%$ of the total area was darkly marked. We recorded dark upright scutes in the code by a capitalized "B" placed before the scute row number on which they occurred. If the scute row was not present in the numeric code then the upright scute character was recorded in parentheses. We recorded the vertical scute character in 
parentheses followed by the row number on which it occurred (e.g., L124B5(B8)9) when the numeric code had multiple missing scute row numbers.

Irregular caudal scale groups (IS) on the ventral and ventrolateral tail surface are not present on genetically uncompromised American Crocodiles, but are present in Morelet's and Morelet-American Crocodile hybrids (Platt and Rainwater, 2005). As such, inclusion of these irregular scales are beneficial not only in differentiating individuals, but also species. We recorded irregular scale groups for rows 1-10 by a lowercase "i" recorded between the scute rows where they occurred (Table 2; Fig. 3). Scale groups must be a true intermediary between scute rows and we did not record IS groups if they fully or partially bisected a single scute row. Following alphabetic order, we recorded IS following the character for dark vertical scutes ("B"). Should one of the IS scute rows not be present in the numeric code, we recorded the IS character in parentheses (e.g., L12457(i)9). If both IS row numbers were not represented in the code we recorded the IS character in parentheses between the respective scute row numbers (e.g., L12456(7i8)9). Irregular scale groups that occurred between rows 9 and 10 were recorded as the last character of the code. We recorded IS in square brackets at the end of the code if scute row 9 was not present in the base numeric code (e.g., L124578[i]).

\section{Visual Tagging:}

We implemented visual tagging of crocodiles through the application of plastic tags on a dorsal vertical caudal scute as a means to verify spot pattern recapture in the field. We acquired round and flexible Perma-Flex self-piercing male and smaller locking female ear tags in bulk from Ear Tags Direct, Inc. Following capture, we affixed tags to the number 1 or 2 vertical single row caudal scutes as this part of the animal's tail is often visible when the individual is swimming or displaying during social interactions (Fig. 4). As each tag is comprised of two 
halves, we assigned a specific color combination to each tagged individual. We noted the positioning of the male or female tag component on either the left or right side of the tail as an additional metric for identification and recorded tag orientation and color for each individual. We did not apply tags to crocodiles measuring $<121 \mathrm{~cm}$ total length $(1.2 \mathrm{~m})$ as the size of the tag may interfere with daily activity. We released crocodiles at the point of capture after we recorded data and tagged individuals.

\section{Data Analysis:}

We amalgamated tail photographs into a single dataset. Each set of photographs for an individual crocodiles was relabeled to describe species, location, date, individual, and photograph number in the series. We referenced this media label to link metadata and tail pattern codes to the associated images. We created a dataset with an entry for each individual crocodile and recorded media label, location, date, tail pattern codes, scute row number for black and irregular scales, method of observation (capture or observation), size estimation, and if applicable, scute clip number, visual tag color, and sex. To identify repeated codes, we performed a search query on the data. We did a comparative visual analysis of the photographed tail patterns to determine errors in coding and possible recaptures for each duplicate code. We aggregated recaptures into a single entry per individual and recorded true duplicate to determine the proportion of distinct pattern codes per coding method. We compared proportion of distinct tail pattern codes for the numeric and additive methods using a test of equal proportion with the Yate's continuity correction at a 95\% confidence interval using RStudio version 0.99 .902 (RStudio Team, 2015). 


\section{RESULTS}

\section{Tail-spot Pattern Coding}

At present, we have analyzed and catalogued 547 photographs from sites on Ambergris Caye, Caye Caulker, Chiquibul National Park, Corozal District, and Stann Creek District. We generated 86 full tail patterns, 12 single right side, and 7 single left side patterns for 105 individual crocodiles. Duplicate codes occurred for single tail sides using both techniques; however, no full pattern duplicates (both tail sides) occurred (Table 3). We reevaluated the photographs for duplicate codes and determined that four duplicates (not included in analysis) to be recaptures. Distinct individuals that we determined not to be recaptures we used as a metric to determine efficacy of the coding method.

The unmodified numeric code generated $83.8 \%$ distinctiveness among all patterns (Table 4). Duplicates occurred between both C. moreletii and C. acutus $(\mathrm{N}=1)$, within C. moreletii ( $\mathrm{N}$ $=1)$, and within $C$. acutus $(\mathrm{N}=7)$ tail patterns. This method did not allow for complete differentiation between species by tail patterns. Additionally, duplicate patterns occurred in the same study areas $(\mathrm{N}=1)$ which impedes the usefulness of this method in distinguishing individuals in the field. Conversely, the use of the additive code yielded significantly improved results $\left(\chi_{1,105}^{2}=13.67 ; P<0.001\right)$. The additive code generated $99 \%$ distinctiveness among all patterns (Table 4). No duplicate codes occurred between $C$. moreletii and C. acutus, thus the code was able to differentiate species. A single duplicate within C. acutus resulted from our additive method, but was negligible as the two crocodiles were geographically distant and markedly different in size $(163 \mathrm{~cm}$ and $380 \mathrm{~cm}$ total length). 


\section{Visual Tagging}

We affixed visual tags to 29 C. acutus and 1 hybrid. Tag retention could not be determined in this study as we did not have the means to ensure continued visual recapture of tagged individuals. However, we did reencounter 9 tagged individuals and confirmed 3 tags present and distinguishable on crocodiles after one year (Fig. 4). Of the 9 individuals reencountered, we confirmed tail spot patterns and determined accuracy in recurring coding of tail patterns.

\section{DISCUSSION}

The management of crocodiles in Belize falls under the authority of the Belize Forest Department (BFD). The BFD relies on a network of collaborators across the country to facilitate the management of wildlife species, as well as mitigate human-wildlife conflicts. Increasingly, all parties involved in the management and conservation of wildlife in Belize face challenges associated with funding projects and conservation initiatives as well as a general need for increased personnel. To provide more cost effective and actionable conservation tools we aimed to adapt visual identification techniques to compliment the management of $C$. acutus and $C$. moreletii in Belize.

\section{Pattern Coding}

Tail-spot identification provides an accurate and passive method of identification that requires little training and does not require expensive, specialized equipment. Naturally occurring tail-spot patterns are present on all crocodiles encountered in Belize and can be used to generate distinct identifiers. The pattern of the spots is what truly dictates the variation between individuals, and the use of pattern coding creates a way to index and reference unique patterns. Working with a limited sample size and open population, we cannot fully validate the methods discussed here and identify rates of miss-identification. However, comparable study of markings 
on other crocodylian species have not confirmed identical spot patterns in studied individuals. The probability of identical patterns, not determined for any crocodylian species, is likely extremely small. Results from our study, particularly for captured individuals in which quality images could be attained, did not find identical patterns for any individuals. Moreover, we captured and photographed one individual multiple years (2014, 2015, and 2016) and generated the same ID code for each separate set of capture photos. Our findings support that patterns do not change over time and that the same pattern indicates the same individual.

Patterns can be collected passively through observation or photography, but are best attained through the processing of captured individuals. Although repeating codes may be generated, size class, sex, and location may be used to further characterize individual crocodiles. As with other techniques, spot pattern coding is not without limitations. Pattern acquisition may be hampered by ability to accurately observe the lateral sides of the tail. Crocodiles are amphibious spending 15-20\% of crepuscular activity fully or partially submerged, making pattern acquisition challenging (Boucher 2017: Chapter 2). Mark recapture success may also be skewed by singular tail patterns that are observed, but logged as separate individuals, if the two sides cannot be matched and amalgamated into a full pattern.

The use of technology can combat some of these pattern acquisition issues through deployment of game cameras at basking sites. Game cameras have been effectively used to capture spot pattern information for a variety of terrestrial mammalian species (Gerber et al., 2010; Heilbrun et al., 2003; Marnewick et al., 2008; McCain and Childs, 2008). We demonstrated that this technique is feasible in Belize after an initial trial using two trail cameras on a field scan interval to capture photos of basking crocodiles. Field cameras have also been effectively used to document nesting behavior of $C$. acutus and to monitor elusive crocodylian 
species (Charruau and Hénaut, 2012; Chowfin and Leslie, 2014; Mazzotti et al., 2015). The use of these cameras for pattern acquisition should be further pursued.

Perhaps the greatest resource for the acquisition and implementation of tail-spot pattern coding is the public. Sightings of crocodiles basking or crossing roadways are often reported within communities and to management entities. The growing availability of digital camera technology and mobile devices is now allowing the general public to capture wildlife images more regularly and, with encouragement, could be a resource for the collection of tail-spot patterns. Much in the way that citizen science has been used to quantify avian species (Sullivan et al., 2009), it could also be used for citizen scientists to contribute to meaningful research on native crocodylian species. Community initiatives to develop passive crocodile identification through tail-spot coding may be an effective approach to expanding population monitoring and engaging communities to become an active part of local management. Individual identification through pattern coding could also be used as a tool to foster greater positive interest in local crocodylians and decrease human-crocodile conflict through increased awareness.

\section{Visual Tagging}

Visual tags are a valuable and cost effective compliment to conventional marking techniques (i.e. scute clipping) and pattern coding. As applied in this project, we used tags to verify and confirm visual recaptures of crocodiles using tail pattern coding. Despite the benefits of this technique, tail tags are not a permanent marking solution and tags may be lost, fouled by aquatic vegetation, or degraded by exposure. Further use of tail tags in a more controlled environment would be beneficial to assess tag retention on crocodiles, and environmental fouling of the tags could be controlled through application of marine grade protective coatings. Modifications to make tags reflective, improving nocturnal visibility, could also facilitate 
quantification of reencounters with tagged crocodiles during nocturnal eyeshine surveys. Regardless of the limitations, visual tags are an effective means to accurately and distinctly identify crocodiles in the field and can enhance other marking techniques. The true success of this method, outside of its use here, is the possible application to an array of research and management activities.

Observation of tagged crocodiles facilitated short-term population monitoring through ability to track individual presence and absence at sites and observe movement patterns. Moreover, tagging corroborated observation of sex dependent behaviors and study of social behavior benefitted greatly from the ability to accurately distinguish sex. In particular, our tagging of adult females led to the detection of previously unrecorded nest sites at several locations on Ambergris Caye. As such, this short-term marking technique could be beneficial for further behavioral studies or cost-effective short-term population monitoring. Tags can also be incorporated into community-based monitoring initiatives. Detection of tags and collection of associated metadata could be done effectively by non-institutional or research-based entities. Thus, visual tail tagging may be a viable means to encourage community involvement and culture positive interest in local crocodylians. Conservation programs that initiate personal connections between communities and wildlife have been successful in fostering positive interactions and sharing management responsibilities (Decker et al., 2005). Although many incidents go unreported, conflict between crocodiles and people appears to be on the rise in Belize (M. Boucher, pers. observ.). Community engagement in crocodile conservation is critical in mitigating further conflict and forging strong community partnerships for future population management. 
Marking techniques proposed here are viable means to augment current research and work in compliment to other marking techniques. The relative ease of implementation and affordability make tail pattern coding and tail tagging attractive options to facilitate population monitoring. Tail-spot pattern coding is effective for characterizing individual pattern markings on the lateral tail sides of both C. acutus and C. moreletii and data can be collected through passive observation or in conjunction with captures. Visual tags are a short-term solution for the distinction and observation of crocodiles at a distance and is a compliment to other marking techniques. The spot pattern technique, is advantageous, as these patterns do not change and are not compromised by loss or fouling. Although tail-spot pattern coding and visual tagging are not without limitation, we conclude that there is considerable potential for their implementation, for crocodylian population monitoring, particularly in areas with constrained financial and human resources.

Acknowledgments - We thank the BFD for their support of this project and the Crocodile Research Coalition for logistic assistance. Thank you to Karl Kohlman, Shawn Heflick, Helen Sung, Danni Brianne, and Andrew Austin for their assistance in the field, and Alexander Doyle for his assistance in data analysis. This is Scientific Article XXXX of the West Virginia Agricultural and Forestry Experiment Station, Morgantown. 


\section{LITERATURE CITED}

Aarts, G., M. MacKenzie, B.,McConnell, M. Fedak, and J. Matthiopoulos. 2008. Estimating space-use and habitat preference from wildlife telemetry data. Ecography 31: 140-160.

Bailey, R. E., J. R. Irvine, F. C. Dalziel, and T. C. Nelson. 1998. Evaluations of visible implant fluorescent tags for marking coho salmon smolts. North American Journal of Fisheries Management 18: 191-196.

Barrett, C. B., K. Brandon, C. Gibson, and H. Gjertsen. 2001. Conserving tropical biodiversity amid weak institutions. BioScience 51: 497-502.

Bayliss, P. 1987. Survey methods and monitoring within crocodile management programmes. Pp. 157-175 In Webb, G. J., S.C. Manolis, and P.J. Whitehead, P. J. (Eds.), Wildlife management: crocodiles and alligators. Surrey Beatty \& Sons, Chipping Norton, Australia.

Bayliss, P., G. J. W. Webb, P. J. Whitehead, K. Dempsey, and A. Smith. 1986. Estimation of the abundance of saltwater crocodiles, Crocodylus porosus Schneider, in tidal wetlands of the Northern Territory-a Mark-Recapture Experiment to Correct Spotlight Counts to Absolute Numbers, and the Calibration of Helicopter and Spotlight Count. Wildlife Research 13: 309-320.

Bouwman, H., and E. Cronje. 2016. An 11-digit identification system for individual Nile crocodiles using natural markings. Koedoe 58: 1-6.

Bradshaw, C. J., N. S. Sodhi, and B. W. Brook. 2009. Tropical turmoil: a biodiversity tragedy in progress. Frontiers in Ecology and the Environment 7: 79-87. 
Brooks, T. M., R. A. Mittermeier, G. A. da Fonseca, J. Gerlach, M. Hoffmann, J. F. Lamoreux, C. G. Mittermeier, J. D. Pilgrim, and A. S. L Rodrigues. 2006. Global biodiversity conservation priorities. Science 313: 58-61.

Bustard, H. R., and B. C. Choudhury. 1981. Marking of crocodiles for release back into the wild for subsequent identification. Indian Forester 107: 477-85.

Calverley, P. M., and C. T. Downs. 2014. Population Status of Nile Crocodiles in Ndumo Game Reserve, Kwazulu-Natal, South Africa (1971-2012). Herpetologica 70: 417-425.

Chabreck, R. H. 1963. Methods of capturing, marking and sexing alligators. In Proceedings of the Annual Conference of the Southeastern Association of Game and Fish Commissioners 17: 47-50.

Charruau, P., and Y. Hénaut. 2012. Nest attendance and hatchling care in wild American Crocodiles (Crocodylus acutus) in Quintana Roo, Mexico. Animal Biology 62: 29-51.

Chenot-Rose, C. R. 2013. American Crocodile, Crocodylus acutus, Population Census in Ambergris Caye, Belize, Central America. (www.rufford.org/files/The\%20Belize\%20 Forest \%20Department\%20and\%20The\%20Crocodile\%20Specialist\%20Group.pdf)

Chowfin, S. M., and A. J. Leslie. 2014. A multi-method approach for the inventory of the adult population of a critically endangered crocodylian, the Gharial (Gavialis gangeticus) at Dhikala, Corbett Tiger Reserve incorporating direct counts and trail cameras. International Journal of Biodiversity and Conservation 6: 148-158.

Decker, D. J., D. A. B. Raik, L. J. Carpenter, J. F. Organ, and T. M. Schusler. 2005. Collaboration for community-based wildlife management. Urban Ecosystems 8: 227236. 
Elsey, R. M., P. L. Trosclair, and J. T. Linscombe. 2004. The American Alligator as a predator of mottled ducks. Southeastern Naturalist 3: 381-90.

Fancy, S. G., L. F. Pank, D. C. Douglas, C. H. Curby, and G. W. Garner. 1988. Satellite telemetry: a new tool for wildlife research and management. Fish and Wildlife Service, FWS-PUB-172.

Franklin, C. E., M. A. Read, P. G. Kraft, N. Liebsch, S. R. Irwin, and H. A. Campbell. 2009. Remote monitoring of crocodylians: implantation, attachment and release methods for transmitters and data-loggers. Marine and Freshwater Research 60: 284-292.

Fuller, M. R. 1987. Applications and considerations for wildlife telemetry. Journal of Raptor Research 21: 126-128.

Gerber, B., S. M. Karpanty, C. Crawford, M. Kotschwar, and J. Randrianantenaina. 2010. An assessment of carnivore relative abundance and density in the eastern rainforests of Madagascar using remotely-triggered camera traps. Oryx 44: 219-222.

Heard, G. W., M. P. Scroggie, and B. Malone. 2009. Visible Implant Alphanumeric tags as an alternative to toe-clipping for marking amphibians-a case study. Wildlife Research 35: $747-759$.

Heilbrun, R. D., N. J. Silvy, M. E. Tewes, and M. J. Peterson. 2003. Using automatically triggered cameras to individually identify bobcats. Wildlife Society Bulletin 31: 748-755.

Janzen, D. H. 2004. Setting up tropical biodiversity for conservation through non- damaging use: participation by parataxonomists. Journal of Applied Ecology 41: 181-187.

Jennings, M. L., D. N. David, and K. N. Portier. 1991. Effect of marking techniques on growth and survivorship of hatchling alligators. Wildlife Society Bulletin 19: 204-207. 
Kellert, S. R. 1985. Social and perceptual factors in endangered species management. The Journal of Wildlife Management 49: 528-536.

Krebs, C. J. 1989. Ecological methodology. Harper \& Row, New York, New York, United States.

Lang, J. W., and S. Whitaker. 2010. Spation Ecology of Gavialis gangeticus in the Chambal River, India. Pp. 183-196 In Crocodiles. Proceedings of the 20th Working Meeting of the Crocodile Specialist Group, IUCN, Gland, Switzerland and Cambridge UK.

Marnewick, K., P. J. Funston, and K. U. Karanth. 2008. Evaluating camera trapping as a method for estimating cheetah abundance in ranching areas. South African Journal of Wildlife Research 38: 59-65.

Mazzotti, F. J., M. McEachern, M. Rochford, M., R. N. Reed, J. K. Eckles, J. Vinci, J. Edwards, and J. Wasilewski. 2015. Tupinambis merianae as nest predators of crocodylians and turtles in Florida, USA. Biological Invasions 17: 47-50.

McCain, E. B., and J. L. Childs. 2008. Evidence of resident Jaguars (Panthera onca) in the southwestern United States and the implications for conservation. Journal of Mammalogy 89: 1-10.

Miller, C. R., P. Joyce, and L. P. Waits. 2005. A new method for estimating the size of small populations from genetic mark-recapture data. Molecular Ecology 14: 1991-2005.

Nair, T. 2010. Ecological and anthropogenic covariates influencing gharial Gavialis gangeticus distribution and habitat use in Chambal River, India. Unpublished Master's Thesis.

Nair, T., J. B. Thorbjarnarson, P. Aust, and J. Krishnaswamy. 2012. Rigorous Gharial population estimation in the Chambal: implications for conservation and management of a globally threatened crocodylian. Journal of Applied Ecology 49: 1046-1054. 
Nifong, J. C., and B. R. Silliman. 2013. Impacts of a large-bodied, apex predator (Alligator mississippiensis Daudin 1801) on salt marsh food webs. Journal of Experimental Marine Biology and Ecology 440:185-191.

Pearse, D. E., C. M. Eckerman, C. M., F. J. Janzen, and J. C. Avise. 2001. A genetic analogue of 'mark-recapture'methods for estimating population size: an approach based on molecular parentage assessments. Molecular ecology: 10: 2711-2718.

Platt S., and T. Rainwater. 2005. A review of morphological characters useful for distinguishing Morelet's Crocodile (Crocodylus moreletii) and American Crocodile (Crocodylus acutus) with an emphasis on populations in the coastal zone of Belize. Bulletin of the Chicago Herpetological Society 40: 25-29.

Platt, S. G., T. R. Rainwater, and S. T. McMurry. 2002. Diet, gastrolith acquisition, and initiation of feeding among hatchling Morelet's Crocodiles in Belize. Herpetological Journal 12: 81-84.

Powell, R. A., and G. Proulx. 2003. Trapping and marking terrestrial mammals for research: integrating ethics, performance criteria, techniques, and common sense. Ilar Journal 44: $259-276$.

Richardson, K. C., G. J. W. Webb, and S. C. Manolis. 2002. Crocodiles: inside out: a guide to the crocodylians and their functional morphology. Sydney: Surrey Beatty and Sons, Ltd. pp. 172.

RStudio Team. 2015. RStudio: Integrated Development for R. RStudio, Inc., Boston, MA URL http://www.rstudio.com/. 
Sánchez-Herrera, O., G. López Segurajáuregui, A. García Naranjo Ortize De La Huerta, and H. Benítez Díaz. 2011. Programa monitoreo del Cocodrilo de Pantano (Crocodylus moreletii) México-Belice-Guatemala. Comisión Nacional para el Conocimiento y Uso de la Biodiversidad, México, D. F., México.

Singh, L. A. K., and H. R. Bustard. 1976. A method to identify individual young gharial (Gavialis gangeticus). British Journal of Herpetology 5: 669-671.

Skalski, J. R., and D. S. Robson. 2012. Techniques in Wildlife Investigations: Design and Analysis of Capture Data. Academic Press, INC, Cambridge, Massachusetts, United States.

Soberon, R., R. Ramos, W. McMahan, and R. Ross. 1996. Reintroduction of Cuban crocodile on the Isle of Pines. Crocodile Specialist Group Newsletter 15: 10-1.

Sullivan, B. L., C. L. Wood, M. J. Iliff, R. E. Bonney, D. Fink, D., and S. Kelling. 2009. eBird: A citizen-based bird observation network in the biological sciences. Biological Conservation 142: 2,282-2,292.

Swanepoel, D. G. J. 1996. Identification of the Nile crocodile Crocodylus niloticus by the use of natural tail marks. Koedoe 39: 113-115.

Twigg, G. I. 1975. Marking mammals. Mammal Review 5: 101-116.

Webb, G. J., and H. Messel. 1977. Crocodile capture techniques. The Journal of Wildlife Management 41: 572-575.

Webb, G. J. W., and H. Messel. 1978. Morphometric analysis of Crocodylus porosus from the north coast of Arnhem Land, northern Australia. Australian Journal of Zoology 26: 1-27

Webb, G. J., Manolis, S. C., \& Whitehead, P. J. (Eds.). 1987. Wildlife management: crocodiles and alligators. Surrey Beatty \& Sons, Chipping Norton, Australia. 
Webb, G. J. W, P. G. Bayliss, and S. C. Manolis. 1989. Population research on crocodiles in the Northern Territory, 1984-86. Pp. 22-60. In Proceedings of the 8th Working Meeting of the Crocodile Specialist Group, IUCN, Gland, Switzerland and Cambridge UK. 


\section{FIGURES}

Figure 1. Belize, Central America, located on the eastern Caribbean seaboard. Letters dictate study area location. (A) Ambergris Caye, (B) Caye Caulker, (C) Placencia Peninsula, (D) Chiquibul National Park, and (E) Corozal district study areas.

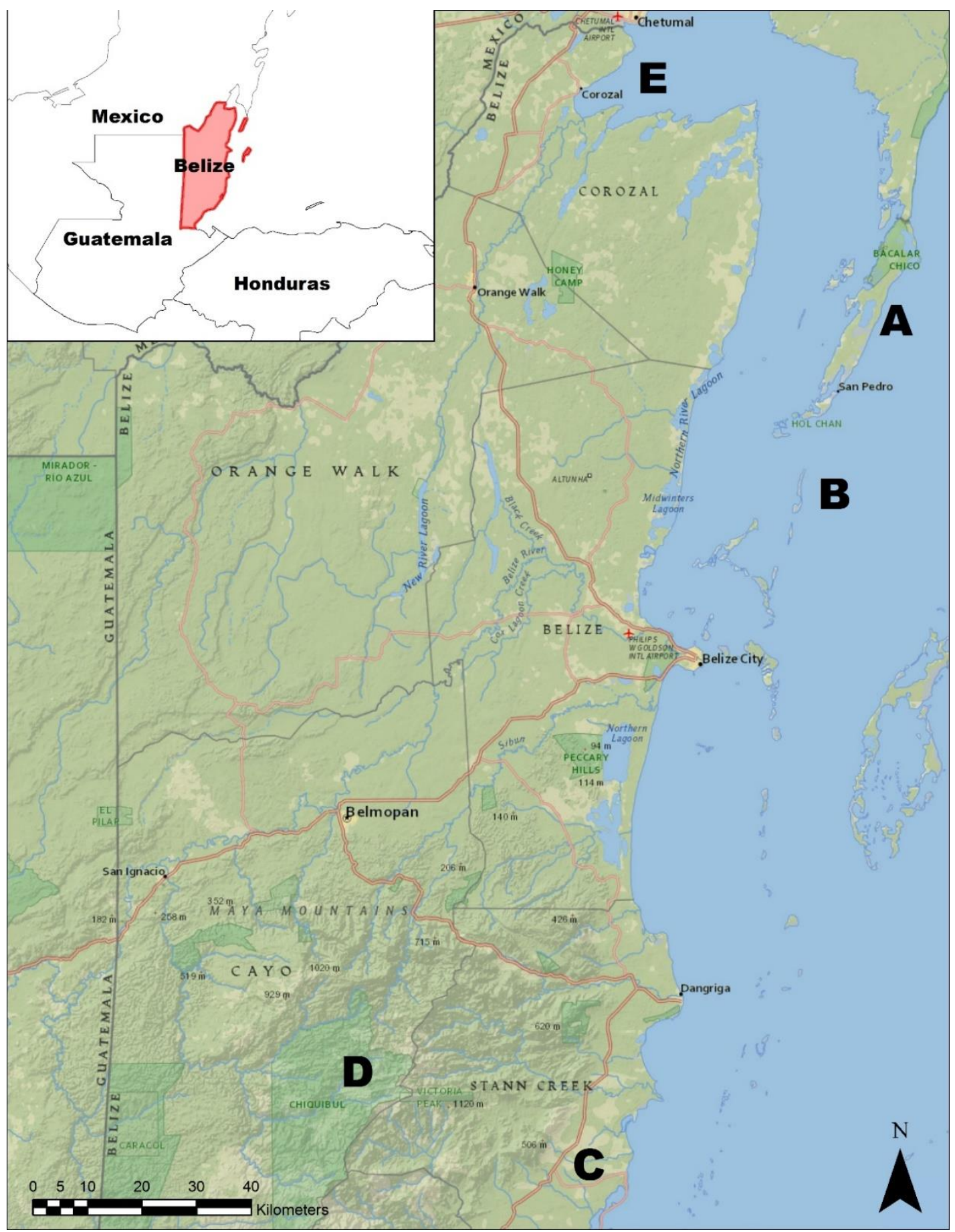


Figure 2. Example of a numeric tail-spot code generated for a juvenile $C$. acutus. Scutes with markings are recorded and rows lacking markings are skipped. The pattern is accessed working up the tail toward the torso of the crocodile.

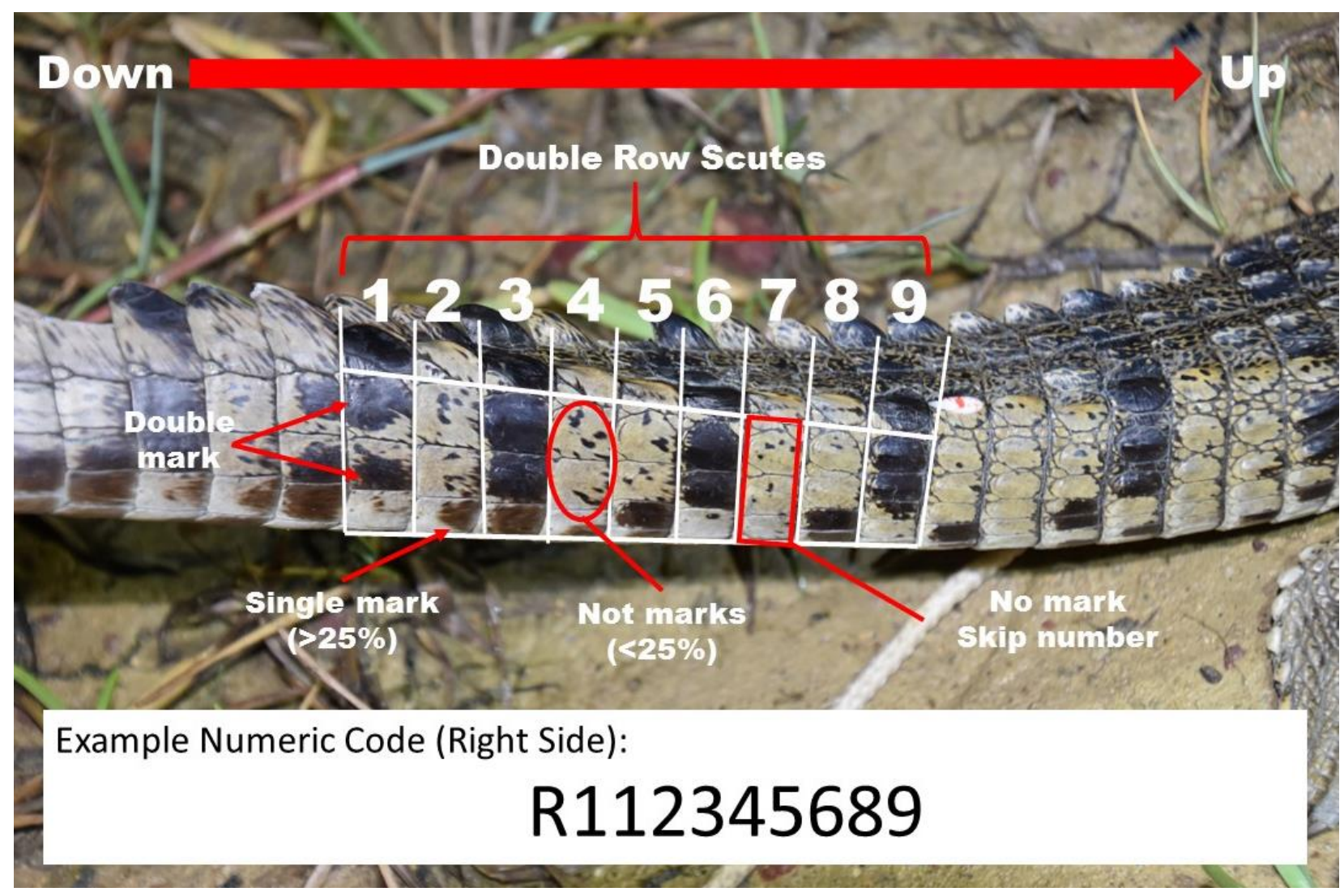


Figure 3. Left side tail pattern code using the additive method for a juvenile C. moreletii. Black vertical scutes and irregular scale groups (intermediate scutes) are integrated into the code.

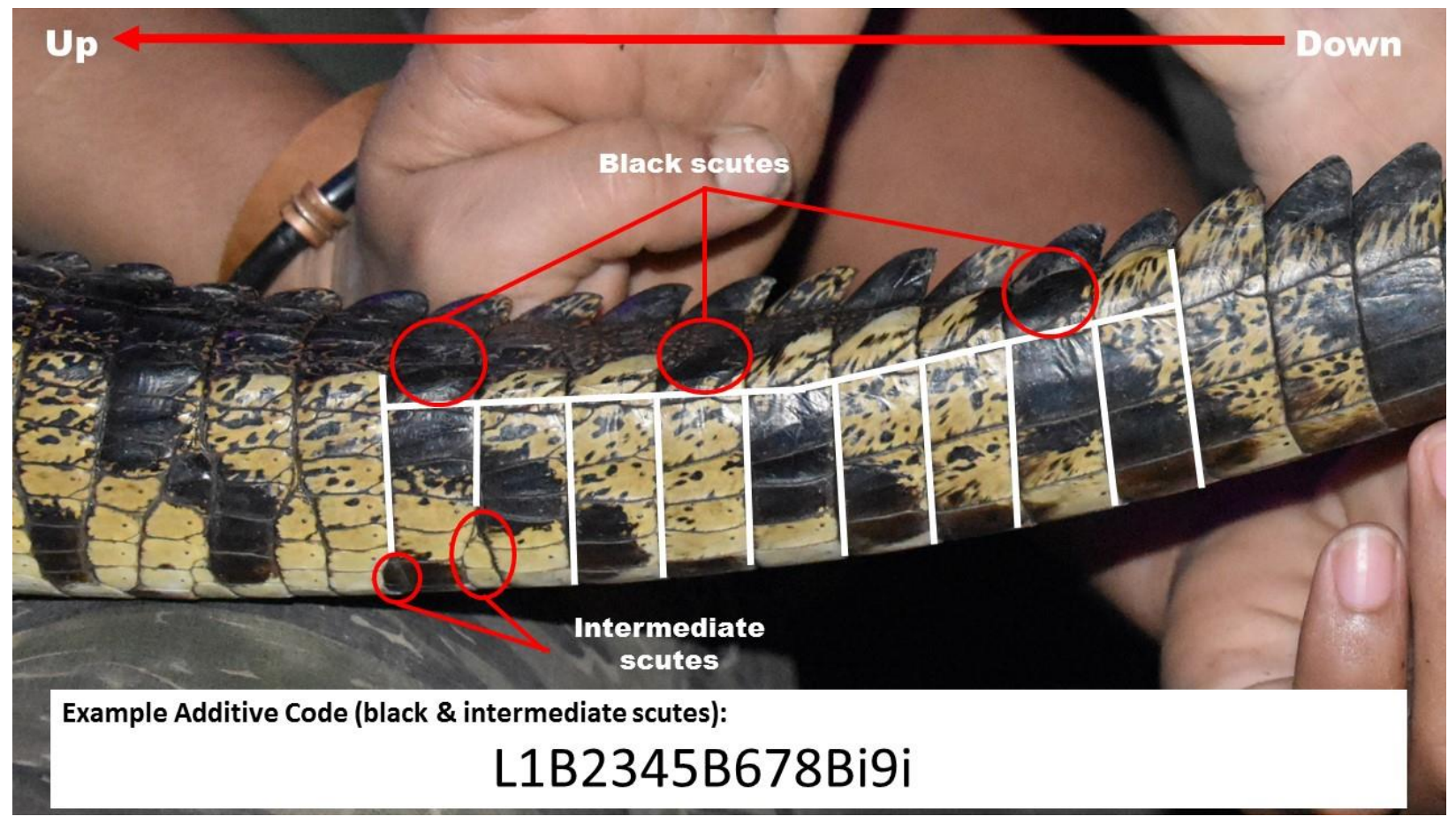


Figure 4. (A) Application of visual tail tag on number 2 single row caudal scute. (B) Visual recapture of tagged C. acutus by distinct tag orientation and color combination.

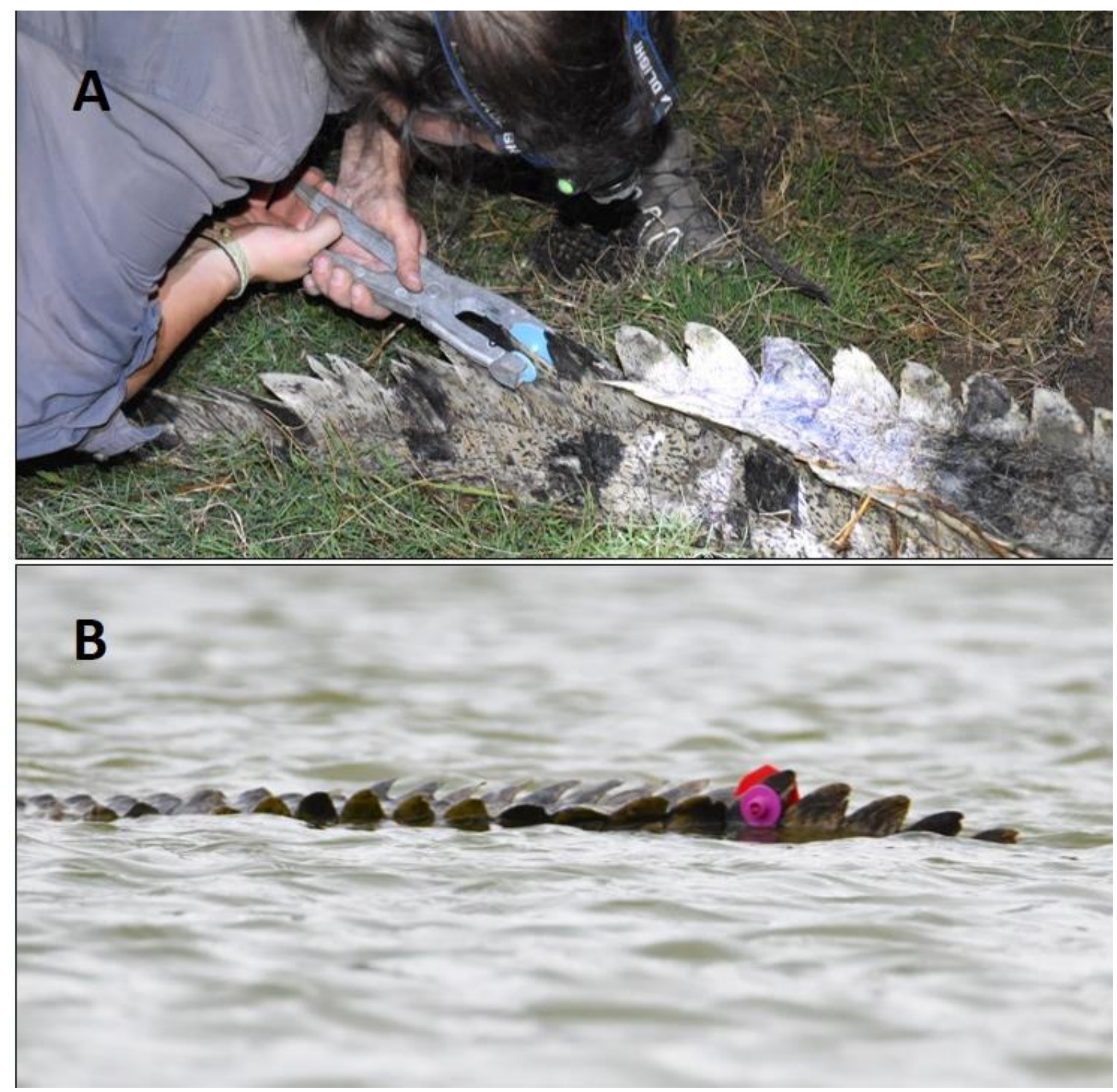




\section{TABLES}

Table 1. Numeric code generation guide. Steps $1-3$ are preceded by alphabetic character "L" (left) or "R" (right) denoting tail side. Steps begin at double scute row number 1 and repeated for scute rows $2-9$.

\begin{tabular}{|c|c|c|}
\hline \multicolumn{2}{|r|}{ Step } & Action \\
\hline 1 & $\begin{array}{l}\text { a) Dark markings present (mark }>25 \% \text { of } \\
\text { scale) }\end{array}$ & Step 2 \\
\hline & b) Dark markings absent or $<25 \%$ of scale & $\begin{array}{l}\text { Do not record (skip) scute row number; } \\
\text { Step } 4\end{array}$ \\
\hline 2 & a) $>1$ distinct (separate) mark on scute row & Step 3 \\
\hline & b) Only 1 distinct mark on scute row & Record scute row number in code; Step 4 \\
\hline 3 & a) Multiple markings $(<25 \%)$ present & Record scute row number in code; Step 4 \\
\hline & b) Multiple markings (> 25\%) present & $\begin{array}{l}\text { Record and repeat scute row number for } \\
\text { number of distinct marks e.g. } \\
122345559 \text {; Step } 4\end{array}$ \\
\hline 4 & $\begin{array}{l}\text { a) All markings on scute row have been } \\
\text { recorded }\end{array}$ & $\begin{array}{l}\text { Move forward on tail to next scute row; } \\
\text { Step } 1\end{array}$ \\
\hline
\end{tabular}


Table 2. Additive code generation guide. Steps $1-10$ are preceded by alphabetic character "L" (left) or "R" (right) denoting tail side. Steps begin at double scute row number 1 and repeated for scute rows $2-10$.

\begin{tabular}{|c|c|c|}
\hline \multicolumn{2}{|r|}{ Step } & \multirow[t]{2}{*}{ Action } \\
\hline 1 & $\begin{array}{l}\text { a) Dark markings present (mark > 25\% } \\
\text { of scale) }\end{array}$ & \\
\hline & $\begin{array}{l}\text { b) Dark markings absent or }<25 \% \text { of } \\
\text { scale }\end{array}$ & Step 4 \\
\hline \multirow[t]{2}{*}{2} & $\begin{array}{l}\text { a) }>1 \text { distinct (separate) mark on scute } \\
\text { row }\end{array}$ & Step 3 \\
\hline & b) Only 1 distinct mark on scute row & Step 4 \\
\hline \multirow[t]{2}{*}{3} & a) Multiple markings (> 25\%) present & $\begin{array}{l}\text { Record and repeat scute row number for } \\
\text { number of distinct marks; Step } 4\end{array}$ \\
\hline & b) Multiple markings $(<25 \%)$ present & $\begin{array}{l}\text { Record scute row number in code; Step } \\
4\end{array}$ \\
\hline \multirow[t]{2}{*}{4} & a) Vertical scute $>90 \%$ darkly marked & Step 5 \\
\hline & b) Vertical scute $<90 \%$ darkly marked & Step 7 \\
\hline \multirow[t]{2}{*}{5} & a) Irregular scale (IS) group present & Step7 \\
\hline & b) IS group absent & Step 6 \\
\hline \multirow[t]{2}{*}{6} & a) Scute row number present in code & $\begin{array}{l}\text { Record "B" before scute row number } \\
\text { e.g. } 6 \text { B789; Step } 11\end{array}$ \\
\hline & b) Scute row number absent in code & $\begin{array}{l}\text { Record "B" in () before scute row } \\
\text { number e.g. 6(B)89; Step } 11\end{array}$ \\
\hline \multirow[t]{2}{*}{7} & a) IS group present between rows $9-10$ & Step 8 \\
\hline & b) IS group absent between rows $9-10$ & Step 9 \\
\hline \multirow[t]{2}{*}{8} & a) Scute row 9 present in code & $\begin{array}{l}\text { Record "i" at end of code e.g. } 6789 \mathrm{i} \text {; } \\
\text { Step } 11\end{array}$ \\
\hline & b) Scute row 9 absent in code & $\begin{array}{l}\text { Record " } i \text { " in [ ] at end of code e.g. } \\
678[i] \text { or before "B" if present e.g. } \\
678(B)[i] \text {; Step } 11\end{array}$ \\
\hline 9 & $\begin{array}{l}\text { a) Both scute row numbers present in } \\
\text { code }\end{array}$ & $\begin{array}{l}\text { Record "i" between rows e.g. } 67 \text { i89 or } \\
\text { before "B" if present e.g. 67Bi89; Step } \\
11\end{array}$ \\
\hline
\end{tabular}


b) Both scute row numbers absent in code

10 a) One scute row number present in code

b) Both scute row numbers absent in code

11 a) All markings on scute row have been recorded
Step 10

Record " $i$ " in () between where scute rows occur e.g. 67(i)9, or before " $B$ " if present e.g. 67(Bi)9; Step 11

Record " $\mathrm{i}$ " in () between scute row numbers e.g. 6(7i8)9 or before " $\mathrm{B}$ " if present e.g. 6(7Bi8)9; Step 11

Move forward on tail to next scute row; Step 1 
Table 3. Tail pattern data by location, species, and completeness of acquired patterns (full or partial), 2014-2016 Belize.

\begin{tabular}{lccccc}
\hline \multirow{2}{*}{ Location } & \multicolumn{5}{c}{ Number of Patterns } \\
\cline { 2 - 6 } & C. acutus & C. moreletii & Full & Left & Right \\
\hline Ambergris Caye & 43 & - & 25 & 7 & 11 \\
Caye Caulker & 23 & - & 23 & - & - \\
Chiquibul & - & 18 & 18 & - & - \\
Placencia & 12 & 6 & 17 & - & 1 \\
Corozal & - & 3 & 3 & - & - \\
\hline Total & 78 & 27 & 86 & 7 & 12 \\
\hline
\end{tabular}


Table 4. Number and percent of duplicate patterns derived from the numeric and additive coding methods. The additive coding method was superior in identifying individuals through distinct pattern codes.

\begin{tabular}{lcccc}
\hline \multirow{2}{*}{ Code type } & \multicolumn{3}{c}{$\begin{array}{c}\text { Duplicate pattern pairs } \\
\mathrm{N}(\%)\end{array}$} & $\begin{array}{c}\text { Percentage of distinct } \\
\text { codes }\end{array}$ \\
\cline { 2 - 4 } & Right & Left & Total pair & \\
\hline Numeric & $7(7.1)$ & $10(10.8)$ & $17(16.2)$ & $83.8 \%$ \\
Additive & $1(1.0)$ & $0(0.0)$ & $1(1.0)$ & $99 \%$ \\
\hline
\end{tabular}




\section{APPENDICES}

\section{APPENDIX I.}

Shapiro-Wilks test for normality, and Bartlett test for equal variance on measured American Crocodile acoustic call parameters for total duration (DT, s), duration at first quartile $\left(\mathrm{D}_{1 / 4}, \mathrm{~s}\right)$, maximal frequency of the fundamental $\left(\mathrm{F}_{\max }, \mathrm{Hz}\right)$, frequency of fundamental at first quartile duration $\left(\mathrm{F}_{1 / 4}, \mathrm{~Hz}\right)$, end frequency of the fundamental $\left(\mathrm{F}_{\mathrm{end}}, \mathrm{Hz}\right)$, slope of the first quartile (Slope $1, \mathrm{~Hz}$ ), slope of the last three quartiles (Slope 2, Hz).

\begin{tabular}{lccccc}
\hline Acoustic & & \multicolumn{2}{c}{ Shapiro-Wilks Test } & & \multicolumn{2}{c}{ Bartlett Test } \\
\cline { 2 - 3 } \cline { 5 - 6 } Parameter & $\mathrm{W}$ & $\mathrm{P}$ & & $\mathrm{K}$ & $\mathrm{P}$ \\
\hline $\mathrm{DT}$ & 0.62 & $<0.001$ & & 245.49 & $<0.001$ \\
$\mathrm{D}_{1 / 4}$ & 0.62 & $<0.001$ & & 245.49 & $<0.001$ \\
$\mathrm{~F}_{\max }$ & 0.98 & 0.03 & & 24.59 & $<0.001$ \\
$\mathrm{~F}_{1 / 4}$ & 0.98 & 0.01 & & 14.46 & 0.002 \\
$\mathrm{~F}_{\text {end }}$ & 0.86 & $<0.001$ & & 25.47 & $<0.001$ \\
Slope 1 & 0.95 & $<0.001$ & & 50.50 & $<0.001$ \\
Slope 2 & 0.98 & 0.007 & & 23.41 & $<0.001$ \\
\hline
\end{tabular}




\section{APPENDIX II.}

Capture metadata of adult (A), sub-adult (SA), juvenile (J), and hatchling (H) American Crocodiles recorded from May 2015 - August 2016 in Belize.

\begin{tabular}{|c|c|c|c|}
\hline Individual & Capture Date & Capture Location & TL $(\mathrm{cm})$ \\
\hline A1 & $5 / 29 / 2015$ & Ambergris Caye & 222.3 \\
\hline $\mathrm{H} 1$ & $7 / 9 / 2015$ & Ambergris Caye & 33.1 \\
\hline $\mathrm{H} 2$ & $7 / 9 / 2015$ & Ambergris Caye & 31.7 \\
\hline $\mathrm{H} 3$ & 7/9/2015 & Ambergris Caye & 31.4 \\
\hline $\mathrm{H} 4$ & 7/9/2015 & Ambergris Caye & 31.5 \\
\hline H5 & 7/9/2015 & Ambergris Caye & 33.4 \\
\hline H6 & 7/9/2015 & Ambergris Caye & 33.4 \\
\hline H7 & $7 / 9 / 2015$ & Ambergris Caye & 29.6 \\
\hline H8 & 7/9/2015 & Ambergris Caye & 30.1 \\
\hline SA1 & $7 / 20 / 2015$ & Ambergris Caye & 127.5 \\
\hline $\mathrm{J} 1$ & $7 / 21 / 2015$ & Ambergris Caye & 87.3 \\
\hline $\mathrm{J} 2$ & $7 / 21 / 2015$ & Ambergris Caye & 87.3 \\
\hline $\mathrm{J} 3$ & $12 / 16 / 2015$ & Ambergris Caye & 79.2 \\
\hline $\mathrm{J} 4$ & $12 / 16 / 2015$ & Ambergris Caye & 48.3 \\
\hline J5 & $12 / 24 / 2015$ & Ambergris Caye & 62.4 \\
\hline J6 & $12 / 24 / 2015$ & Ambergris Caye & 71.7 \\
\hline J7 & $12 / 29 / 2015$ & Ambergris Caye & 78.8 \\
\hline A2 & $12 / 30 / 2015$ & Ambergris Caye & 223 \\
\hline J8 & $1 / 10 / 2016$ & Caye Caulker & 89.5 \\
\hline J9 & $1 / 11 / 2016$ & Caye Caulker & 87 \\
\hline SA2 & $6 / 10 / 2016$ & Belize Aquaculture Limited & 112 \\
\hline $\mathrm{J} 10$ & $6 / 18 / 2016$ & Belize Aquaculture Limited & 70.7 \\
\hline H9 & $6 / 29 / 2016$ & Belize Aquaculture Limited & 29.5 \\
\hline $\mathrm{H} 10$ & $7 / 5 / 2016$ & Ambergris Caye & 30 \\
\hline H11 & $7 / 5 / 2016$ & Ambergris Caye & 30 \\
\hline $\mathrm{H} 12$ & $7 / 5 / 2016$ & Ambergris Caye & 30 \\
\hline H13 & $7 / 5 / 2016$ & Ambergris Caye & 30 \\
\hline H14 & 7/8/2016 & Ambergris Caye & 30 \\
\hline H15 & $7 / 8 / 2016$ & Ambergris Caye & 30 \\
\hline J11 & $7 / 16 / 2016$ & Belize Aquaculture Limited & 84.8 \\
\hline H16 & $7 / 22 / 2016$ & Belize Aquaculture Limited & 29 \\
\hline H17 & $7 / 22 / 2016$ & Belize Aquaculture Limited & 29 \\
\hline J12 & $8 / 21 / 2016$ & Ambergris Caye & 87.1 \\
\hline
\end{tabular}




\section{APPENDIX III.}

Number of crocodiles recorded per size class and number of calls produced in 10, 20, and 30 second intervals beginning with the first call recorded, Belize, $2014-2016$. Analysis of variance found no significant difference in number of calls produced by size class within each call period.

\begin{tabular}{|c|c|c|c|c|c|c|c|c|c|c|}
\hline \multirow{2}{*}{ Size Class } & \multirow{2}{*}{$\mathrm{N}$} & \multicolumn{3}{|c|}{10 seconds } & \multicolumn{3}{|c|}{20 seconds } & \multicolumn{3}{|c|}{30 seconds } \\
\hline & & $\mathrm{N}$ & $\bar{x}$ & SE & $\mathrm{N}$ & $\bar{x}$ & SE & $\mathrm{N}$ & $\bar{x}$ & SE \\
\hline Hatchling & 17 & 140 & 8.24 & 3.87 & 231 & 13.59 & 1.60 & 301 & 17.71 & 2.38 \\
\hline Juvenile & 12 & 73 & 6.08 & 0.87 & 120 & 10.00 & 1.55 & 164 & 13.67 & 2.16 \\
\hline Sub-adult & 2 & 9 & 4.50 & 2.50 & 16 & 8.00 & 5.00 & 23 & 11.50 & 5.50 \\
\hline Adult & 2 & 11 & 5.50 & 3.50 & 19 & 9.50 & 4.50 & 20 & 10.00 & 5.00 \\
\hline Total & 33 & 233 & 7.06 & 0.24 & 386 & 11.70 & 0.32 & 508 & 15.39 & 0.39 \\
\hline
\end{tabular}

